\title{
Mechanisms of Hypersensitivity
}

\begin{abstract}
Allergic reactions to drugs are not always the result of the drug's protein-binding capacity, biotransformation, or degradation. Mediator release may occur via cross-linking of cell-bound IgE by di-(multi-) valent free drug. Physiological and pharmacological effects of histamine are mediated through four receptors, $\mathrm{H}_{1}, \mathrm{H}_{2}, \mathrm{H}_{3}$, and $\mathrm{H}_{4}$. The $\mathrm{H}_{3}$ receptor has a regulatory role in the release of neurotransmitters such as serotonin and dopamine; the $\mathrm{H}_{4}$ receptor exerts a chemotactic effect on several cell types associated with allergy and asthma. Cysteinyl leukotrienes and PAF are powerful mediators of anaphylaxis, asthma, and shock. Sphingosine-1phosphate, elevated in the lungs of asthmatics, regulates pulmonary epithelium permeability and contributes to the pathogenesis of anaphylaxis. Urticaria is a heterogeneous disease with many subtypes. Both ACE inhibitors and angiotensin II receptor blockers may cause angioedema. Abacavir changes the shape of the HLA antigen-binding cleft producing an alteration in the repertoire of self-peptides that bind HLA-B*57:01 and a $\mathrm{T}$ cell response to self-proteins. Drug-induced delayed-type cutaneous hypersensitivity reactions are mediated by CD4+ and CD8+ CD3+ T cells in the dermis and epidermis. Granulysin appears to be a key molecule for keratinocyte killing in TEN/SJS. Drugs provide good examples of types II (immune hemolytic anemia, drug-induced thrombocytopenia) and III (serum sickness-like) hypersensitivities.
\end{abstract}

In this chapter, emphasis has been placed on the core mechanisms underlying the broad categories of hypersensitivity responses distinguished on the basis of the Gell and Coombs classification and based on differences in the immune reactants (antibodies or cells), the form of the presented antigen, and the effector mechanisms involved. Mechanisms involved in individual drug hyper- sensitivities including, for example, responses to reactive metabolites from chemically "inert" parent drugs such as sulfamethoxazole; relationships between chemical structures and immune responses seen with, for example, anaphylactic reactions to neuromuscular blocking drugs during anesthesia; hypersensitivities and other intolerances to nonsteroidal anti-inflammatory 
drugs (NSAIDs); and mechanisms underlying the killing of malignant cells by some drugs used in chemotherapy are not confined to this chapter but presented in the relevant chapters dealing with pharmacologically different groups of drugs. Most hypersensitivities to drugs manifest as type I or type IV reactions. Type II and type III drug hypersensitive reactions are far less often seen and are considered after the discussions of the type I and IV responses. Mechanisms, to the extent that they are currently understood, of other types of "hypersensitivity" reactions or intolerances, some mediated by antibodies other than $\mathrm{IgE}$, and others by cells, are also discussed. We begin by examining the mechanisms underlying type I drug-induced IgE antibody allergic sensitization, regulation and production, and the effector mechanisms operative in IgE-mediated allergic reactions.

\subsection{Allergic Sensitization to Drugs and the Dogma of Previous Exposure}

\subsubsection{Immunogenicity of Free and Conjugated Drugs}

As well as the chemical nature of a drug, its size and complexity influence its antigenicity. Chemicals of molecular mass less than $5 \mathrm{kDa}$ and sometimes up to about $10 \mathrm{kDa}$ are often poorly or non-antigenic. From the time of the early immunochemical studies on antigenicity and haptens, organic chemicals of small molecular mass have been assumed to be antigenic and capable of stimulating an immune response only as a complex with a macromolecular carrier, usually protein. By coupling a wide range of different chemicals that are not antigenic in their free state, for example, steroids, sugars, purines, pyrimidines, nucleosides, and aromatic ring compounds such as phenols, etc., Landsteiner and other early investigators demonstrated clear and specific antibody responses in laboratory animals. Chemicals such as drugs may form hapten-carrier complexes in vivo in three different ways-by direct chemical covalent interaction with a soluble or cell-bound protein, by biotransformation of the drug to form a reactive metabolite able to bind to a carrier protein, or by degradative changes to the parent molecule forming reactive groupings (Fig. 3.1). In practice, however, it is often not possible to show protein binding by a drug or to even offer a satisfying explanation of how such binding might occur given the known chemical properties of the drug and the metabolic processes to which it is exposed. While a number of allergenic drugs such as the $\beta$-lactams undergo well-known ring-opening and subsequent protein-binding reactions (Chap. 5), for many drugs chemical reactivity, protein binding, biotransformation, or the involvement of degradative products and/or reactive impurities has not been demonstrated. This raises the question of another possible mechanism(s) to explain the immune recognition of "small" drug molecules and the subsequent immunological steps involved in the drug-induced hypersensitivity responses (see Sects. 3.1.2, 3.1.3, 3.4, 6.2.3.3, 7.4.2.3, and 7.4.5.3). Over the last few decades, a large number of drugs have been implicated as provoking agents for a range of hypersensitivity states, and although the list of identified drug allergenic determinants has expanded, this aspect of hypersensitivity research is still in its infancy. Structures as diverse as substituted ammonium ions, simple disaccharides, small side chain groups and ring structures on $\beta$-lactams, halogenated isoxazolyl groups, and whole molecules as seen with trimethoprim and chlorhexidine are known to be recognized as allergenic determinants in some drug-allergic patients. Of the presently known drug allergenic determinants, most have been reliably identified in IgE antibody recognition studies using quantitative immunochemical hapten inhibition techniques. The approaches and methods already applied so successfully to a range of drugs (see Chaps. 5-8) need to be expanded to cover other yet-to-bedefined $\operatorname{IgE}$ antibody-binding determinants and extended to $\mathrm{T}$ cell-mediated drug hypersensitivity reactions where progress has been slow. Results from the IgE studies have demonstrated that more than one allergenic determinant generally occurs on drugs and such antigenic 


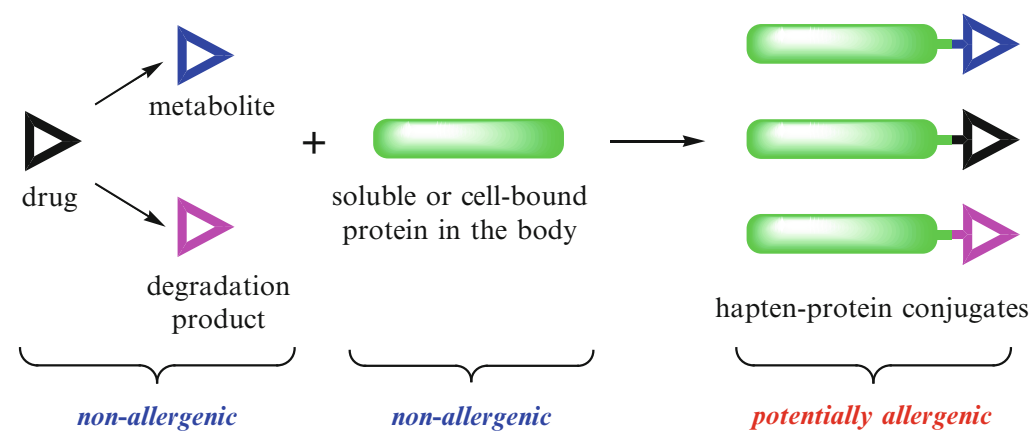

Fig. 3.1 Diagrammatic representation of possible, and potentially allergenic, hapten-protein complexes that may form in vivo from a drug and/or its metabolite(s) and degradative product(s). From Baldo
BA \& Pham NH. Structure-activity studies on druginduced anaphylactic reactions. Chem Res Toxicol 1994; 7: 703. Reproduced with permission from American Chemical Society heterogeneity is reflected in patients' $\operatorname{IgE}$ antibody recognition responses. As more drug allergies and more allergic individuals are studied, the extent of this heterogeneity will emerge and with it the possibility of gaining greater insights into the structural basis of drug allergenicity.

For an allergic reaction to a given drug, immunological dogma requires that the response occurs on reexposure to the drug after the initial sensitizing exposure to that drug. However, this seemingly obvious requirement may not always hold true or appear to hold true. Some allergic responses, sometimes even life-threatening as with anaphylaxis, occur on first exposure to a drug. Such reactions to the neuromuscular blocking drugs are well known and there are numerous other investigations and case studies involving a variety of pharmacologically different drugs including trimethoprim, iodinated contrast media, opioids, and some antibiotics that report the same phenomenon. In some cases, this might be explained by previous exposure to a structurally similar drug or to a structurally similar compound that may not even be administered as a drug. An example of the former case is a reaction to a cephalosporin in a patient previously given a penicillin while a reaction to a drug may also result from previous exposure to the drug (e.g., an antibiotic in meat) or an antigenically cross-reactive chemical in some foods or in the environment. Although $\operatorname{IgE}$ antibodies are almost invariably thought of as induced humoral responses to allergens, parasites, and fungi, some of the antibodies are "natural," that is, antibodies formed without exposure to foreign antigens via infection or passive or active immunization. Examples of such antibodies appear to be those that are complementary to various cross-reactive carbohydrate determinants (the so-called CCDs), and to phosphorylcholine connected by phosphodiester linkages in some $N$-linked proteoglycans and glycolipids and found in pneumococcal teichoic acid ("C substance") and other " $\mathrm{C}$ substances" in bacteria, fungi, arthropods, helminthes, protozoa, and plants. The curious connection between IgE natural antibodies to the D-galactose disaccharide found on cetuximab, a chimeric mouse-human $\operatorname{IgG}_{1}$ monoclonal antibody used for cancer treatment, and anaphylaxis in some treated patients (see Sect. 11.1.3.2) and the possible cross-reaction of natural antiphosphorylcholine IgE antibodies with ammonium groups on neuromuscular blocking drugs (Sect. 7.4.5.3) are indicators of the likely existence of other natural IgE antibodies with potentially cross-reactive specificities. Although some of these antibodies may appear to have no connection whatsoever with a particular drug, structural features recognized by the antibody combining site may resemble structures on the drug molecule resulting in allergenic crossreactivity. It should also be kept in mind, however, that not all exposures to a potentially sensitizing drug will result in a patient becoming 
sensitized and every sensitized patient will not necessarily respond with allergic symptoms following reexposure to the sensitizing drug.

Findings so far on immune recognition of drugs, especially recognition by $\operatorname{IgE}$ antibodies in cases of type I immediate hypersensitivity and to a much lesser extent for drug recognition by specific $\mathrm{T}$ cells, have shown that small parts of drug molecules, sometimes only one or a few chemical groups that form part of the molecule, constitute the allergenic determinant structures that are complementary to the immunoglobulin E combining sites and $\mathrm{T}$ cell receptors. In addition to allergic cross-sensitivity to drugs in the same family, for example, between different $\beta$-lactams, recognition of widely distributed structures commonly occurring in many different drugs and chemicals also represents potentially immunologically cross-reactive determinants. Substituted ammonium ions identified as the most important $\mathrm{IgE}$ antibody-binding structures in neuromuscular blocking drugs (Sect. 7.4.2.1) occur in many drugs and chemicals frequently encountered by humans. Bioisosteres, that is, groups with similar physical and/or chemical properties that impart similar biological properties to a drug, should also be kept in mind when prior allergic sensitization is suspected in patients who are first time reactors to a drug. In this era of so-called rational drug design, bioisosteres are commonly seen for example, in the replacement of a six-membered phenyl ring with a five-membered thiophene ring in many synthesized drugs. The importance of bioisosterism in the identification of allergenic structures and allergic cross-reactivity is discussed further in Chap. 5.

\subsubsection{Mediator Release by Free and Conjugated Drugs in Immediate Allergic Reactions}

In allergic subjects, IgE antibodies, as well as being free in serum, are fixed to the extracellular D1 distil and D2 proximal domains of the FceRI receptor on mast cells and basophils via the $\mathrm{C} \varepsilon 2$ and $\mathrm{C} \varepsilon 3$ domains of the antibody $\mathrm{Fc}$ region.
Bridging of adjacent cell-bound IgE molecules by at least bivalent allergenic determinants reacting with their complementary antibody combining sites (Fig. 3.2a-d) triggers cell degranulation and release of a variety of mediators that cause the signs and symptoms of a type I hypersensitivity reaction. In the case of drug-carrier conjugates, cross-linking of $\mathrm{IgE}$ antibodies is readily explained by the presence on the conjugates of multiple reactive drug determinant sites, but for free, uncomplexed drug molecules both the size and number of reactive determinants would appear to be too small for cross-linkage of antibody combining sites to occur. Drugs with a single IgE-binding determinant cannot, of course, cross-link adjacent cell-bound antibody molecules (Fig. 3.2e), but even if two or more determinants are present, they must be separated by a suitable distance and/or be suitably spatially arranged if cross-linking via adjacent complementary antibody combining sites is to occur (Fig. 3.2f, g). Despite this problem of explaining the mechanism of apparently monovalent druginduced allergic mediator release, there is at least one group of drugs, the neuromuscular blockers (and probably more to be identified) that can specifically elicit antibody-induced mast cell activation and release without first undergoing coupling to a macromolecular carrier. For these drugs, di- or multi-valency is an inherent part of the molecular structure and, even in the absence of protein binding, cross-linking of cellbound antibodies can be effected (Fig. 3.2a). Of the polymethylene bismethonium compounds, the $2 \mathrm{~nm}$ molecular length of the $\mathrm{C}-10$ congener decamethonium is optimal for neuromuscular block, that is, it best fits the distance between the receptive sites on the muscle nicotinic acetylcholine receptor. Interonium distances, however, are less, for example, $1.4 \mathrm{~nm}$ for decamethonium, $1.08 \mathrm{~nm}$ for $d$-tubocurarine (molecular length $1.8 \mathrm{~nm}$ ), and $1.14 \mathrm{~nm}$ for pancuronium (molecular length $1.9 \mathrm{~nm}$ ). These distances appear to be suitable for the neuromuscular blockers to bridge and thus activate adjacent IgE molecules on the mast cell surface (see also Sects. 7.4.2.1 and 7.4.2.3). 
a
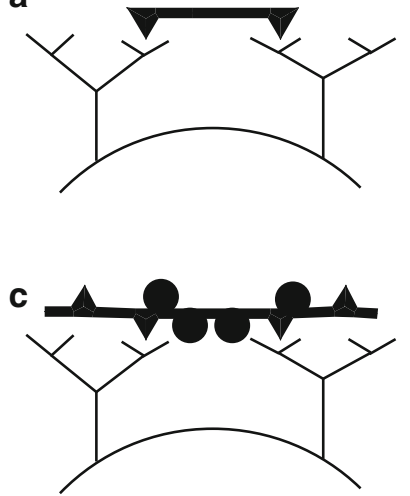

b
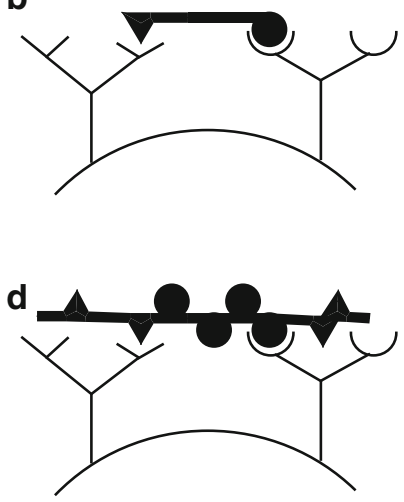

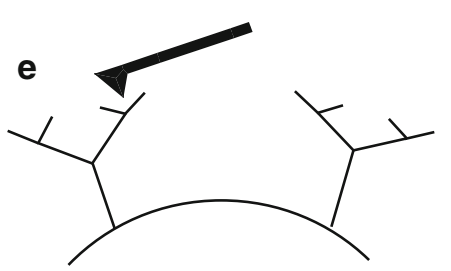

Fig. 3.2 Different ways in which a free drug (shown in bold in $\mathbf{a}, \mathbf{b}, \mathbf{e}, \mathbf{f}$, and $\mathbf{g}$ ) and a drug-protein conjugate (c, d) may cross-link or bridge adjacent cell-bound IgE molecules which triggers release of the mediators of immediate hypersensitivity. (a) Bridging via an allergenically divalent unconjugated drug molecule with the same or closely related allergenic determinants. This is the mechanism thought to occur in patients who experience anaphylaxis following administration of a neuromuscular blocking drug. (b) Bridging via a free, unconjugated drug molecule containing two (or more) different determinants that elicit an $\operatorname{IgE}$ response. (c) and (d) Bridging via conjugated drug molecules with cross-linking effected by the same, or different, determinants, respectively. Failure to bridge adjacent cell-bound $\operatorname{IgE}$ molecules because: (e) drug is allergenically monovalent; (f) and (g) drug determinants are not positioned to effect cross-linkage. From Baldo BA \& Pham NH. Structure-activity studies on drug-induced anaphylactic reactions. Chem Res Toxicol 1994; 7: 703. Adapted with permission from American Chemical Society

\subsubsection{Immunological Recognition of Free, Unconjugated Drug Molecules}

The generally accepted explanation for the recognition of drugs causing an immune-mediated hypersensitivity reaction is based on the binding of drug to a protein carrier molecule, immune recognition and processing of the drug-protein complex, presentation of drug-peptide conjugates to the $\mathrm{T}$ cells, and recognition and reaction of the $\mathrm{T}$ cell with the drug antigen. However, although there is no evidence that many drugs, either as the parent compound or as a metabolite, bind to a suitable carrier, there is evidence that $\mathrm{T}$ cells recognize metal ions such as $\mathrm{Ni}^{2+}$ and some drugs like sodium aurothiomalate that do not require antigen processing. In one explanation, the drug is said to bind directly to self-peptides in the antigen-binding cleft of the major histocampatibility complex (MHC). In another possible alternative, the drug may couple directly to the MHC itself on regions involved in binding to the $\mathrm{T}$ cell receptor. In drug interaction with the MHC, recognition may be restricted to a limited number of peptides or it may be promiscuous, that is, independent of peptide. For some drugs at least, direct stimulation of $\mathrm{T}$ cells via the $\mathrm{T}$ cell receptor in an MHC-dependent way has been suggested. With sulfamethoxazole for example, a drug known to be metabolized to its reactive nitroso derivative, only a minority of $\mathrm{T}$ cell clones reactive with this metabolite were isolated from sulfamethoxazole-allergic patients. The short time period for $\mathrm{T}$ cell activation to occur with some free, unmetabolized drugs, $\mathrm{T}$ cell clone 
reactivity with glutaraldehyde-fixed antigenpresenting cells, and removal of free drug by washing all suggests a drug-T cell receptor interaction that is independent of metabolism and processing. Further consideration of the recognition and the immune response to free, unconjugated drugs is set out in Sect. 3.4 below.

\subsection{IgE Antibodies and IgE-Mediated Drug Hypersensitivities}

The central importance of $\operatorname{IgE}$ antibodies in both the immediate and late phases of an allergic response involving inflammatory reactions is well established. IgE mediates the allergic inflammatory response by binding to both its high-affinity receptor FceRI on mast cells and basophils and its low-affinity IgE receptor FceRII (CD23) (on a number of different hematopoietic cells including $\mathrm{B}$ cells) to augment humoral and cellular responses.

\subsubsection{Initiating Events in the Production of IgE Antibody}

$\operatorname{IgE}$ is produced by plasma cells at the site of an allergic reaction generally in mucosal, cutaneous, and gut lymphoid tissue. IgE antibody production begins with the interaction between antigen-bearing antigen-presenting cells (APC) and lymphocytes. APCs can be dendritic cells, the most important cell in initiating the adaptive immune response, macrophages, and B cells. Naïve T lymphocytes not only need to have antigen presented in a special way, they also require precise signals to become activated. Both of these requirements are fulfilled by the APC firstly via the membrane-associated MHC that interacts with the $\mathrm{T}$ cell receptor (TCR) (activation signal 1) and secondly by the provision of co-stimulatory signals in the form of the membrane protein ligand CD80 (B7-1) working in tandem with another membrane ligand CD86 (B7-2) (activation signal 2). These ligands interact with their complementary receptor CD28 constitutively expressed on naïve $\mathrm{T}$ cells to allow the cells to undergo clonal expansion (Fig. 3.3).
Resting or naïve B cells are also nondividing, and to undergo clonal expansion and differentiation to effector B cells, that is, to produce allergen-reactive $\operatorname{IgE}$ antibodies, B cells also require the participation of a specific receptor, the $\mathrm{B}$ cell receptor or $\mathrm{BCR}$, and co-stimulation from $\mathrm{T}$ helper cells. The BCR has immunoglobulin anchored in the cell membrane, and, in concert with the B cell co-receptor complex, it is the interaction between this surface immunoglobulin and its complementary antigen that initiates $B$ cell activation. Upon binding to the antigen, the BCR-antigen complex is internalized within an endosome, processing follows, and the processed antigen is presented back on the surface by MHC type II molecules. If maturation of the B cell to a plasma cell or a memory cell is to continue, interaction with, and co-stimulation by, an activated $\mathrm{T}$ helper cell is required. Interaction between the $\mathrm{B}$ cell and an activated Th2 cell with the appropriate TCR involves recognition of the MHC-processed antigen by the TCR and co-stimulatory CD80/CD86 (B7) signals. Co-stimulation of the $\mathrm{B}$ cell that eventually leads to clonal expansion and isotype switching is also enabled through upregulation of the CD40 ligand (CD40L) (Fig. 3.3). If CD40L-CD40 receptor interaction and co-stimulation do not eventuate, B cells undergo apoptosis and are eliminated. Cell proliferation and isotype switching for the synthesis of IgE are aided by the cytokines Il-4 and IL-13 generated by Th2 cells. These two cytokines initiate transcription of germ-line mRNA for IgE antibodies and are regarded as the first of two signals necessary for class switching from IgM- to IgE-bearing cells. The second signal is delivered by the interaction of CD40L on the T cell surface with its receptor CD40 on the B cell. This interaction results in all of the elements necessary for the $\varepsilon$-heavy chain being brought into close proximity.

IgE levels influence $\mathrm{IgE}$ receptor density on cells. High levels of antibody increase both the number of FceRI receptors and the degranulation of mast cells and basophils. Along with degranulation, increased release of cytokines such as IL-4 occurs and these in turn stimulate increased $\operatorname{IgE}$ levels and receptor density. A reduction of $\mathrm{IgE}$ results in a reduction of receptor levels on mast 


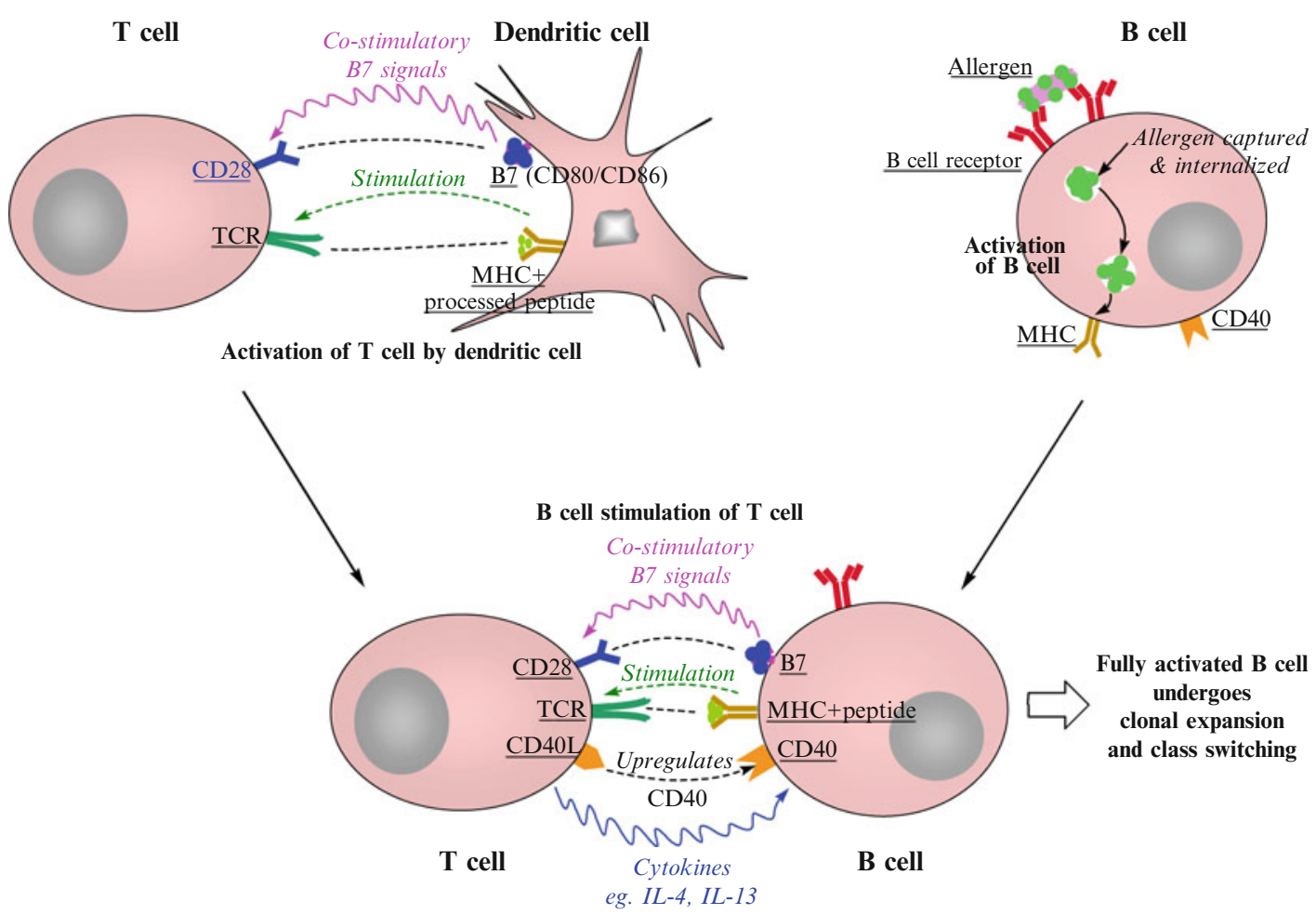

Fig. 3.3 Cellular events in the production of $\operatorname{IgE}$ antibodies. Presentation of antigen (usually in peptide form) to $\mathrm{T}$ cells via MHC molecules on dendritic cells. This results in the $\mathrm{T}$ cells undergoing clonal expansion.

cells and decreased degranulation. IgE is also capable of upregulating the FceRII receptor (see below). From the therapeutic aspect then, inhibition of $\operatorname{IgE}$ is desirable since it leads to a decrease in the release of mediators from mast cells and basophils. This is, in fact, the rationale for the use of omalizumab, a recombinant humanized IgG1k monoclonal antibody (see Sect. 11.1.3.1) used for patients with difficult-to-manage severe persistent allergic asthma. Omalizumab binds to the $C \varepsilon 3$ region of circulating human $\mathrm{IgE}$ antibodies inhibiting their binding to the FceRI and FceRII receptors and thus ultimately suppressing IgE-mediated mast cell activation and the allergic inflammatory response. It does not target receptor-bound $\operatorname{IgE}$ on mast cells and thus does not trigger mast cell degranulation. Another potential therapeutic approach to treat allergic disorders is the interference with the interaction between IL-4 and its receptor. Without this interaction, B cells do not
Antigen presentation to activated T cells by activated B cells ultimately results in co-stimulation of the B cells, class switching, clonal expansion, and differentiation to effector cells

differentiate into IgE-secreting plasma cells and Th2 cells and their functions in the allergic response are inhibited. Modulation of cytokines involved in the production of $\mathrm{IgE}$ is yet another therapeutic strategy. For example, IL-12 and IFN- $\gamma$ inhibit cytokine production by Th2 cells so interference with the expression of these cytokines suppresses IgE synthesis. For further biologic strategies in directing therapies for hypersensitivities, see Chap. 11.

\subsubsection{Allergic Release of Mediators of Hypersensitivity from Mast Cells}

The critical role of $\operatorname{IgE}$ in both the immediate and late phases of the allergic response is well established and, together with the mast cell, the resultant humoral and cellular interactions produce 

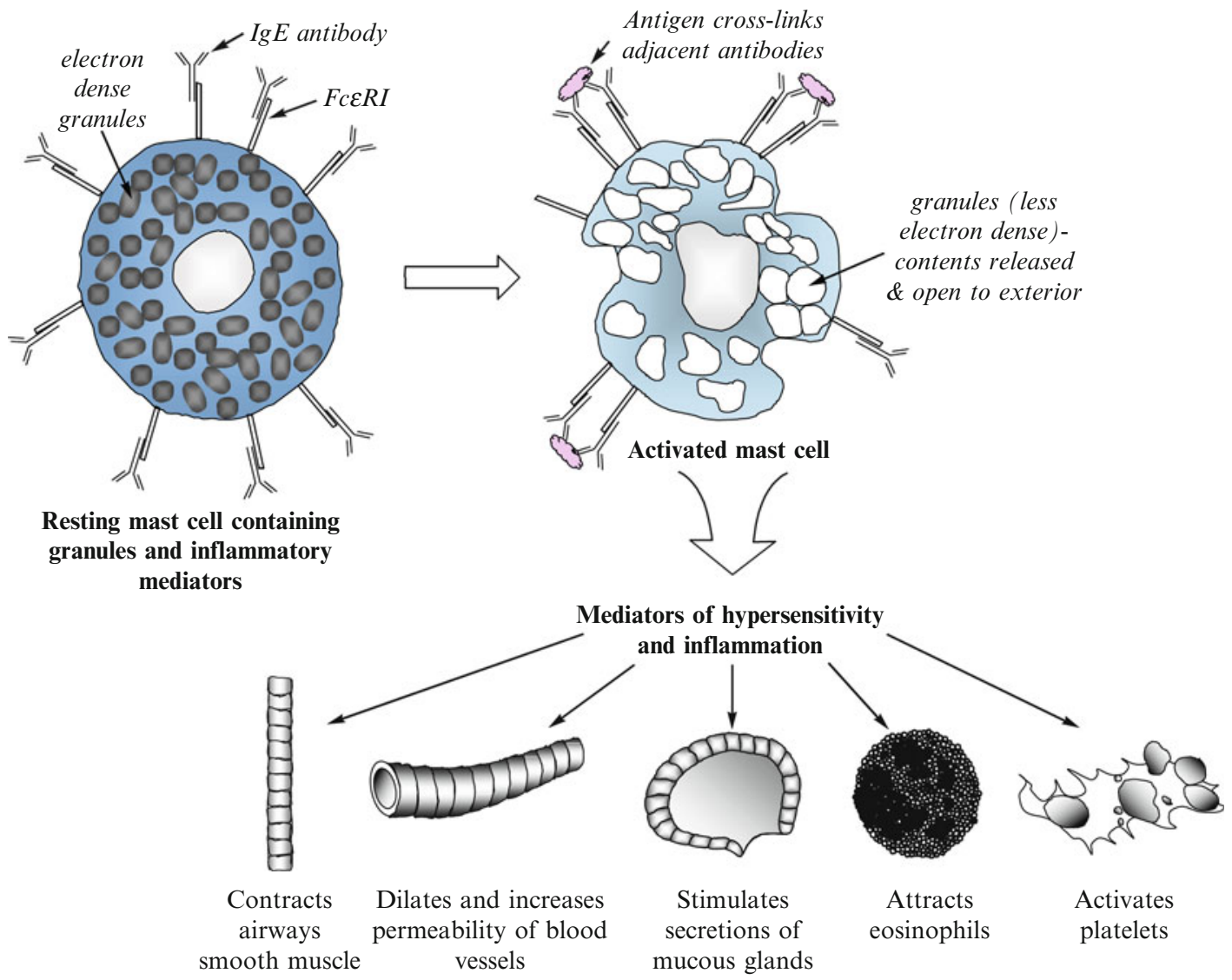

Fig. 3.4 Diagrammatic representation of antigeninduced degranulation of, and mediator release from, mast cells by antigen-effected cross-linking of adjacent cellbound complementary IgE antibodies the inflammatory mediators and symptoms characteristic of allergic reactions. On the basis of the type of proteases and proteoglycans in their granules, human mast cells can be divided into three populations: tryptase-only positive mast cells in the lungs and intestinal mucosa; tryptase, chymase, and carboxypeptidase positive mast cells in the skin, connective tissues, and intestinal mucosa; and a smaller population of chymase-only positive cells in the nasal and intestinal mucosae. For more details of tryptase and its importance as a diagnostic marker for anaphylaxis, the reader is referred to Sect. 4.5.1. The initial event in the activation of mast cells for mediator release is the binding of $\operatorname{IgE}$ antibodies to the high-affinity FceRI IgE receptor abundantly expressed on the mast cell and basophil surfaces (Fig. 3.4). The high affinity of the receptor $\left(\sim K_{\mathrm{a}} 10^{-10} \mathrm{M}\right)$ means that a high proportion of $\operatorname{IgE}$ is bound even in situations where there are low levels of circulating $\operatorname{IgE}$ antibodies. The FceRI complex is a receptor in tetramer form made up of a ligand-binding $\alpha$ chain structurally related to the $\alpha$ chains of $F c \gamma R$, a tetraspan $\beta$ chain, and the Fc $\gamma \mathrm{R} \gamma$ chain dimer. The $\alpha$ chain has two protruding Ig type domains that bind the $\mathrm{C} \varepsilon 3$ region of $\mathrm{IgE}$ and in the presence of the antibody the receptor is upregulated while the Fc receptor for IgG is downregulated. The $\beta$ and $\gamma$ chains each contain an ITAM (Immunoreceptor Tyrosine-based Activation Motif) that interact with the Lyn, Syk, and Fyn protein tyrosine kinases. The critical event and signal for mediator release, as occurs in anaphylaxis, is the cross-linking 
of receptor-bound $\mathrm{IgE}$ antibodies by allergen molecules reacting with the bivalent antibody combining sites. The IgE-FceRI complex is long-lasting and dissociates exceptionally slowly. Cross-linking of receptors causes their aggregation, rapid migration to lipid rafts, activation of the Lyn and Fyn protein tyrosine kinases, and ultimately transphosphorylation of the $\beta$ and $\gamma$ chains and involvement of the Syk kinase. Mast cell degranulation (Fig. 3.4), which can occur within seconds, follows a series of activation steps induced by phosphorylation reactions discussed in more detail in Sect. 3.2.6. Some of the released mediators of inflammation and anaphylaxis stored in the cytoplasmic granules including histamine (see below, Sect. 3.2.5.1), heparin, platelet-activating factor (PAF) (Sect. 3.2.5.3), serotonin, the enzymes tryptase, chymase, and carboxypeptidase, and eosinophil, neutrophil, and monocyte chemotactic factors are preformed while others are newly synthesized. The preformed mediators are responsible for the immediate signs and symptoms of vasodilation, edema, bronchoconstriction, and itching. The newly synthesized group of released mediators includes prostaglandin $\mathrm{D}_{2}\left(\mathrm{PGD}_{2}\right)$, thromboxanes, and leukotrienes $\mathrm{LTB}_{4}, \mathrm{LTC}_{4}$, and $\mathrm{LTD}_{4}$ (Sect. 3.2.5.2). A host of cytokines (pro- and anti-inflammatory), chemokines, and chemotactic, stimulating, and growth factors including interleukins $-1,-3,-4$, $-5,-6,-8,-9,-10,-11$, and -13 , tumor necrosis factor (TNF), granulocyte-macrophage colonystimulating factor (GM-CSF), monocyte chemotactic protein-1 (MCP-1), regulated upon activation normal $\mathrm{T}$ cell expressed and secreted (RANTES; CCL5), and eotaxin (CCL-11) are also released.

\subsubsection{Amplification of IgE Antibody Production by Cellular Interaction}

Mast cells, basophils, and even dendritic cells can accentuate B cell production of IgE antibodies by direct interaction (Fig. 3.5). IgE antibodies newly synthesized by plasma cells bind to the FceRI receptors on the surfaces of mast cells and basophils. Cross-linkage of antibodies by antigen that reacts with the combining sites of adjacent receptor-bound IgE molecules activates the receptors and triggers the cells to express CD40 ligand (CD40L) and secrete IL-4. These molecules react with their complementary receptors expressed on the B cell surface, and hence, like Th2 cells, mast cells and basophils can induce class switching and increase the production of IgE antibody.

\subsubsection{Low-Affinity IgE Receptor FCERII (CD23)}

A second receptor for IgE, the low-affinity receptor FceRII also known as CD23, is expressed on airways smooth muscle cells and several types of hematopoietic cells including mature B lymphocytes, macrophages, monocytes, dendritic cells, and eosinophils. The designation "low" affinity is derived from the receptor's lower affinity $\left(K_{\mathrm{D}}=\sim 10^{-7}-10^{-8}\right)$ than the affinity of the FceRI receptor $\left(K_{\mathrm{D}}=\sim 10^{-10}-10^{-11}\right)$. CD23 has multiple functions by virtue of its capacity to bind a range of different ligands. As well as binding IgE in both its secreted and B cell-bound form, CD23 binds CD21 (also known as complement receptor 2), CD18/CD11b (complement receptor 3), CD18/11c (complement receptor 4 ), and $\alpha_{v} \beta_{3}$, the vitronectin receptor. $\mathrm{CD} 23$ is a $45 \mathrm{kD}$ type II membrane protein with homology to calciumdependent (C-type) lectins. It is involved in both the up- and downregulation of IgE synthesis by B cells, augmentation of humoral and cellular responses, and facilitation of the phagocytosis of IgE opsonized antigens. Upon antigen-mediated cross-linking of bound IgE, the low-affinity receptor on B cells downregulates IgE synthesis. Augmentation of IgE-mediated responses can be demonstrated in vivo by the prevention of an immunogen and antigen-specific IgE-induced increase in serum IgE titers following pretreatment with anti-CD23 antibodies. As well as its effects on the FceRI receptor, IgE can also upregulate CD23 resulting in an increased allergic response in the bronchial mucosa. This is thought to occur via enhancement of allergen uptake and 


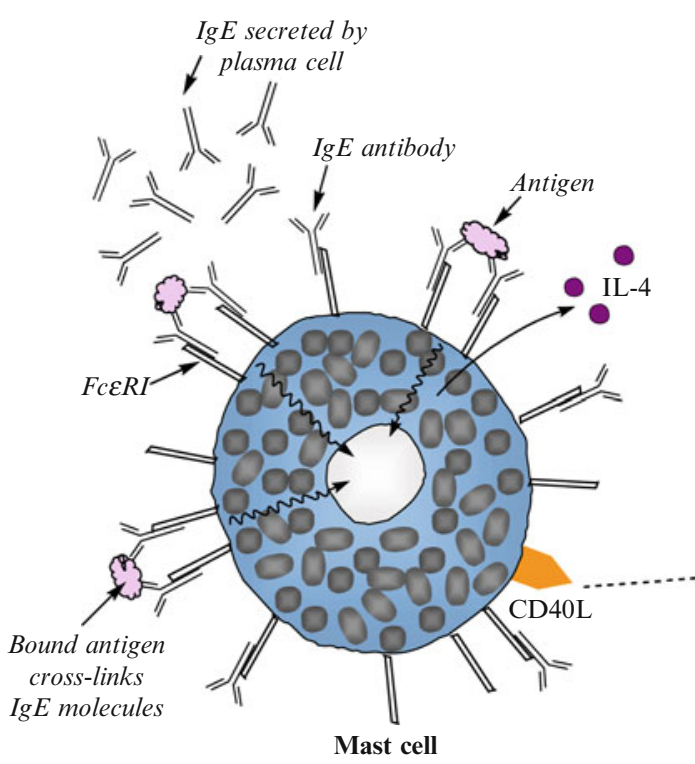

Fig. 3.5 Amplification of IgE antibody production by $\mathrm{B}$ cells by direct interaction of mast cells expressing CD40L and secreting IL-4. These interact with

presentation. Considering the effects of $\operatorname{IgE}$ on the high and low IgE receptors, inhibition of the antibody leads to downregulation of both receptors and ultimately decreased mediator release from mast cells and basophils.

Important findings on CD23 control of $\operatorname{IgE}$ antibody synthesis and homeostasis in human B cells have recently been forthcoming. The endogenous metalloprotease, a disintegrin and metalloproteinase domain-containing protein 10 (ADAM10), demonstrated the existence of two forms of $\mathrm{CD} 23$ by releasing its soluble form (sCD23) from membrane CD23 (mCD23). Upregulation of mCD23 in tonsil B cells following treatment with Il-4 and anti-CD40 led to accumulation of sCD23 in the medium prior to class switching to $\operatorname{IgE}$ synthesis. Inhibition of mCD23 cleavage by an inhibitor of ADAM10 or small interfering RNA inhibition of CD23 synthesis suppressed IL-4- and anti-CD40-induced $\mathrm{IgE}$ synthesis, but addition of recombinant sCD23 enhanced IgE synthesis. Since this occurred even when mCD23 is protected from cleavage, it seems that IgE synthesis is positively
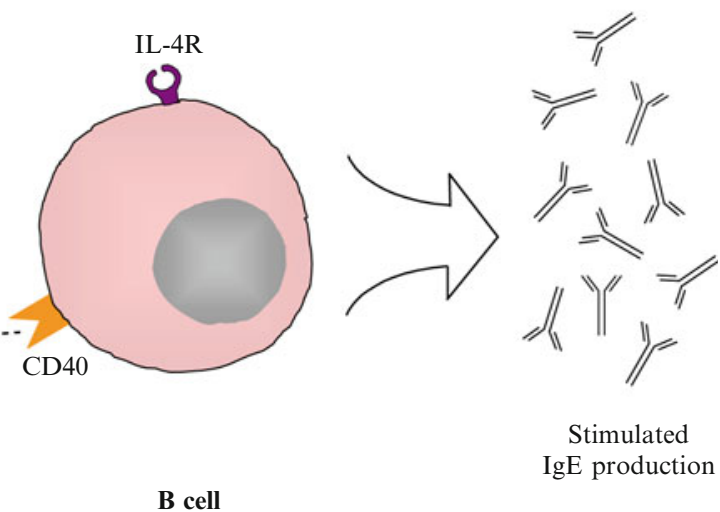

Stimulated IgE production

their complementary receptors on the B cell surface inducing class switching and the production of $\operatorname{IgE}$ antibodies

controlled by sCD23, and further, sCD23 binds to cells co-expressing IgE and membrane CD21. These results have been interpreted as membranebound IgE and CD21 having a role in the SCD23mediated positive regulation of $\mathrm{IgE}$ synthesis with feedback occurring when the concentration of IgE becomes great enough to allow binding to $\mathrm{mCD} 23$, thus preventing further release of its soluble form.

\subsubsection{Important Mediators of the Type I Immediate Allergic Response}

\subsubsection{Histamine}

The reader is also referred to Sect. 4.5.2 for a consideration of the place of histamine in the diagnosis of drug allergies and to Sect. 8.4.1 for a summary of histamine receptors and their relevance to opioid analgesics.

Histamine (2-(imidazol-4-yl)ethylamine) is one of the most intensely studied molecules in all biological systems. This fact, and its appar- 
ent myriad physiological and pathological effects, is behind a seemingly ever-expanding literature on an extraordinarily broad spread of activities including its role in inflammatory and allergic reactions; many aspects of the immune response; differentiation; cell proliferation; hematopoiesis; neurotransmission; regulation of circulatory functions, vasodilation, and blood pressure; wound healing; gastrointestinal function; and, no doubt, numerous others yet to be elucidated. In peripheral tissues, more than $90 \%$ of body stores of histamine are found in mast cells and basophils, although there are two other main sources in humans-enterochromaffin-like cells of the gut and histaminergic nerves in the brain. In mast cells and basophils, histamine is stored in granules in association with different anionic proteoglycans-heparin in mast cells and condroitin-4-sulfate in basophils. Upon degranulation elicited by specific IgE antibodies, cytokines, or histamine releasers like compound 48/80, calcium ionophore, $\mathrm{N}$-formyl-met-leu-phe, phorbol 12-myristate 13-acetate, and some drugs such as opioid analgesics and neuromuscular blockers, histamine is released from the granules in large amounts with the associated proteoglycan.

\subsection{Histamine Biosynthesis and Metabolism}

Histamine is synthesized from L-histidine exclusively by the inducible enzyme L-histidine decarboxylase located in the cytosol and widely expressed in the body in various cells including mast cells, basophils, parietal cells, gastric mucosa, neurons, and cells of the central nervous system. The mammalian enzyme requires pyridoxine-5-phosphate as an active site cofactor (Fig. 3.6). Once synthesized, histamine is transported from the cytosol to the secretory granules by vesicular monoamine transporter 2 (VMAT2). L-Histidine decarboxylase is detectable only in cells producing histamine since it is synthesized only when the mediator is required and degraded as soon as synthesis is terminated. Given histamine's pronounced physiological actions, its inactivation to metabolites that do not interact with histamine receptors is a requirement.
This is achieved by methylation and oxidation. In mammals, histamine is inactivated in two main ways-methylation of the imidazole ring effected by histamine $N$-methyltransferase (HMT) and oxidative deamination of the primary amino group catalyzed by diamine oxidase (DAO) - to form $N$-methylhistamine and imidazole-4-acetaldehyde, respectively (Fig. 3.6). HMT, which is specific for histamine, is present in most tissues and responsible for the inactivation of intracellular histamine. The enzyme catalyzes the transfer of a methyl group from $S$-adenosyl-L-methionine to the secondary amino group of the imidazole ring. DAO is stored in secretory vesicles and expressed mainly in intestinal and kidney epithelial cells. Its release is stimulated by heparin which is liberated together with histamine by activated mast cells. Heparin terminates the action of histamine by inactivating it locally. DOA is also active in the gut where it catabolizes histamine present in some foods, thus preventing it from entering the circulation. The products of histamine inactivation by the two different routes are further metabolized (Fig. 3.6). $N$-methylhistamine is converted to $\mathrm{N}$-methylimidazole-4-acetaldehyde by mitochondrial monoamine oxidases and this aldehyde, in turn, is catalyzed by aldehyde dehyrogenases to $\mathrm{N}$-methylimidazole-4-acetic acid. In the DAO pathway, the first product from the breakdown of histamine, imidazole-4-acetaldehyde, is also catalyzed to the acetic acid derivative by aldehyde dehydogenase before its subsequent ribosylation for transport and excretion.

\subsection{Histamine Receptors}

The physiological and pharmacological effects of histamine are mediated through four different receptors $\mathrm{H}_{1}, \mathrm{H}_{2}, \mathrm{H}_{3}$, and $\mathrm{H}_{4}$, all members of the 7-transmembrane $\mathrm{g}$ protein-coupled receptor (GPCR) family with amino terminal glycosylation sites and phosphorylation sites for protein kinases $\mathrm{A}$ and $\mathrm{C}$. The receptors are widely expressed on different tissues that are responsive to histamine. For the $\mathrm{H}_{1}$ receptor these tissues include smooth muscle cells of the airways and vasculature, the gastrointestinal tract, cardiovascular system, neutrophils, endothelial cells, T and B cells, hepatocytes, nerve 


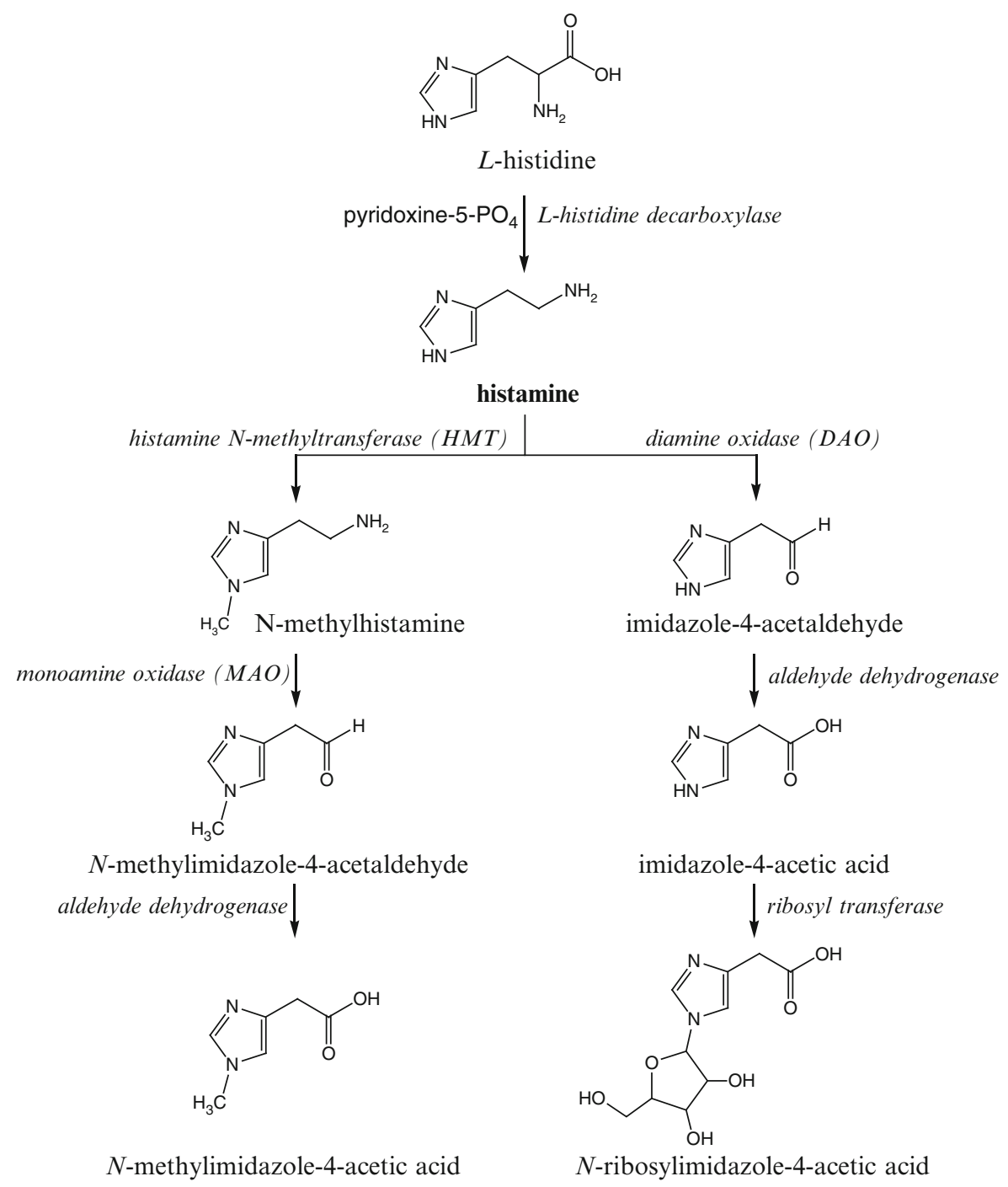

Fig. 3.6 Biosynthesis of histamine from L-histidine by the widely expressed enzyme L-histidine decarboxylase

cells, and cells of the genitourinary system suggesting an important role for the autacoid in the modulation of immune, inflammatory, and allergic processes. The $\mathrm{H}_{2}$ receptor is expressed in gastric parietal cells, the central nervous system, vascular smooth muscle, heart, neutrophils, and uterus. $\mathrm{H}_{3}$ receptors appear to be less widely distributed occurring in the central and peripheral nervous and its metabolism by methylation (via histamine $\mathrm{N}$-methyltransferase) and oxidation (via diamine oxidase)

systems while $\mathrm{H}_{4}$ receptors are largely expressed in hemopoietic cells where they modulate eosinophil migration and selective recruitment of mast cells. For signal transduction, the $\mathrm{H}_{1}$ and $\mathrm{H}_{2}$ receptors activate $\mathrm{G}_{\mathrm{q}}$ and $\mathrm{G}_{\mathrm{s}}$-coupled proteins respectively while both $\mathrm{H}_{3}$ and $\mathrm{H}_{4}$ are coupled to, and activate, $\mathrm{G}_{\mathrm{i} / \mathrm{o}}$ proteins. 
Pathophysiological effects resulting from stimulation of the $\mathbf{H}_{1}$ receptor include those responses seen in immediate allergic reactions, viz, redness, itch, swelling, asthma, anaphylaxis, bronchoconstriction, and vascular permeability. The primary activation of the $\mathrm{H}_{1}$ receptor, a $\mathrm{G} \alpha_{\mathrm{q} / 11}$-coupled protein, proceeds through phospholipase $\mathrm{C}$ which catalyzes the formation of inositol-1,4,5-triphosphate $\left(\mathrm{IP}_{3}\right)$ and 1,2diacylglycerol (DAG) from phosphatidylinositol 4,5-biphosphate. $\mathrm{IP}_{3}$, released into the cytosol, binds to its receptor in the endoplastic reticulum causing an increase in cytosolic $\mathrm{Ca}^{2+}$ levels. $\mathrm{DAG}$, acting as a second messenger, activates protein kinase $\mathrm{C}$ (PKC). This pathway is activated and proceeds in the brain, airways, and intestinal and vascular smooth muscle. $\mathrm{H}_{1}$ receptor activation in some other tissues can stimulate adenyl cyclase and cAMP formation. The signaling pathways are not yet fully understood, particularly details of the involvement of $\mathrm{Ca}^{2+}$. Some of the resultant responses in vascular endothelial cells after stimulation of the $\mathrm{H}_{1}$ receptor and elevated intracellular $\mathrm{Ca}^{2+}$ levels are permeability changes, synthesis of prostacyclin and plateletactivating factor (PAF), and release of Von Willebrand factor and nitric oxide (NO).

Whereas $\mathrm{H}_{1}$ receptors are involved with positive effects, $\mathbf{H}_{2}$ receptors appear to mainly mediate suppressive activities of histamine including gastric acid secretion, heart contraction, cell proliferation, differentiation, and some effects on the immune response. $\mathrm{H}_{2}$ receptors are coupled to the adenylate cyclase as well as the phosphoinositide second messenger systems via separate GTPdependent mechanisms, but $\mathrm{H}_{2}$-dependent effects, particularly those of the central nervous system, are predominantly mediated through cAMP. It has been shown that receptor binding stimulates activation of c-Fos, c-Jun, PKC, and P70S6 kinase. Alternative signaling pathways have been reported (Fig. 3.7). These include a receptor-mediated increase in intracellular $\mathrm{Ca}^{2+}$ and/or $\mathrm{IP}_{3}$ levels in HL-60 human promyelocytic leukemia cells and an increase in cAMP and inhibition of release of arachidonic acid in Chinese hamster ovary $(\mathrm{CHO})$ cells transfected with rat cDNA and induced by calcium ionophore.
The $\mathbf{H}_{3}$ receptor regulates the synthesis and release of histamine and also has a regulatory role in the release of neurotransmitters such as serotonin, dopamine, and norepinephrine. The receptor is expressed in those regions of the central nervous system associated with cognition, in particular, the hippocampus, basal ganglia, and cortical areas, and in the peripheral nervous system, namely, the cardiovascular system, gastrointestinal tract, and airways. The $\mathrm{H}_{3}$ receptor signals through $\mathrm{G}_{\mathrm{i} / \mathrm{o}}$ proteins and alternative signaling pathways appear to be activated by these proteins. Stimulation of the receptor results in adenyl cyclase inhibition and lower levels of cAMP and PKA. Alternative signaling pathways may be activated including activation of phospholipase $\mathrm{A}_{2}\left(\mathrm{PLA}_{2}\right)$, stimulation of mitogenactivated protein kinase (MAPK), the inhibition of $\mathrm{Na}^{+} / \mathrm{H}^{+}$exchange, and $\mathrm{K}^{+}$-induced $\mathrm{Ca}^{2+}$ mobilization. A study of $\mathrm{H}_{3}$ receptor-mediated attenuation of norepinephrine exocytosis in cardiac sympathetic nerves identified a novel pathway in which stimulation of the receptors on nerve endings produces intraneuronal activation of the MAPK cascade. $\mathrm{PLA}_{2}$, phosphorylated by MAPK, translocates to the cell membrane where it acts on membrane phospholipids producing arachidonic acid, the substrate for cyclooxygenase and the production of prostaglandin $\mathrm{E}_{2}$ $\left(\mathrm{PGE}_{2}\right) . \mathrm{PGE}_{2}$ activates prostaglandin $\mathrm{E}$ receptor $3\left(\mathrm{EP}_{3} \mathrm{R}\right)$ on the cell membrane where the $\mathrm{G} \beta \gamma_{\mathrm{i}}$ subunit of $\mathrm{EP}_{3} \mathrm{R}$ inhibits $\mathrm{Ca}^{2+}$ entry resulting in attenuation of norepinephrine exocytosis. It is apparent that with the $\mathrm{H}_{3}$ receptor, different signaling can be employed in different cell systems. A further illustration of this is the demonstration of $\mathrm{H}_{3}$ receptor-mediated activation in the inhibition of the growth of cholangiocarcinoma in vitro and in vivo. Activation of $\mathrm{H}_{3}$ receptors by a highaffinity $\mathrm{H}_{3}$ agonist decreased cholangiocarcinoma growth by increasing levels of $\mathrm{IP}_{3}$, translocation of $\mathrm{PKC} \alpha$, and $\mathrm{IP}_{3} / \mathrm{Ca}^{2+}$-dependent dephosphorylation of the extracellular signalregulated kinases ERK 1/2.

A new signaling pathway of the $\mathrm{H}_{3}$ receptor involving receptor modulation of the activity of the serine/threonine-specific protein kinase Akt (protein kinase B, PKB)/GSK-3 $\beta$ (glycogen 


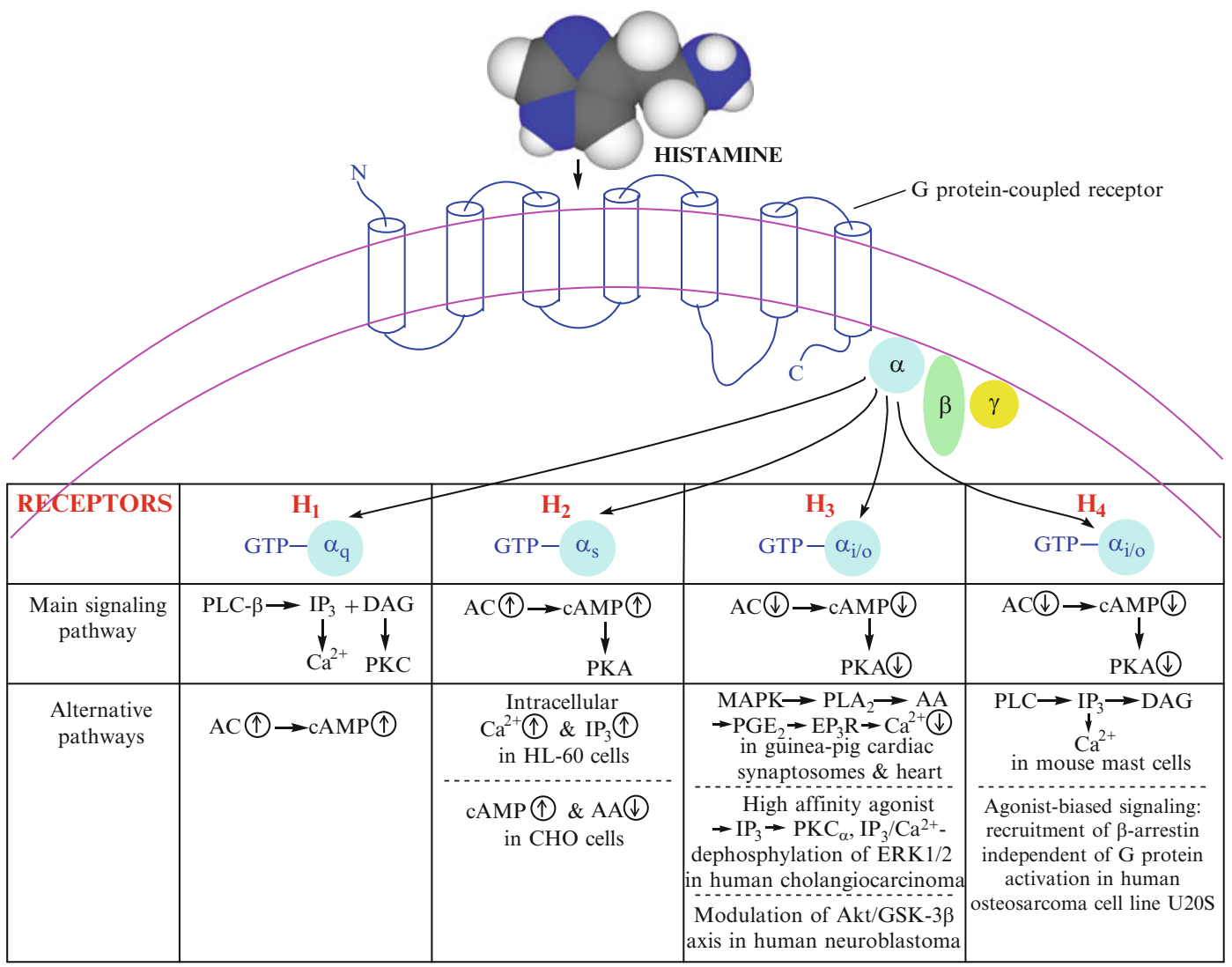

Fig. 3.7 Summarized comparisons of $\mathrm{G}$ protein coupling and main and alternative signaling pathways for the four histamine receptors $\mathrm{H}_{1}, \mathrm{H}_{2}, \mathrm{H}_{3}$, and $\mathrm{H}_{4}$. (see also Table 3.1)

synthase kinase $3 \beta$ ) axis was recently demonstrated in SK-N-MC cells from a neuroepithelioma cell line. Receptor stimulation with an $\mathrm{H}_{3}$ agonist induced the phosphorylation of Ser473 and Thr308 on Akt, a kinase important for neuronal development and function. Studies suggested that the Akt activation occurs via a $\mathrm{G}_{\mathrm{i} / \mathrm{o}}$-mediated activation of PI3K (see Sect. 3.2.6.1). $\mathrm{H}_{3}$ receptor activation also resulted in phosphorylation of Ser 9 on GSK-3 $\beta$, a ser/thr kinase which acts downstream of Akt. This kinase is important in brain function and this newly identified signaling pathway adds important knowledge to our understanding of the role of $\mathrm{H}_{3}$ receptor-controlled histamine in brain function. The three aboveoutlined alternative pathways are summarized in Fig. 3.7.
Following the realization that not all of the biological effects of histamine could be attributed to histamine receptors $\mathrm{H}_{1}, \mathrm{H}_{2}$, and $\mathrm{H}_{3}$, a fourth receptor was postulated and histamine receptor $\mathbf{H}_{4}$ was subsequently cloned in 2000-2001. Receptor $\mathrm{H}_{4}$ shows a $35 \%$ amino acid sequence homology with the $\mathrm{H}_{3}$ receptor and the two are similar in gene structure. The receptor, essentially confined to hemopoietic cells, exerts a chemotactic effect on several cell types associated with immune and inflammatory responses such as allergy, asthma, rheumatoid arthritis, and inflammatory bowel disease and this has led to interest in the development of new agents targeting these diseases. $\mathrm{H}_{4}$ receptors are functionally expressed on mast cells, eosinophils, monocytes, dendritic cells, and CD8+ T cells. Although the presence 
Table 3.1 Summarized comparison of function, $\mathrm{G}$ protein coupling and signaling pathways of histamine $\mathrm{H}_{1}, \mathrm{H}_{2}, \mathrm{H}_{3}$, and $\mathrm{H}_{4}$ receptors ${ }^{\mathrm{a}}$

\begin{tabular}{lllll}
\hline Receptor & $\mathrm{H}_{1}$ & $\mathrm{H}_{2}$ & $\mathrm{H}_{3}$ & $\mathrm{H}_{4}$ \\
\hline Best characterized function & $\begin{array}{l}\text { Acute allergic } \\
\text { reaction }\end{array}$ & Gastric acid secretion & $\begin{array}{l}\text { Modulation of } \\
\text { neurotransmitters }\end{array}$ & $\begin{array}{l}\text { Immuno- } \\
\text { modulation }\end{array}$ \\
\hline Indications for antagonists & $\begin{array}{l}\text { Allergy, } \\
\text { pruritus }\end{array}$ & $\begin{array}{l}\text { Gastroesophageal reflux } \\
\text { disease, peptic ulcer }\end{array}$ & $\begin{array}{l}\text { Sleep and cognition } \\
\text { disorders }\end{array}$ & $\begin{array}{l}\text { Pruritus, } \\
\text { asthma }^{\mathrm{c}}\end{array}$ \\
\hline G protein coupling & $\mathrm{G}_{\mathrm{\alpha q} / 11}$ & $\mathrm{G}_{\mathrm{\alpha s}}$ & $\mathrm{G}_{\alpha \mathrm{\alpha} / \mathrm{o}}$ & $\mathrm{G}_{\mathrm{\alpha i} / \mathrm{o}}$ \\
\hline Main signaling pathway & $\mathrm{Ca}^{2+} \uparrow$ & $\mathrm{cAMP} \uparrow$ & Inhibition of cAMP $^{\mathrm{Ca}^{2+} \uparrow}$ \\
\hline
\end{tabular}

${ }^{\text {a See also Fig. } 3.7}$

${ }^{\mathrm{b}}$ Approved indications

'Potential indications

of large amounts of histamine in mast cells and the cell's histamine-releasing properties are well known, expression of histamine receptors on mast cells had not been convincingly demonstrated and there has been little information on the effect of histamine on the cell. It is now known that mast cells express the $\mathrm{H}_{4}$ but not the $\mathrm{H}_{3}$ receptor, but exposure to histamine, or histamine in combination with antigen-IgE antibody complexes, does not lead to degranulation of mast cells. The $\mathrm{H}_{4}$ receptor has, however, been clearly implicated in inflammation and pruritus in animal models. In a rat model of carrageenaninduced acute inflammation, antagonists of the receptor inhibited edema formation and reversed the thermal hyperalgesia. In a histamine-induced itch model in mice, $\mathrm{H}_{4}$ antagonists inhibited but did not abolish scratching and itch was reduced in $\mathrm{H}_{4}$-deficient mice. Centrally acting $\mathrm{H}_{1}$ receptor antagonists produced a partial reduction and combined treatment with both antagonists completely eliminated itch. Further evidence for the involvement of both $\mathrm{H}_{4}$ and $\mathrm{H}_{1}$ receptors in histamine-induced itch was the production of itch following administration of agonists of both receptors. There are many mediators of itch and mechanisms are complex. With the belief that the mechanisms underlying itch in chronic conditions such as atopic dermatitis are more likely those associated with mast cell degranulation, a mouse model of itch was set up by injecting antigen-specific IgE intradermally and challenging with antigen $24 \mathrm{~h}$ later. $\mathrm{H}_{4}$ receptor antagonists significantly reduced itch and this was also the result seen in mice deficient in the $\mathrm{H}_{4}$ receptor. Interestingly, expression of the $\mathrm{H}_{4}$ receptor on mast cells or any other cell was not required for the pruritic activity, leading to the speculation that $\mathrm{H}_{4}$ receptor-mediated pruritus may result from actions on peripheral neurons. While the relevance to pruritus in humans of the results with animal models is uncertain, there is optimism that antihistamines specifically targeting the $\mathrm{H}_{4}$ receptor may lead to more effective treatment of pruritic conditions in humans.

The $\mathrm{H}_{4}$ receptor is mainly coupled to $\mathrm{G}_{\mathrm{i} / \mathrm{o}}$ proteins and, in common with the $\mathrm{H}_{3}$ receptor, this leads to inhibition of adenyl cyclase and decreased production of cAMP and downstream effects on cAMP response element-binding (CREB) gene transcription. As with the other histamine receptors, other signaling pathways have been reported (Fig. 3.7). From a study of the signaling pathways of the endogenous mouse $\mathrm{H}_{4}$ receptor of bone marrow-derived mast cells, histamine activation of the receptor was shown to induce chemotaxis without affecting degranulation of the mast cells. The following interpretations and sequence of events were suggested. Binding of histamine to the receptor on mast cells and eosinophils activates the pertussis toxinsensitive $\mathrm{G} \alpha_{\mathrm{i} / \mathrm{o}}$ proteins triggering PLC possibly via the $G$ protein $\beta \gamma$ subunits dissociated from the $\mathrm{G} \alpha_{\mathrm{i} / \mathrm{o}}$ proteins. PLC hydrolyzes phosphatidylinositol 4,5-biphosphate to $\mathrm{IP}_{3}$ and DAG. $\mathrm{IP}_{3}$ diffuses into the cytosol and binds to its receptor on the endoplastic reticulum where it activates a $\mathrm{Ca}^{2+}$ channel causing the release of intracellular 
$\mathrm{Ca}^{2+}$. The increased $\mathrm{Ca}^{2+}$ triggers mast cell chemotaxis toward histamine by pathways yet to be worked out. It has been suggested that this mechanism might be responsible for mast cell accumulation in allergic tissues.

There is mounting evidence that when the same receptor can activate more than one pathway, some agonists can activate one pathway in preference to another. The need to consider more than one downstream signaling pathway in histamine-GPCR studies was again reinforced by a recent investigation of signaling at the $\mathrm{H}_{4}$ receptor using the selective antagonist for $\mathrm{G}$ protein-dependent signaling JNJ7777120 (1-[(chloro-1- $H$-indol-2-yl)carbonyl]-4-methylpiperazine). Downstream signaling measurements of $G$ protein activation and $\beta$-arrestin recruitment demonstrated that the antagonist is what has been described as a biased agonist, acting as an agonist in a non- $G$ protein-dependent manner to recruit $\beta$-arrestin to the receptor. $\beta$-Arrestin is part of the mechanism for regulating the activity of GPCRs. In stabilizing an alternative active conformation of the $\mathrm{H}_{4}$ receptor that initiates $\beta$-arrestin recruitment but not $G$ protein activation, that is, agonist-biased signaling, JNJ7777120 may be exhibiting the capacity to exist in multiple active conformations. This may result in an agonist stabilizing a slightly different state that preferentially couples to one pathway and not another.

Summarized comparisons of functions, indications for antagonists, G protein coupling, and signaling pathways for the four histamine receptors are shown in Table 3.1 and Fig. 3.7.

\subsubsection{Cysteinyl Leukotrienes}

For a discussion of cysteinyl leukotrienes in relation to diagnostic investigations of suspected drug allergies, see Sect. 4.5.3.

Originally isolated after stimulation of lung tissue by histamine and snake venom and named over 70 years ago as "slow reacting substance of anaphylaxis," (SRS-A), leukotrienes are a family of bioactive peptide-conjugated eicosanoid lipids produced by mast cells, basophils, eosinophils, and macrophages. The name "cysteinyl leukotrienes" is derived from the facts that the com- pounds are synthesized by leukocytes, they contain three conjugated double bonds or alkenes, and four members of the group, $\mathrm{LTC}_{4}, \mathrm{LTD}_{4}$, $\mathrm{LTE}_{4}$, and $\mathrm{LTF}_{4}$, contain the amino acid cysteine. Although the leukotrienes were originally identified by their contractile effect on smooth muscle, they are now recognized as potent inflammatory mediators with a range of other biologic effects. In particular, $\mathrm{LTC}_{4}$ and $\mathrm{LTD}_{4}$ are powerful mediators of asthma, airway hypersensitivity, and allergies, inducing bronchoconstriction, increasing vascular permeability, and promoting mucous secretion. Upon inhalation, both mediators are up to 1,000 times as potent as histamine whereas $\mathrm{LTE}_{4}$ is only 39 times as potent as histamine in reducing maximum expiratory flow at $30 \%$ of vital capacity. $\mathrm{LTE}_{4}$, the most stable of the three cysteinyl leukotrienes, is present in greatest amount in vivo where it induces bronchial eosinophilia and airway hyperresponsiveness. Unlike $\mathrm{LTC}_{4}$ and $\mathrm{LTD}_{4}, \mathrm{LTE}_{4}$ persists longer in serum, urine, and bronchoalveolar lavage fluid of asthmatics. Urinary excretion of $\mathrm{LTE}_{4}$ is therefore sometimes used as an indicator of asthma. The bronchoconstriction provoked by $\mathrm{LTE}_{4}$ is strong in patients with aspirin-sensitive asthma but much weaker in other asthmatics, whereas $\mathrm{LTD}_{4}$ is much more pronounced in asthmatic patients not sensitive to aspirin (see Chap. 9). Another difference between the two mediators in their effects on asthmatics is the recruitment into sputum of basophils, mast cells, and eosoniphils by $\mathrm{LTE}_{4}$ but not by $\mathrm{LTD}_{4}$. $\mathrm{LTD}_{4}$ aids the adhesion and migration of some cancer cells and increases proliferation of mast cells. All three cysteinyl leukotrienes produce an equiactive wheal and flare reaction characteristic of an allergic response when injected intradermally at a concentration of $1 \mathrm{nmol}$ per site.

\subsection{Biosynthesis}

As part of the response to leukocyte cell activation, cysteinyl leukotrienes are generated de novo from arachidonic acid liberated from cell membrane phospholipid by cytosolic phospholipase A2 (Fig. 3.8). In concert with 5-lipoxygenaseactivating protein (FLAP), the enzyme 5-lipoxygenase (5-LO) converts arachidonic 


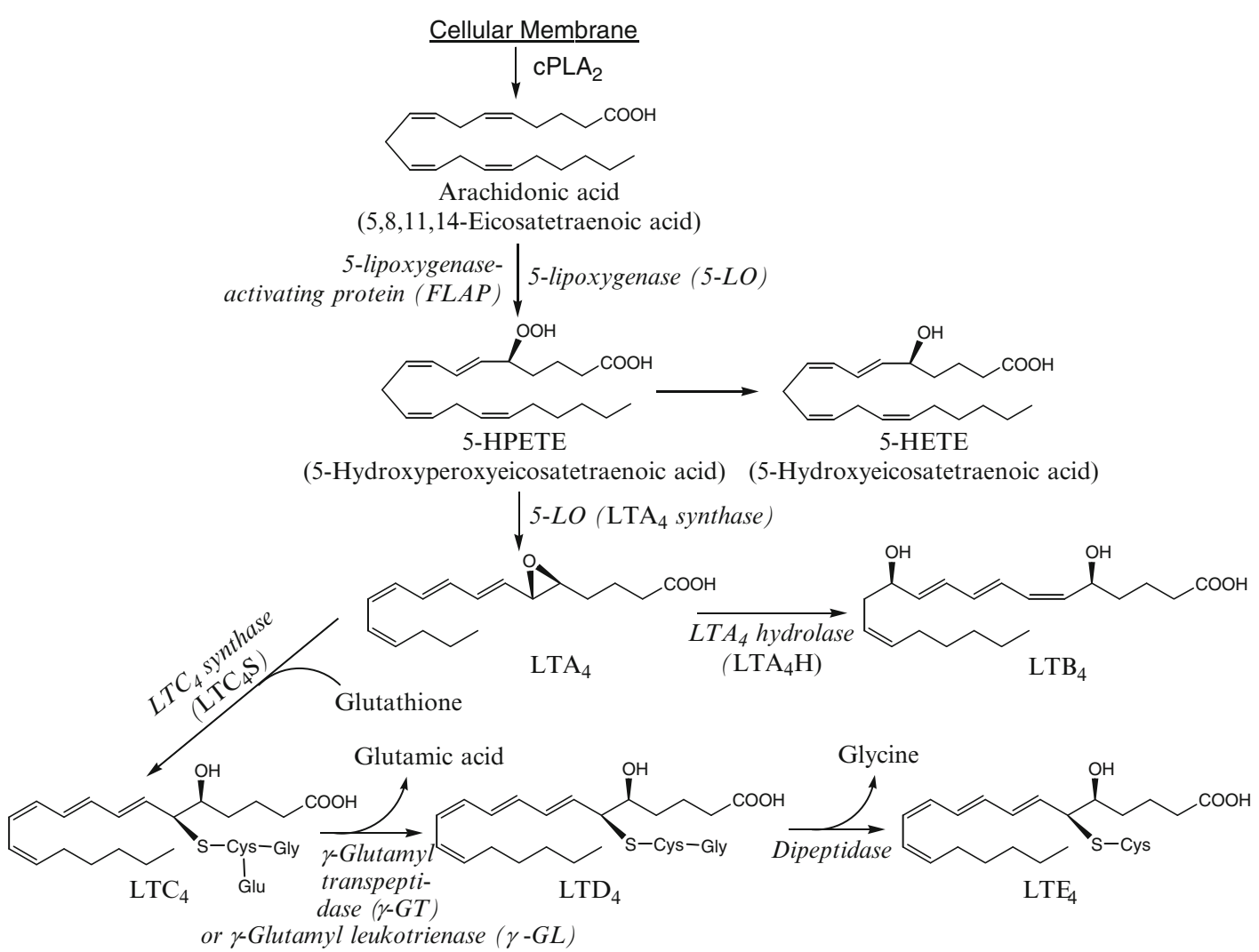

Fig. 3.8 Biosynthesis of cysteinyl leukotrienes from arachidonic acid showing the pathways to the formation of LTA $_{4}$, $\mathrm{LTB}_{4}, \mathrm{LTC}_{4}, \mathrm{LTD}_{4}$, and $\mathrm{LTE}_{4}$

acid to 5-hydroxyperoxyeicosatetraenoic acid (5-HPETE) which spontaneously reduces to 5-hydroxyeicosatetraenoic acid (5-HETE). 5-LO converts 5-HPETE to leukotriene $\mathrm{A}_{4}$, an unstable peroxide. Note that the enzyme involved in this step is sometimes referred to as $\mathrm{LTA}_{4}$ synthase. $\mathrm{LTA}_{4}$ synthase activity co-purifies with 5-LO and the same cytosolic and membrane-bound active proteins are required for reactions catalyzed by 5-LO and the so-called $\mathrm{LTA}_{4}$ synthase in crude human leukocyte homogenates leading to the conclusion that a single enzyme is responsible for the production of 5-HPETE from arachidonic acid and for its subsequent conversion to $\mathrm{LTA}_{4}$. In neutrophils and monocytes which have the enzyme $\mathrm{LTA}_{4}$ hydrolase, $\mathrm{LTA}_{4}$ is converted to the dihydroxyacid leukotriene $\mathrm{LTB}_{4}$, a chemoattractant for neutrophils, whereas in mast cells, basophils, eosinophils, and macrophages, all of which express $\mathrm{LTC}_{4}$ synthase, $\mathrm{LTA}_{4}$ is conjugated to reduced tripeptide glutathione to form the cysteinyl leukotriene $\mathrm{LTC}_{4}$. After transportation to the cell surface in an energy-dependent step with the assistance of multidrug resistance-associated protein 1 (MRP-1), LTC $_{4}$ is converted extracellularly to $\mathrm{LTD}_{4}$ by a $\gamma$-glutamyl transpeptidase $(\gamma$-GT) or $\gamma$-glutamyl leukotrienase $(\gamma$-GL). In the final step in the pathway, a dipeptidase removes glycine from $\mathrm{LTD}_{4}$ producing $\mathrm{LTE}_{4}$ which is excreted unchanged in the urine. $\mathrm{LTF}_{4}$ which has an $S$-glutamylcysteinyl group has been prepared in vitro from $\mathrm{LTE}_{4}$ with glutathione and $\gamma$-glutamyltranspeptidase but, as yet, it has not been found in vivo. In comparison to the other cysteinyl leukotrienes, $\mathrm{LTF}_{4}$ contracts vascular smooth muscle poorly - the rank order of potency being $\mathrm{LTD}_{4}>\mathrm{LTC}_{4}>\mathrm{LTE}_{4}>>\mathrm{LTF}_{4}$. Although leukotriene synthesis generally proceeds 
via the 5-LO pathway, a second family of leukotrienes (eoxins, given the prefix EX) can be generated from the action of 15-LO (and 12-LO) first on arachidonic acid and then, for the 15-lipoxygenase compounds, 15-HPETE to form the 15-epoxytriene 15-LTA 4 (EXA $)$ followed by the pro-inflammatory cysteinyl 15-leukotrienes $15-\mathrm{LTC}_{4}\left(\mathrm{EXC}_{4}\right), 15-\mathrm{LTD}_{4}\left(\mathrm{EXD}_{4}\right)$, and $15-\mathrm{LTE}_{4}\left(\mathrm{EXE}_{4}\right)$ in eosinophils, mast cells, and nasal polyps of allergic subject (see also Sects. 9.4.1, 9.4.3 and Fig. 9.3). IL-4-primed human mast cells incubated with arachidonic acid synthesize and release $\mathrm{EXC}_{4}$ and possess the capacity to produce $\mathrm{EXD}_{4}$ cells while nasal polyps spontaneously release $\mathrm{EXC}_{4}$. Eoxins modulate and enhance vascular permeability, being 100 times more potent in this respect than histamine and almost as potent as $\mathrm{LTC}_{4}$ and $\mathrm{LTD}_{4}$. Two types of the 15-LO enzyme are known, 15-LO-1 (which also has about $10 \%$ 12-lipoxygenating activity) and 15-LO-2, both of which produce 15(S)-HETE from arachidonic acid but 15-LO-1 oxygenates arachidonic acid at carbons 15 and 12 while 15-LO-2 adds oxygen only at carbon 15 . Human eosinophils and airways epithelial cells contain high amounts of 15-LO-1 as do some subsets of human mast cells, macrophages, and dendritic cells. Expression of 15-LO-2 appears to be restricted to lung, skin, prostate, and cornea.

\subsection{Cysteinyl Leukotriene Receptors}

Two human cysteinyl leukotriene receptors $\operatorname{CysLT}_{1} \mathrm{R}$ and $\operatorname{CysLT}_{2} \mathrm{R}$, cloned at the turn of the century, do not bind the three cysteinyl leukotriene ligands equally. The rank order of binding for CysLT $_{1} \mathrm{R}$ is $\mathrm{LTD}_{4}>\mathrm{LTC}_{4}=\mathrm{LTE}_{4}$ and for $\mathrm{CysLT}_{2} \mathrm{R}$, $\mathrm{LTC}_{4}=\mathrm{LTD}_{4}>\mathrm{LTE}_{4}$. The receptors are expressed on a wide range of organ tissues and cell types$\mathrm{CysLT}_{1} \mathrm{R}$ on spleen, lung, small intestine, placenta, bronchial smooth muscle, mast cells, neutrophils, eosinophils, macrophages, monocytes, and hemopoietic progenitor cells and $\mathrm{CysLT}_{2} \mathrm{R}$ on lung, heart, lymph node, spleen, brain, bronchial and coronary smooth muscle, adrenal medulla, mast cells, eosinophils, macrophages, and monocytes. The receptors were ini- tially studied with prototypes of the later-to-bedeveloped "lukast" antagonists. CysLT $\mathrm{C}_{1} \mathrm{R}$, which bound $\mathrm{LTD}_{4}$ much more strongly than $\mathrm{LTC}_{4}$, was competitively blocked by the antagonists while $\mathrm{CysLT}_{2} \mathrm{R}$ bound the two cysteinyl leukotrienes with equal affinity and bound $\mathrm{LTD}_{4}$ at one-tenth the affinity shown by $\mathrm{CysLT}_{1} \mathrm{R}$. $\mathrm{LTE}_{4}$, however, did not display any appreciable binding to either receptor. Despite this, some early recognized pharmacologic properties of $\mathrm{LTE}_{4}$, viz, its superior potency to its related compounds in contracting guinea pig tracheal smooth muscle and enhancement of this effect produced by histamine, its known peripheral and central airway effects in guinea pigs, and its capacity to increase permeability in guinea pig and human skin, all suggested a distinct pathobiologic role and the existence of a distinct receptor for $\mathrm{LTE}_{4}$. Studies by K. Frank Austen's group of cysteinyl leukotriene-dependent swelling of ear tissue in mice lacking both CysLT receptors proved the existence of a distinct $\mathrm{LTE}_{4}$-reactive cutaneous receptor. Ear swelling, a measure of $\mathrm{LTE}_{4}$-mediated vascular leakage, was inhibited by pretreatment with pertussis toxin or a Rho kinase inhibitor, indicating the involvement of a human GPCR to $\mathrm{G} \alpha_{i}$ proteins and Rho kinase. Until this cutaneous receptor is cloned, it has been designated $\mathrm{CysLT}_{\mathrm{E}} \mathrm{R}$. Further studies of single receptordeficient strains of mice compared to wild-type mice showed that the permeability response to $\mathrm{LTC}_{4}$ or $\mathrm{LTD}_{4}$ was reduced by half in $\mathrm{Cs}_{\mathrm{S}} 1 \mathrm{r}^{-/-}$ mice but was normal in magnitude and delayed in Cslt $2 r^{-/-}$mice. These results suggested that $\mathrm{CysLT}_{1} \mathrm{R}$ is the major signaling receptor for $\mathrm{LTC}_{4}$ and $\mathrm{LTD}_{4}$ while $\mathrm{CysLT}_{2}$ negatively regulates CysLT $_{1}$ R. Vascular leakage was not reduced by $\mathrm{LTE}_{4}$ in $\mathrm{Cs}_{\text {t } 1 r^{-/-}}$mice but again sustained and delayed in the $\mathrm{Cslt}_{2 r^{-/}}$strain, indicating that $\mathrm{CysLT}_{\mathrm{E}} \mathrm{R}$ is the dominant receptor for $\mathrm{LTE}_{4}$ and that $\operatorname{CysLT}_{2} \mathrm{R}$ once again acts as a negative regulator.

Studies on expression of cysteinyl leukotriene receptors by human mast cells unexpectedly revealed that $\mathrm{LTE}_{4}$ helps to induce greater numbers of mast cells from cord blood progenitor cells cultured together with IL-6 and IL-10 than 
both $\mathrm{LTC}_{4}$ and $\mathrm{LTD}_{4}$ and it is also more potent for the production of the inflammatory chemokine macrophage inflammatory protein-1 $\beta$ (MIP-1 $\beta$ ) and for the expression of COX-2 and prostaglandin $\mathrm{D}_{2}$. Sequence homologies of the classical type 1 and 2 cysteinyl leukotriene receptors and the $\mathrm{P} 2 \mathrm{Y}$ receptor family together with computer modeling studies indicated that $\mathrm{LTE}_{4}$ might be a surrogate ligand for a previously unrecognized receptor on mast cells. Human mast cells express the $\mathrm{P} 2 \mathrm{Y}_{12}$ receptor, a Goi-linked receptor for adenosine diphosphate. Subsequent investigations by Austen's group using ovalbumin-sensitized and Cyslt1r/Clt2r $r^{-/-}$mice, expression of IL-13, and the $\mathrm{P} 2 \mathrm{Y}_{12}$ receptor-selective antagonist clopidogrel suggested that $\mathrm{LTE}_{4}$ acted as an agonist for platelet activation in the pulmonary vasculature. It seems, therefore, that $\mathrm{P} 2 \mathrm{Y}_{12}$ is the receptor for $\mathrm{LTE}_{4}$-mediated amplification of allergic pulmonary infiltration and proliferation of mast cells and this receptor is separate and distinct from the CysLT $_{\mathrm{E}} \mathrm{R}$ in the skin.

\subsubsection{Platelet-Activating Factor}

Platelet-activating factor (PAF), a preformed mediator of anaphylaxis released by degranulating mast cells, is one of the most powerful autacoids yet discovered. The PAF story began in the early 1970s when Benveniste, Henson, and Cochrane demonstrated the release of a substance with both powerful anaphylactic and platelet aggregating properties from allergically sensitized rabbit leukocytes. Although first investigated in relation to anaphylaxis and other allergic manifestations, later studies revealed a wide diversity of other biological actions and involvement in diseases such as asthma, some delayed hypersensitivity reactions, septic shock, adult respiratory distress syndrome, rheumatoid arthritis, necrotic bowel disease, and a wide range of other inflammatory conditions. This diversity of biological actions and pathogenic involvements is due to the mediator's activation of other cells besides platelets, in particular, eosinophils, neutrophils, fibrocytes, neurocytes, and endothelial, vascular, cardiac, smooth muscle, pancreatic, and secretory cells.

\subsection{Chemistry and Structure- Activity Relationships}

PAF, 1-O-alkyl-2-acetyl-sn-glycero-3-phosphocholine, a phospholipid of relatively simple but unique structure, belongs to a relatively minor class of lipids, the ether-linked phospholipids. The distinguishing feature of its unique structure is an acetyl group at position 2 of the glycerol backbone (Fig. 3.9). Removal of the acetyl group produces lyso-PAF which is devoid of biological activity. When produced and liberated naturally in the cellular environment, PAF is made up of a mixture of homologs differing in the number of carbons and the degree of unsaturation of the alkyl chain at position 1 of the glycerol backbone. The main homologs usually present are the $\mathrm{C}_{16: 0}, \mathrm{C}_{18: 0}$, and $\mathrm{C}_{18: 1}$ structures. The structures for maximum activity are a 16 carbon chain, the 1 - $O$-alkyl ether linkage, the acetyl group at position 2, the $s n$ configuration, and the phosphate group at carbon 3 (Fig. 3.9). Activity decreases progressively as the C chain backbone is shortened or lengthened; replacement of the ether linkage leads to no or little biological activity; the unnatural enantiomer with the $(S)$-configuration is inactive; for any biological activity the only substituents tolerated at carbon 2 are propionyl and $N$-methyl carbamoyl groups (the 2-ethoxy analog has only $10 \%$ of the activity of PAF); and fairly major modifications of the substituents on the nitrogen diminish activity. These specific structural requirements suggest that PAF exerts its biological effects by binding to specific receptors and this is in fact so.

\subsection{Biosynthesis and Cellular Sources of PAF}

Because PAF is such a potent mediator of a range of biological effects, its concentration in body fluids and tissues needs to be restricted to avoid adverse or even lethal consequences. This is achieved intracellularly and extracellularly by a specific acetylhydrolase and by regulation of the conversion of precursor molecules. The activity of PAF acetylhydrolase for its substrate is extremely high ensuring that the half-life of the mediator in blood is of the order of only a few minutes. PAF is synthesized by two metabolic 


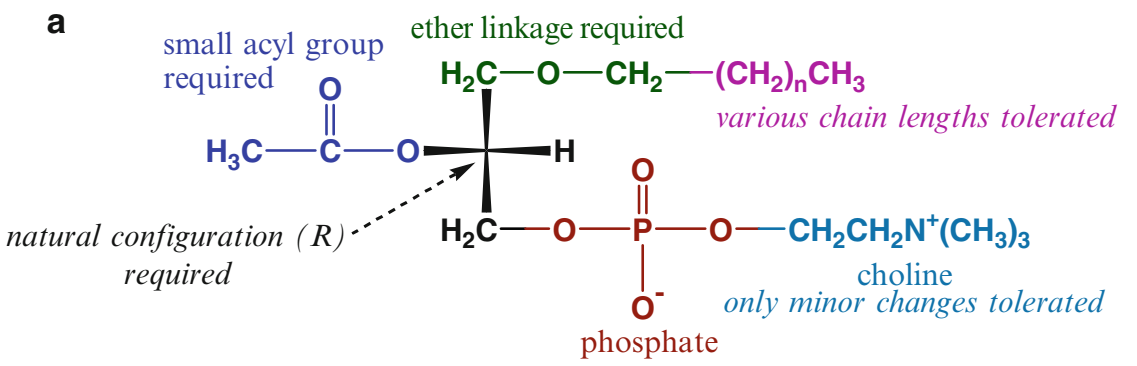

PAF
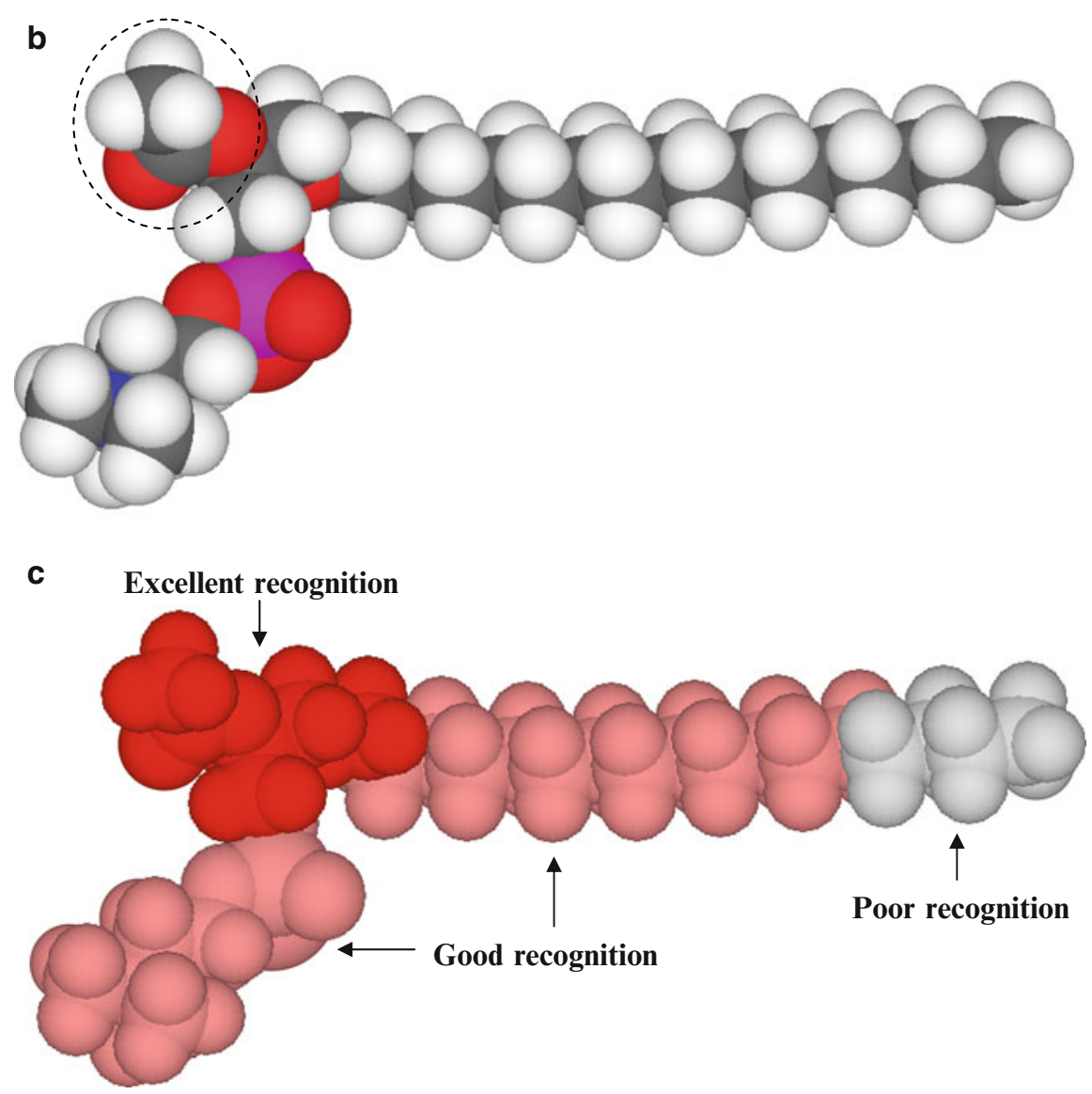

Fig. 3.9 (a) Two-dimensional structure of PAF highlighting the important structural features necessary for maximum biological activity and recognition by antiPAF antibody combing sites. (b) Three-dimensional space-filling CPK model of PAF with the acetyl group circled. Removal of this group alone produces a mole-

pathways - the de novo and remodeling pathways. In the de novo pathway (Fig. 3.10a), the specific enzyme alkylacetylglycerol cholinephosphotransferase, widely distributed in tissues cule devoid of biological activity. (c) Outline of PAF model indicating regions of excellent, good, and poor recognition by anti-PAF antibodies. The antibody recognition pattern is very similar to that of the PAF receptor (see Smal MA, Baldo BA and Harle DG. J Mol Recogn 1990; 3: 169-73)

on the cytoplasmic surface of the endoplasmic reticulum, catalyzes the reaction between 1-O-alkyl-2-acetyl-sn-glycerols and cytidinediphosphocholine (CDP-choline) in the presence of 
a<smiles>[R]OCC(CO)OC(C)=O</smiles><smiles>[2H]OCC(COP(=O)(OCC[NH3+])OC(C)=O)OC(C)=O</smiles>

1-O-alkyl-2-acetyl-sn-glycerol (AAG)

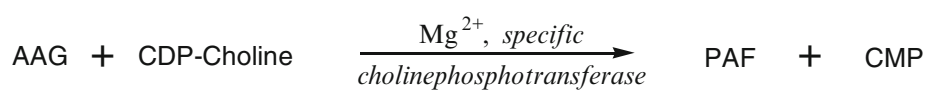

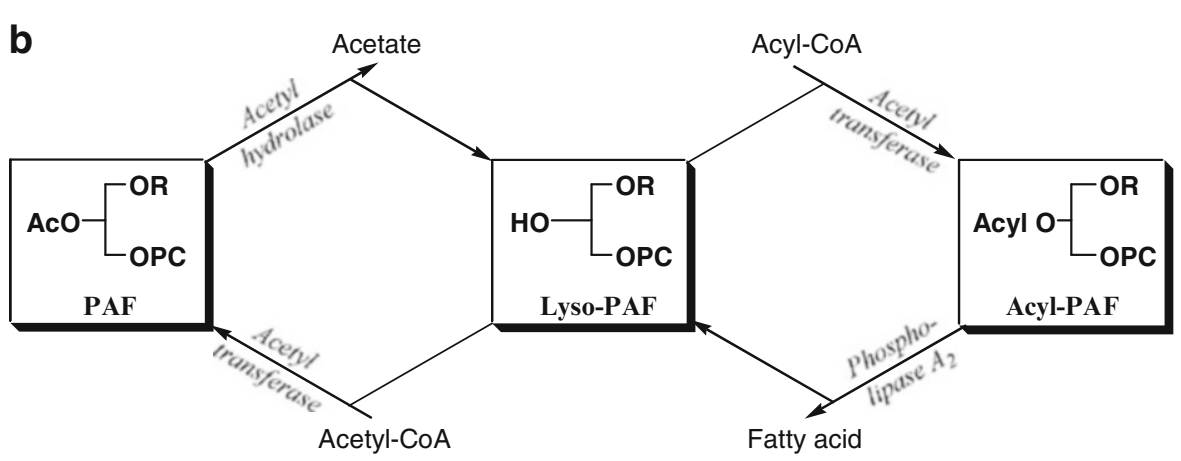

Fig. 3.10 The two biosynthetic pathways for the synthesis of PAF. (a) The de novo pathway; (b) the remodeling pathway

$\mathrm{Mg}^{2+}$ generating PAF and cytidinemonophosphate. This synthetic pathway appears to maintain PAF levels for normal physiological processes. The remodeling pathway (Fig. 3.10b) both activates and deactivates PAF via the calcium-dependent enzymes phospholipase A2 and acetyltransferase, the latter being the rate-limiting enzyme. These enzymes are found particularly in cells of the immune system such as basophils, eosinophils, platelets, polymorphonuclear cells, macrophages, and endothelial cells and can be stimulated by a variety of agents including immune complexes, thrombin and histamine.

\subsection{Biological Actions of PAF and Its Role in Health and Disease}

PAF is a hydrophobic molecule and for crossing cell membranes and transportation to its various sites of action, serum albumin serves a carrier function. When injected into mammals, PAF produces both the signs and symptoms of anaphylaxis with hypotension, increased vascular permeability and hemoconcentration, thrombo- cytopenia, neutropenia, and eventually death. Infusion of PAF into the heart decreases myocardial contractility and coronary flow, effects resembling cardiac anaphylaxis. Intradermal injection produces a biphasic inflammatory response similar to the response of allergic subjects to allergen. PAF has a profound effect on the lung producing bronchoconstriction, edema, and hyperresponsiveness. PAF is also one of the most powerful ulcerogenic agents known, provoking hemorrhage and vascular congestion in both the stomach and small intestine.

PAF has been implicated in many disease states but since it is often only one of a range of other mediators present, any preeminent role is understandably often difficult to establish. For example, it is frequently present along with histamine, numerous metabolites of the cyclooxygenase and lipoxygenase pathways, and a range of chemokines and cytokines including TNF. As well as its undoubted role in anaphylaxis and some other allergic reactions, PAF is an important mediator in the asthmatic response. 
Administration of PAF into the lungs produces severe bronchoconstriction, mucous secretion, inflammation, and long-lasting airway hyperreactivity. The latter two effects may be contributed to by PAF-induced recruitment and activation of inflammatory cells such as macrophages and eosinophils. Recent findings, particularly in studies in the mouse, have identified a second pathway of anaphylaxis involving the $\mathrm{IgG}$ receptor FcyRIII and the release of PAF as the major mediator (see Sect. 3.2.7). Although long suspected, a central role for PAF in anaphylaxis is confirmed and explained by this alternative pathway. In a model of peanut allergy for example, although both histamine and PAF are involved in the response, PAF is more important in shock pathogenesis. Along with anaphylaxis and asthma, septic shock is a disease in which PAF is suspected of having a leading role. PAF induces systemic responses similar to those provoked by bacterial endotoxin and is found in the spleen and peritoneum of rats with endotoxic shock. Some PAF antagonists protect animals against septic shock caused by infection with gram-negative organisms or injection of endotoxin. Because of its potent effect on platelets, PAF is thought to be involved in some thrombotic diseases including stroke. Other suspected roles are in acute graft rejection and immune complex deposition in, for example, systemic lupus erythematosis, psoriasis, and other allergic conditions.

\subsection{The PAF Receptor}

The PAF receptor is a MW $48 \mathrm{kD}$, G-proteincoupled single 342 amino acid protein that shows structural characteristics of the rhodopsin gene family. The human, guinea pig, and rat receptors have been cloned and characterized as a seventransmembrane receptor that induces phosphoinositol turnover. The receptor shows wide tissue distribution being expressed in lung, kidney, liver, spleen, small intestine, and brain. In leukocytes, it is expressed on platelets, neutrophils, monocytes, and $\mathrm{B}$ cells but not on resting $\mathrm{T}$ cells and natural killer cell lines. Human monocytes treated with IFN- $\gamma$ show a two- to sixfold increase in PAF receptor expression compared to untreated cells.

\subsection{Measurement of PAF in the Laboratory}

Accurate measurement of the very small amounts of PAF in fluids and extracts is a prerequisite for studying the role of the mediator in health and disease. The most widely used method relies on the interaction of PAF with platelets, but the procedures are not strictly quantitative, lack specificity, and are difficult to standardize and reproduce; fresh platelet suspensions are required; and throughput capacity is poor. Mass spectrometric techniques are sensitive and specific but the specialized nature of the equipment, absence of easy access for many laboratories, and difficulty of assessing large numbers of samples side by side make this method problematic for routine use by many researchers. Other methods such as measurement of ${ }^{3} \mathrm{H}$-serotonin after PAF-induced platelet degranulation and radioreceptor assays are specialized procedures in some laboratories but can be difficult to standardize, require cell labeling, or membrane preparations and may show high nonspecific binding. Perhaps the best all-round, high-throughput procedure for quantitating PAF levels in research and test samples is a specific immunoassay, available since the first such assay was introduced in the authors' laboratory in 1989 . This method is highly specific, sensitive in the range $10-1,000 \mathrm{pg}(0.02-2$ pmoles), has a high capacity, and is not affected by inhibitors of platelet aggregation.

\subsubsection{Anaphylaxis}

Anaphylaxis is a sudden, systemic reaction involving a number of different organs of the body that may be severe enough to cause death. It is usually provoked by exposure to allergens with drugs and foods being the most common causes. For the clinical features of anaphylaxis the reader is referred to Chap. 2. Progress continues in identifying key intermediates and elucidating mechanisms of regulatory systems and signaling pathways during mast cell activation and degranulation and some impressive advances in our understanding of the pathways, the mediators involved, and their contribution to the pathobiology of anaphylaxis are under way. 


\subsubsection{Mechanisms of FceRI- Mediated Mast Cell Activation in Anaphylaxis}

Understanding anaphylaxis involves study of the cellular events leading to the release of mediators of inflammation and hypersensitivity with emphasis on the mechanisms, in particular the signaling processes, of mast cell and basophil activation and degranulation. Upon activation of mast cells and basophils following cross-linking by allergen of receptor-bound $\mathrm{IgE}$ and aggregation of the high-affinity IgE FceRI receptors, the cells quickly release preformed mediators from the secretory granules. These mediators, including histamine, leukotrienes, $\mathrm{PGD}_{2}, \mathrm{PAF}$, and TNF, causing vasodilation, increased vascular permeability and heart rate, bronchoconstriction, airway remodeling, pulmonary and coronary vasoconstriction, and a host of other detrimental effects, including cell recruitment with cytokine and chemokine production, are responsible for the pathophysiology of anaphylaxis. Crosslinking initiates the signaling cascade that ultimately results in anaphylaxis. FceRI receptor aggregation causes Lyn, the tyrosine kinase associated with the $\beta$ and $\gamma$ subunits of the receptor, to phosphorylate the tyrosines of the ITAMs of these two subunits. The phosphorylated ITAMS, mainly on the $\gamma$ subunit, then act as scaffolds for binding the cytoplasmic tyrosine kinase Syk. As outlined above in Sect. 3.2.2, recruitment of the Syk kinase and subsequent phosphorylation activation steps involving Lyn lead to mast cell activation demonstrating the importance of protein tyrosine kinases in the pathways that result in allergic inflammation and anaphylaxis. These pathways involved in mast cell triggering are summarized in a simplified form in Fig. 3.11. Activated Syk is involved in the phosphorylation of the transmembrane adaptor linker for activation of T cells (LAT) as well as the $\mathrm{SH} 2$ domain-containing leukocyte-specific

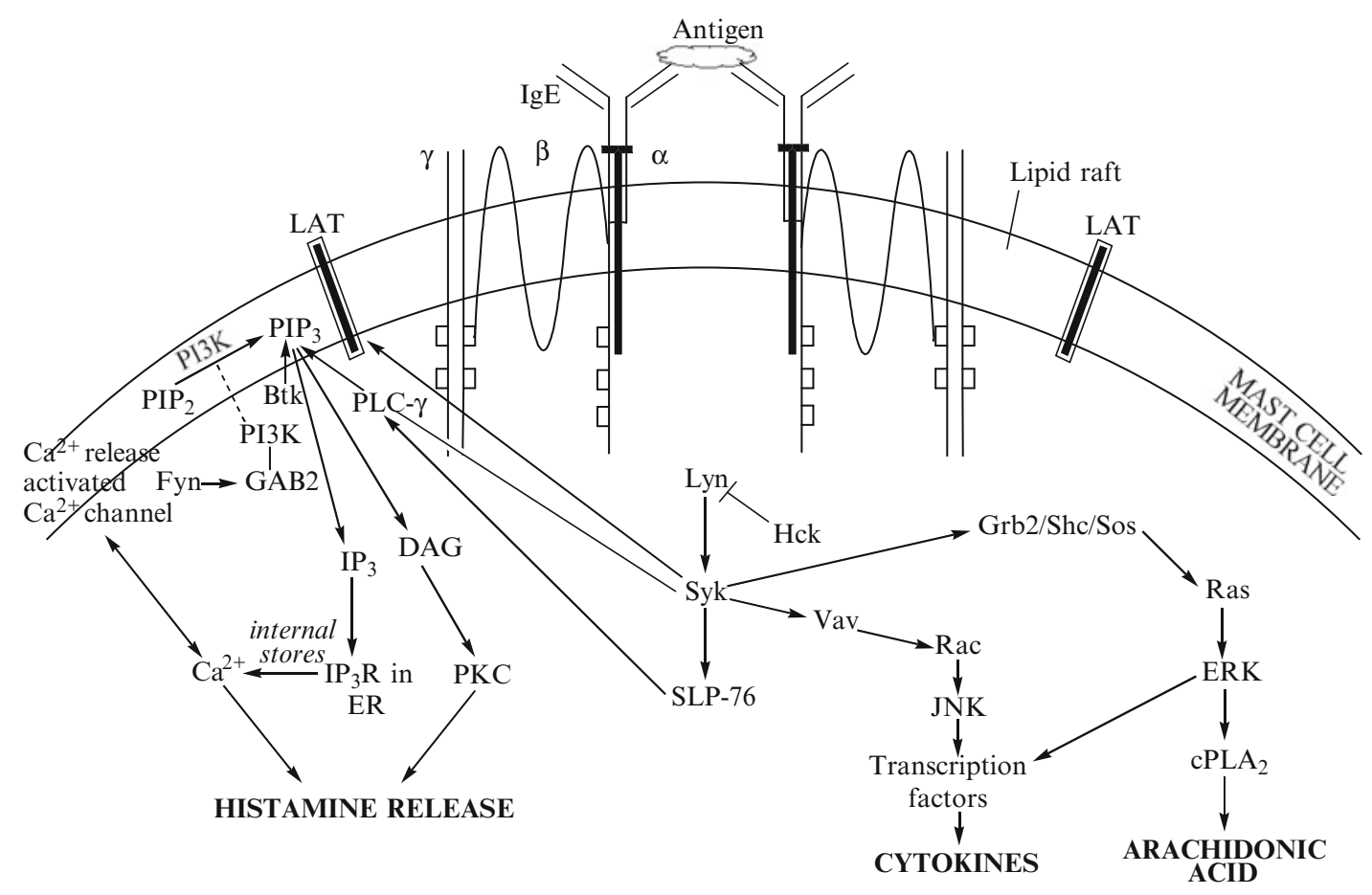

Fig. 3.11 Simplified summary of FceRI-mediated signaling pathways in the mast cell leading to allergic inflammation and anaphylaxis 
protein of MW $76 \mathrm{kD}$ (lymphocyte cytosolic protein 2 LCP2 or SLP-76), the guanine nucleotide exchange factor Vav, phospholipase C- $\gamma 1$ (PLC- $\gamma 1$ ), and PLC- $\gamma 2$. After involvement of the enzyme proto-oncogene tyrosine-protein kinase (Fyn), tyrosine phosphorylated GAB2 (GRB2 [growth factor receptor-bound protein 2]-associated-binding protein 2) binds a subunit (p85) of phosphatidylinositol 3-kinase (PI3K). In the membrane, PI3K catalyzes the conversion of phosphatidylinositol-4,5-diphosphate $\left(\mathrm{PIP}_{2}\right)$ to phosphatidyl-3,4,5-triphosphate $\left(\mathrm{PIP}_{3}\right)$. This attracts a number of proteins containing the pleckstrin homology (PH) domain, a 120 amino acid domain occurring in a variety of proteins involved in intracellular signaling. The attracted proteins include Bruton's tyrosine kinase (Btk) and the PLCs $\gamma_{1}$ and $\gamma_{2}$ which in tyrosinephosphorylated form catalyze the hydrolysis of $\mathrm{PIP}_{2}$ to inositol-1,4,5-triphosphate ( $\left.\mathrm{IP}_{3}\right)$ and 1,2-diacylglycerol (DAG). Both compounds act as second messengers, the former releasing $\mathrm{Ca}^{2+}$ resulting in a depletion of $\mathrm{Ca}^{2+}$ stores and entry of $\mathrm{Ca}^{2+}$ from the extracellular medium and the latter activating protein kinase $\mathrm{C}$ (PKC). These events lead to mast cell degranulation. This activity takes place in two regions on the inner side of the plasma membrane. Electron microscopy has revealed a primary region of activity near the FceRI receptor involving Gab2, the p85 subunit of PI3K, and PLC- $\gamma 2$ and a second region near LAT involving PLC- $\gamma 1$ and the $\mathrm{p} 85$ subunit. Tyrosine phosphorylation and activation of other enzymes and adaptors, including Vav, Grb2, the SHC-adaptor protein (Shc) involved in signaling, and Son of sevenless (Sos) protein (a guanine nucleotide exchange factor), stimulate the small GTPases Ras, Rho, and Rac. These reactions lead to activation of the extracellularsignal-regulated kinase ERK, Jun amino-terminal kinase JNK, the p38 mitogen-activated protein (MAP) kinase cascade, and histamine release. Phosphorylation of the transcription factors activating protein-1 (AP-1), nuclear factor of activated T cells (NFAT), and nuclear factor kappa-light-chain-enhancer of activated B cells $(\mathrm{NF}-\mathrm{\kappa B})$ induces the synthesis of cytokines and the activation of cytoplasmic phospholipase A2
(PLA-A2) to release arachidonic acid with the production of lipid mediators (Fig. 3.11).

Further research, much of it in mice, has continued to highlight the key role of tyrosine kinases in FceRI activation and the subsequent signaling events, although other involved tyrosine kinases such as Hck have been identified. The intensity of stimulation of the FceRI receptor has been shown to be important. Low-intensity stimulation by IgE with low antigen concentration or by antiIgE positively regulates mast cell degranulation and the production of cytokines by inhibiting Lyn activity. High-intensity stimulation with high IgE and high antigen concentrations negatively regulates mast cells by enhancing Lyn activity and increased Syk activation. Genetic variation appears to influence the role of tyrosine kinases. For example, an epilepsy- and anaphylaxis-prone strain of mice was found to be deficient in the expression of Lyn while a related epilepsy-prone variant proved anaphylaxis resistant. Bone marrow-derived mast cells (BMMCs) from the anaphylaxis-sensitive mice had reduced Lyn and Syk activities and showed degranulation typical of BMMCs of phenotype Lyn(-/-) whereas the phenotype of the anaphylaxis-resistant mice was similar to wild-type animals.

\subsubsection{Sphingosine-1-Phosphate, an Emerging Mediator of Anaphylaxis}

Activated Fyn, involved in a second tyrosine kinase pathway, has been shown to be required for cytokine production as well as degranulation and to have a role in generating sphingosine-1phosphate (S1P) (Fig. 3.12) a blood-borne bioactive lipid mediator that is a major regulator of the vascular system and B and T cell trafficking. S1P from mast cells and circulating S1P from macrophages, platelets activated by the release of PAF, endothelial cells, and many other nonimmune cells are elevated in the lungs of asthmatics where they regulate pulmonary epithelium permeability and are thought to contribute to the pathogenesis of asthma and diseases such as rheumatoid arthritis. The detection of elevated S1P levels in bronchial alveolar lavage fluid of challenged asthmatics and demonstration that it is necessary 


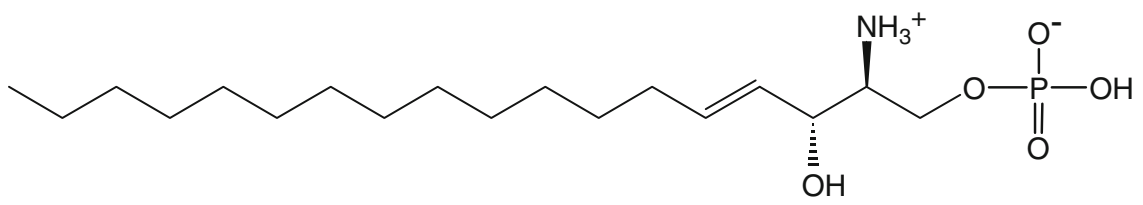

Sphingosine-1-phosphate

Fig. 3.12 Structure of the bioactive signaling phospholipid sphingosine-1-phosphate, a regulator of immune and vascular systems

for sustained mast cell degranulation through the $\mathrm{S}_{1} \mathrm{P}_{2}$ receptor were indications that this lysosphingolipid has a previously unrecognized relationship with anaphylaxis. It is produced by sphingosine kinase (Sphk1 and Sphk2)-catalyzed addition of phosphate to sphingosine, broken down by a S1P lysate and converted back to sphingosine by S1P phosphatase. Recent research has shown that susceptibility to anaphylaxis appears to be due to S1P generated within the mast cell and by free, circulating S1P from nonmast cell sources. The gene $\mathrm{SphK} 2$ regulates the influx of $\mathrm{Ca}^{2+}$ into mast cells and the responses to it, making it a determinant of intrinsic mast cell function whereas SphK1 appears to act extrinsically affecting mast cell responsiveness by regulating levels of circulating S1P. The surprising demonstration of a relationship between circulating levels of S1P and anaphylaxis is made more intriguing by the demonstration that reduced S1P levels due to a deficiency of SphK1 are associated with resistance to anaphylaxis. While it is well known that only a small number of individuals from a large group with similar circulating levels of allergen-specific IgE antibodies will experience anaphylactic shock when challenged with the allergen, the amount of circulating S1P might help to provide the explanation. Finally, as exciting as these developments in our understanding of the underlying mechanisms of anaphylaxis are, it should be remembered that many of the findings result from research on mice not man and that is also true for most of the S1P studies where mice with SphK1 and 2 genes, individually or jointly deleted, were used. Given the diversity of mast cells and differences in gene expression of mouse and human mast cells, the roles of SphK1 and SphK2 may prove to be significantly different in the two species.

\subsubsection{Other Mechanisms of Anaphylaxis: IgG, PAF, and Nitric Oxide}

Mechanisms of anaphylaxis independent of IgE have been suggested, for example, anaphylatoxins produced during complement activation, generation of immune complexes, the involvement of $\mathrm{T}$ cell activation and cytotoxicity, release of neuropeptides, and a number of different mechanisms acting coincidently without the involvement of allergen-specific IgE. Intriguingly, anaphylaxis can occur in the mouse via the classic pathway involving allergen-induced crosslinking of mast cell FceRI receptor-bound IgE antibodies with release of histamine (and other mediators) but also by an IgG pathway in which allergen-antibody complexes activate macrophages by cross-linking FcyRIII receptors and with PAF as the main mediator of anaphylaxis. Although there is, as yet, no compelling evidence for an IgG-mediated mechanism in humans, what appears to be anaphylaxis has been described in a few cases where there is an apparent absence of mast cell degranulation, that is, with no increase in serum tryptase. Certainly there are many similarities between the immune systems of mice and men; PAF is produced by macrophages of both species, it has the same affect on vascular permeability, and consequently allergen-IgG complexes may have an important role in anaphylaxis in 
humans as well as the mouse. However, human anaphylaxis tends to result from low-dose exposure whereas mouse IgG-mediated anaphylactic reactions may occur in response to relatively larger antigen doses and/or adjuvants that elicit IgG as well as IgE antibodies. What may be evidence in favor of anaphylaxis in humans independent of $\mathrm{IgE}$ are the responses seen in patients after receiving the chimeric mouse-human anti-TNF monoclonal antibody infliximab (see also Sect. 11.1.3.3). None of the subjects appeared to have complementary IgE antibodies, all had IgG to the mouse immunoglobulin determinants, and there was no increase (at only $20 \mathrm{~min}$ ) in serum tryptase. From insights gained from his extensive studies of mechanisms of anaphylaxis in mouse models, F. D. Finkelman has suggested that large doses of antigen might be used in humans to look for evidence of anaphylaxis accompanied by macrophage activation and PAF secretion.

PAF contributes to hypotension and cardiac dysfunction during shock and stimulates, via its receptor, a number of signaling pathways including those that activate $\mathrm{PLA}_{2}$ and PI3K. Studies of PAF and anaphylactic shock in mice have shown that PAF-induced shock depends on PI3K signaling and on NO produced by constitutive nitric oxide synthase (eNOS) not the inducible form of the enzyme (iNOS). Mouse models showed that inhibition of NOS, PI3K, or Akt, or deficiency of eNOS, gave complete protection against anaphylaxis. These findings appear to support the belief that eNOS has a detrimental role in vascular function during shock and in regulating inflammation. Further, if eNOSderived NO is the principal vasodilator in anaphylactic shock, eNOS and/or PI3K or Akt might prove to be important targets for treating anaphylaxis.

Clearly, there is much to learn and understand about anaphylaxis and the list of interesting questions that remain unanswered is disconcertingly extensive. The following topics are suggested as important and potentially productive areas of investigations that could be near the top of any current research agenda for anaphylaxis:
- Relationships, if any, between the risk of anaphylaxis and levels of allergen-specific IgE and the affinities of IgE antibodies.

- The relationship between mediator activity and their turnover, for example, PAF acetylhydrolase may be less active in some individuals allowing PAF to remain active for longer.

- Further studies of the relationship of sphingosine-1-phosphate with anaphylaxis.

- Continuing searches for more mediators and markers of anaphylaxis, especially more sensitive ones.

- Is there an IgG-dependent pathway for anaphylaxis in humans? If so, what is the mechanism?

- Identification of signaling pathways that stimulate or inhibit anaphylaxis and how these pathways can be manipulated.

- Further studies on the roles and importance of NO, eNOS, and iNOS.

- The role of the heart in anaphylaxis, in particular, the heart mast cells in cardiovascular collapse.

- Estimation of levels and searches for polymorphisms of relevant cytokines and cytokine receptors such as IL-4, IL-13, and TNF.

- The role, if any, of IgG blocking antibodies. This list is far from exhaustive.

\subsubsection{Drug-Induced Urticaria and Angioedema}

For the clinical manifestations of urticaria, see Sect. 2.2.1.2.

Of the drugs implicated in provoking urticaria and angioedema, the NSAIDs are perhaps the most important. What is currently understood of their proposed mechanisms of action together with a review of the arachidonic acid cascade is considered in Chap. 9. Formation of the cysteinyl leukotrienes is detailed in Sect. 3.2.5.2 (above) and is also referred to in Chap. 9.

Urticaria may be classified as acute or chronic. The acute form appears early after exposure, perhaps within minutes, and can last from hours 
to several weeks whereas the chronic form persists for about six weeks or more. Urticaria is often an isolated event but drug-induced urticaria, regarded as one of the most common cutaneous drug reactions, can be seen in association with anaphylaxis, angioedema, and serum sickness. Urticaria is a heterogeneous disease with many subtypes caused by a range of agents and stimuli. Some infections (e.g., Helicobacter pylori), intolerance to foods, and autoantibodies to the high-affinity IgE receptor FceRI have been implicated, but, apart from the NSAIDs and angiotensin-converting enzyme (ACE) inhibitors, there is a dearth of information on mechanisms underlying drug-induced urticaria and angioedema.

\subsubsection{Genetic Mechanisms}

Knowledge of drug-induced mechanisms of urticaria and angioedema is limited and this is even more apparent when considering current progress on the molecular genetic mechanisms involved. Information on genetic polymorphisms of relevant genes together with supporting functional studies is needed to help elucidate molecular mechanisms and identify genetic markers. Some progress made in identifying HLA alleles and promoter polymorphism genetic markers for aspirin-induced urticaria/angioedema is covered in Chap. 9, Sect. 9.5.5.

\subsubsection{Urticaria Due to Immune Mechanisms}

Urticaria following drug administration may occur without previous exposure to the drug or after previously tolerated exposures. Drugs appear to cause only a minority of cases of chronic urticaria and while they are often assumed to be the cause of a high proportion of cases of acute urticaria during drug treatment, some results cast doubt on this. An examination, including skin testing, of 350 patients with suspected drug-induced reactions made up of 343 with urticaria/angioedema and seven with anaphylaxis revealed that only $22(6.3 \%)$ were allergic and had a positive skin test to the suspected drug. The positive reactors proved to be the patients who presented with the most severe symptoms. An immediate (within $20 \mathrm{~min}$ ) positive skin test is usually presumed to result from an IgE antibody-mediated mechanism or a direct histamine-releasing effect but one cannot necessarily presume that these are the only mechanisms operative in all cases of drug-induced acute urticaria. Symptoms of urticaria are caused by the mediators histamine, leukotrienes, prostaglandin D2, bradykinin, and other vasoactive substances released from mast cells and basophils into the skin. Cases of acute urticaria may be immune or nonimmune mediated. Druginduced immune-mediated reactions can be elicited by cross-linking of high-affinity (FceRI)-bound $\operatorname{IgE}$ antibodies on mast cells and basophils by free drug or drug-carrier complex molecules reacting with the bivalent antibody combining sites via their complementary allergenic determinants. This results in degranulation of the cells and histamine release.

Other hypersensitivity responses may lead to urticarial reactions. A rare cause of the acute form is a type II hypersensitivity cytotoxic reaction mediated by cytotoxic antibodies and complement activation. An example of this type of reaction occurs in transfusion reactions when IgG and IgM antibodies activate complement and lyse transfused incompatible red cells. Urticaria may also result from a type III antigen-antibody complex-mediated hypersensitivity reaction, in particular, serum sickness lasting for several weeks and presenting with fever, arthralgias, and glomerulonephritis as well as urticaria. Note that there is a drug-induced serum sickness-like reaction that is not associated with circulating immune complexes. Drugs implicated in these reactions include penicillins, cephalosporins, tetracyclines, quinolones, sulfonamides, NSAIDs, carbamazepine, thiouracil, allopurinol, and barbiturates. Other drug-induced type III hypersensitivity reactions involving skin inflammation include erythema nodosum leprosum induced by dapsone and the Jarisch-Herxheimer reaction following treatment of some microorganisms (e.g., in syphilis) with antimicrobials such as penicillins and tetracyclines. The inflammatory cytokines TNF, IL-6, and IL-8 appear to be released in these reactions. Urticarial vasculitis is 
another type III hypersensitivity skin eruption that can resemble urticaria and which is sometimes drug induced. Antigen-antibody complexes formed in the vascular lumina lead to complement activation, chemotaxis of neutrophils, and the release of proteolytic enzymes that damage the vascular lumina. Drugs implicated include ACE inhibitors, penicillins, sulfonamides, thiazides, and the antidepressant fluoxetine. Urticarial reactions are also sometimes seen along with other skin manifestations during some druginduced type IV hypersensitivity responses, but the presence of other skin manifestations, frequently more severe, makes it difficult to distinguish and study the specific mechanisms.

\subsubsection{Urticaria with an Autoimmune Basis}

A significant proportion of cases of chronic urticaria demonstrate no connection with drugs. Observations during the 1980s of the association of chronic urticaria and angioedema with thyroid autoimmunity and on the prevalence of anti-IgE autoantibodies in urticarial syndromes suggested that autoimmunity might have a role in some cases of chronic urticaria. These findings led to the occasional demonstration of the presence of IgG anti-immunogloulin E autoantibodies and functional autoantibodies against the alpha subunit of the high-affinity $\operatorname{IgE}$ receptor (i.e., FceRI $\alpha$ ) in at least one-third of patients with chronic urticaria. These autoantibodies activate normal cell function by cross-linking the receptors on cutaneous mast cells and blood basophils, thus releasing histamine and other mediators responsible for the urticaria and angioedema. Activity of the autoantibodies was later shown to be augmented by complement activation with a critical role for component C5a. Chronic urticaria is now divided into autoimmune and idiopathic subgroups since in about $55-60 \%$ of patients the etiology remains obscure. As well as releasing histamine and leukotrienes from basophils, sera with the autoimmune antibodies also release IL-4. A study of lymphocytes from patients with chronic urticaria showed that activated CD4+ T cells produced high amounts of IL-4 and IFN- $\gamma$, strengthening the evidence for an immune basis of the disease and supporting histological demonstrations of predominant CD4+ $\mathrm{T}$ cell infiltrates in biopsies of chronic urticaria lesions. The observed cytokine profile of Il-4, IL-5, and IFN- $\gamma$ does not reflect a predominance of Th 1 or Th2 cells and cellular infiltrates indicate a Th0 profile or a mixture of activated Th1 and Th2 cells.

Omalizumab, a recombinant humanized monoclonal antibody that inhibits the binding of human IgE to its high-affinity receptor FceRI by selectively binding the immunoglobulin in solution, has been used as a successful treatment of intractable allergic asthma. The efficacy of the monoclonal antibody treatment was therefore investigated in patients with chronic autoimmune urticaria who remained symptomatic on antihistamine therapy. Of the 12 patients treated, seven showed complete resolution of the urticaria, four responded with a decrease in the urticaria activity score but the urticaria persisted, and one patient showed no improvement.

\subsubsection{Basophils in Chronic Urticaria}

CD203c is a basophil activation marker that is upregulated by cross-linking the FceRI receptors on mast cells and basophils. Incubation of basophils with sera from patients with chronic idiopathic urticaria and a positive autologous serum skin test (ASST; an intradermal test with the patient's own serum) demonstrated significant upregulation of CD203c and this upregulation correlated with basophil histamine release and the ASST. Basophils from chronic urticaria patients are less responsive to anti-IgE and $\mathrm{C} 5 \mathrm{a}$ but highly responsive when incubated with sera, even normal sera. The stimulatory factor(s) in serum has not been identified and the increased response of the cells is not yet understood. In a flow cytometric evaluation of the expression of basophil cell surface markers CD203c, CD63, CD123, and the receptor FceRI $\alpha$, both CD203c and CD63 were upregulated on basophils from patients with chronic idiopathic urticaria regardless of their ASST response. High expression of IL-3 receptor on basophils and activated $\mathrm{T}$ cells was detected only in ASST-positive patients. 


\subsubsection{Nonimmune-Mediated Urticaria and Angioedema}

Angioedema does not always have an allergic basis. Nonallergic angioedema not involving IgE antibodies and unassociated with urticaria can occur. The prototype example is hereditary angioedema arising from a deficiency of the inhibitor for $\mathrm{C} 1$ esterase that results in the maintenance of undegraded bradykinin. Acquired angioedema may be due to the accelerated consumption of $\mathrm{C} 1$ esterase inhibitor or, with an immune component, to autoantibody production. During acute attacks of hereditary and acquired angioedemas, plasma bradykinin has been shown to rise to up to 12 times the normal level.

\subsection{Drugs that Directly Trigger Mast Cell Release}

These reactions are sometimes referred to as pseudoallergic responses since their clinical course and presentation are similar to allergic urticaria and angioedema. Drugs including the antimicrobial vancomycin (Chap. 6), neuromuscular blockers used in anesthesia (Chap. 7), opioid analgesics such as morphine (Chap. 8), NSAIDs (Chap. 9), radiocontrast media (Chap. 10), and a wide range of other less often used medications can trigger urticaria by directly stimulating mast cell degranulation and histamine release. The mechanism of mediator release by the NSAIDs is particularly interesting. The drugs inhibit cyclooxygenase which in turn leads to overproduction of the vasoactive and pro-inflammatory leukotrienes (Sect. 3.2.5.2 above). This subject is discussed in more detail in Chap. 9.

\subsection{Angiotensin-Converting Enzyme (ACE) Inhibitors and Angioedema}

ACE occurs as somatic and germinal isozymes. The somatic enzyme, expressed in the lungs and in vascular endothelial, kidney, and testicular Leydig cells, is part of the renin-angiotensinaldosterone system, one of the body's mechanisms for maintaining blood pressure. ACE has two actions - it catalyzes the conversion of the ten amino acid peptide angiotensin I to the potent vasoconstrictor eight amino acid peptide angiotensin II and degrades bradykinin, a potent vasodilator. The vasoconstrictor action of angiotensin II may lead to increased blood pressure and hypertension, the effect that led to the development and application of the ACE inhibitor drugs. ACE inhibitors increase bradykinin levels and prolong its action and decrease angiotensin II levels (and therefore a decrease in aldosterone secretion from the adrenal cortex) leading to dilation of blood vessels and a coincident decrease in arterial blood pressure. ACE inhibitors, now widely used to treat hypertension, congestive heart failure and diabetic nephropathy include the drugs benazapril, captopril, enalapril, fosinopril, lisinopril, perindopril, quinapril, ramipril, and trandolopril. The combination of actions of decreasing angiotensin II and aldosterone levels and increasing and maintaining bradykinin levels may lead to fluid extravasation into subcutaneous tissue ultimately producing angioedema. The increased levels of bradykinin are thought to be related to the high incidence of cough in patients on ACE inhibitors and elevated bradykinin levels in the peripheral tissues, resulting in rapid fluid accumulation, are suspected of playing a key role in angioedema seen in a small number of patients taking ACE inhibitors. The association between ACE inhibitors and angioedema, first reported in the early 1980s, is now well recognized as a potentially serious but rare side effect of the drugs. Reactions occur with an incidence of about $0.1-0.5 \%$ but the incidence in blacks (black Americans and Afro-Caribbeans) is about three times higher than in white populations. This, and the decreased antihypertensive response to ACE inhibitions in blacks, is thought to be due to decreased production of bradykinin and/or decreased vasodilation in response to the peptide vasodilator. In terms of the number and severity, ACE inhibitor-induced angioedema is said to account for $17 \%$ of patients admitted for the treatment of angioedema and from 13 to $22 \%$ of patients with this form of angioedema require airway intervention. In a 2008 study in Boston, USA, records of 220 patients who presented to five hospital emergency departments were reviewed. The frequency of ACEinhibitor-induced angioedema in all patients who presented with 
angioedema was $30 \%$. The annual rate of visits for the drug-induced reaction was 0.7 per 10,000 emergency department visits. Eleven percent of the patients were admitted to intensive care and $18 \%$ admitted to hospital for observation for a $24 \mathrm{~h}$ period. This study confirmed past experience and surveys concluding that ACE inhibitorinduced angioedema remains a rare condition, it represents a significant proportion of angioedema patients, and a subgroup of these patients require hospitalization for management of upper airway angioedema.

Figure 3.13 summarizes the individual reactions and the interactions and relationship between the renin-angiotensin system and the plasma kallikrein-kinin system. Activation by the enzyme prolylcarboxypeptidase (lysosomal carboxypeptidase) of the prekallikrein-high molecular weight kininogen complex on endothelial cells produces kallikrein which cleaves high (sometimes low) molecular weight kininogen liberating bradykinin. Bradykinin stimulates vasodilation and leads to the formation of nitric oxide (NO), superoxide and prostacyclin and the liberation of tissue plasminogen activator. Kallikrein in plasma and tissues also activates prorenin to renin, an aspartyl protease, which in turn activates angiotensinogen to angiotensin I. ACE converts the inactive decapeptide angioten$\sin$ I to the biologically active octapeptide angiotensin II which, like bradykinin, stimulates NO and superoxide formation as well as contributing to the elevation of blood pressure and local vasoconstriction and stimulating the release of plasminogen activator inhibitor I. ACE is also a major degrading enzyme for bradykinin (in fact, bradykinin is its preferred substrate over angiotensin I) producing the breakdown pentapeptide bradykinin(1-5) and in addition to its role in the formation of kallikrein, prolylcarboxypeptidase (with other enzymes) degrades angiotensin II to form angiotensin(1-7) which has vasodilatory and blood pressure-lowering activities. Overall then, stimulation of the bradykinin and angiotensin II receptors results in vasodilation and the production of NO and prostacyclin. Stimulation of the angiotensin I receptor leads to vasoconstriction and the elevation of blood pressure.
It can be seen therefore, that the kallikrein-kinin and renin-angiotensin systems interact and are linked in a mutually dependent way.

Although it is beyond our requirements here, it should be pointed out that a homolog of ACE, angiotensin-converting enzyme 2 (ACE2), has recently been recognized. The two enzymes show different recognition of bradykinin. ACE2, a carboxypeptidase found mainly in the heart, kidney, and testis, does not degrade bradykinin but degrades des-Arg(9)-bradykinin at its carboxy-terminal amino acid and, unlike ACE which degrades angiotensin I by cleaving at the penultimate phenylalanine to produce angiotensin II [angiotensin(1-8)], ACE2 removes the carboxy-terminal leucine to form angiotensin(1-9). This peptide has been reported to enhance arachidonic acid release.

\subsection{Angioedema Following Administration of Angiotensin II Receptor-Binding Inhibitors}

Angiotensin II receptor blockers (ARBs) are primarily prescribed for high blood pressure but may also be used to treat heart attack, stroke, and congestive heart failure. Unlike ACE inhibitors, ARBs are not associated with cough. When first approved for the treatment of hypertension in 1995, ARBs were considered safe from the risk of edema and they are generally a safe alternative to ACE inhibitors, blocking the renin-angiotensin system more effectively than the latter drugs. By binding selectively to the angiotensin 1 receptors (AT1), ARBs do not affect ACE and therefore should not affect bradykinin levels but angioedema to ARBs does occur with an incidence ranging from about 0.1 to $0.4 \%$. From limited numbers examined, the risk of patients with angioedema to ACE inhibitors developing angioedema to an ARB is said to be from 2 to $17 \%$ and for developing confirmed angioedema, 0-9.2\%. A review of 19 cases of ARB-induced angioedema found that 13 (68\%) had never received an ACE inhibitor. Angioedema has been reported after administration of losartan, candesartan, eprosartan, irbesartan, olmesartan medoxomil, and telmisartan. Cross-reactivity between ACE inhibitor- and ARB inhibitor-induced angioedema has been estimated to be from 3 to $8 \%$. 


\section{High MW Kininogen-Prekallikrein $\stackrel{\text { prolylcarboxypeptidase }}{\longrightarrow}$ KALLIKREIN}

\section{RENIN-ANGIOTENSIN SYSTEM}

\section{$\underline{\text { Extracellular }}$}

\section{Kallikrein}

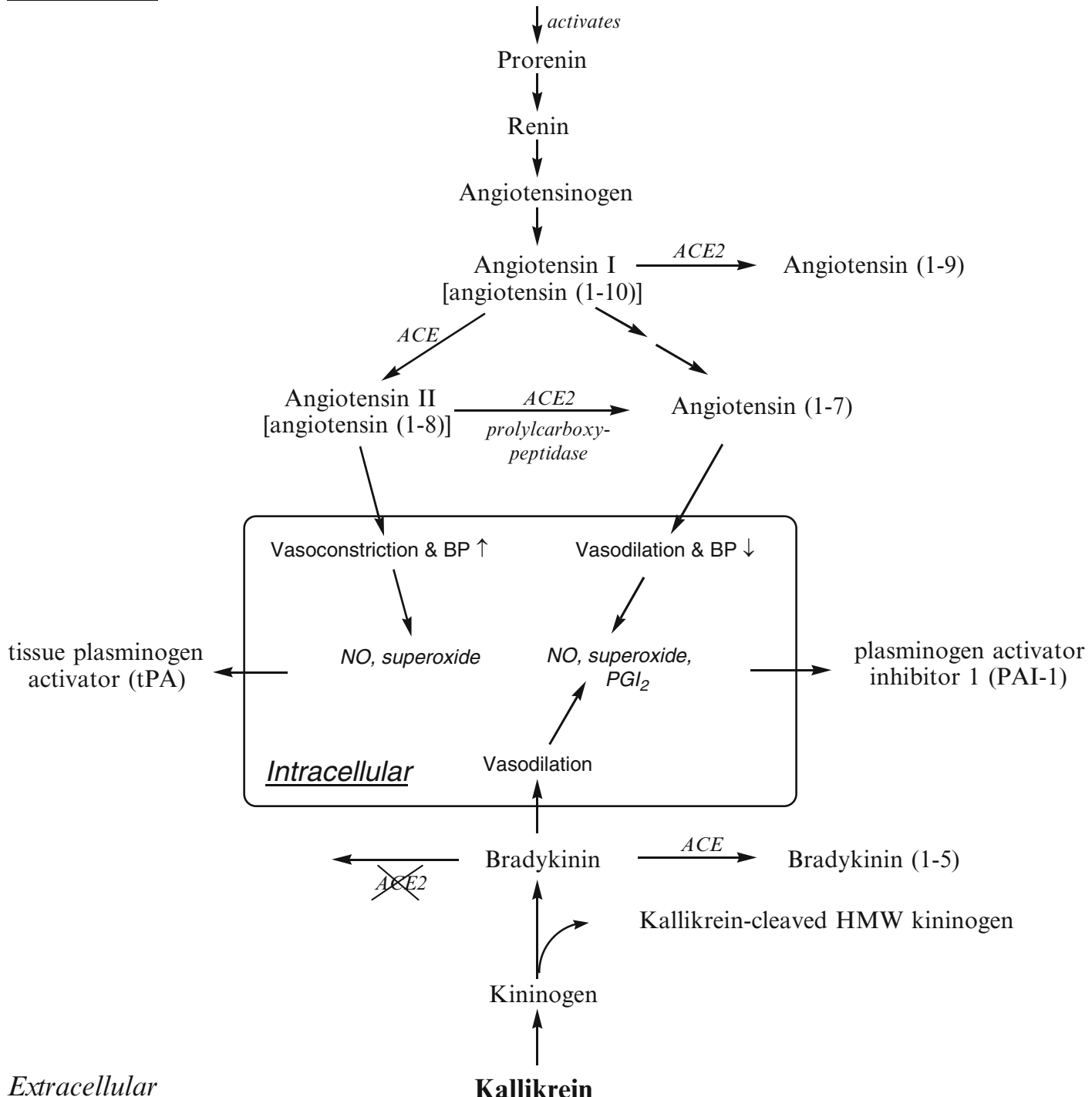

\section{KALLIKREIN-KININ SYSTEM}

Fig. 3.13 Summary of the individual reactions involved in, and relationships between, the renin-angiotensin and plasma kallikrein-kinin systems. ACE angiotensin-con- verting enzyme, $B P$ blood pressure, $M W$ molecular weight, $N O$ nitric oxide 
Since angioedema to ACE inhibitors occurs as a result of increased bradykinin levels and ARBs are not known to affect these levels, the mechanism of ARB-induced angioedema is not understood. One suggested explanation is that unblocked angiotensin II receptors (AT2) are subjected to secondary stimulation by high levels of angiotensin II producing an increase in tissue bradykinin and hence angioedema. Another suggestion is an abnormality in the degradation of the active metabolite of bradykinin, des-Arg(9)-bradykinin.

\subsection{The Allergen-Induced Late Phase Reaction}

Exposure to allergen in the skin, lung, nose, or eye of atopic patients provokes an immediate or early response that is maximal at $20-30 \mathrm{~min}$, resolves within about an hour, and is often followed 3-4 $\mathrm{h}$ after allergen challenge by a delayed reaction peaking at 6-12 $\mathrm{h}$ and subsiding by $24 \mathrm{~h}$. The two reaction phases are well illustrated by an asthmatic response in the lungs of an allergic patient measured as falls in the peak expiratory flow rate (PEFR) following inhalation challenge with allergen. Figure 3.14 shows that the immediate response bottoms at about $30 \mathrm{~min}$ after allergen challenge before beginning to recover and climbing back over the next 30 min toward, but not reaching, the pre-challenged PEFR figure. Three to four hours after the initial allergen challenge there is a late phase response reflected in a pronounced fall in PEFR which reaches its maximum at $5-10 \mathrm{~h}$. Thereafter there is a steady climb back to normal levels. The immediate response is caused by the release of histamine and some other preformed mediators from mast cells that have direct effects on blood vessels and smooth muscle. The initial release of the preformed mediators is supplemented over time by other powerful inflammatory agents including vasoactive agents that dilate blood vessels and produce edema, swelling, and pain. Figure 3.15 shows good examples of immediate and late phase cutaneous reactions. An immediate wheal and flare reaction and a late phase edematous response are seen $15 \mathrm{~min}$ and $6 \mathrm{~h}$, respectively, following intradermal injection of antigen.

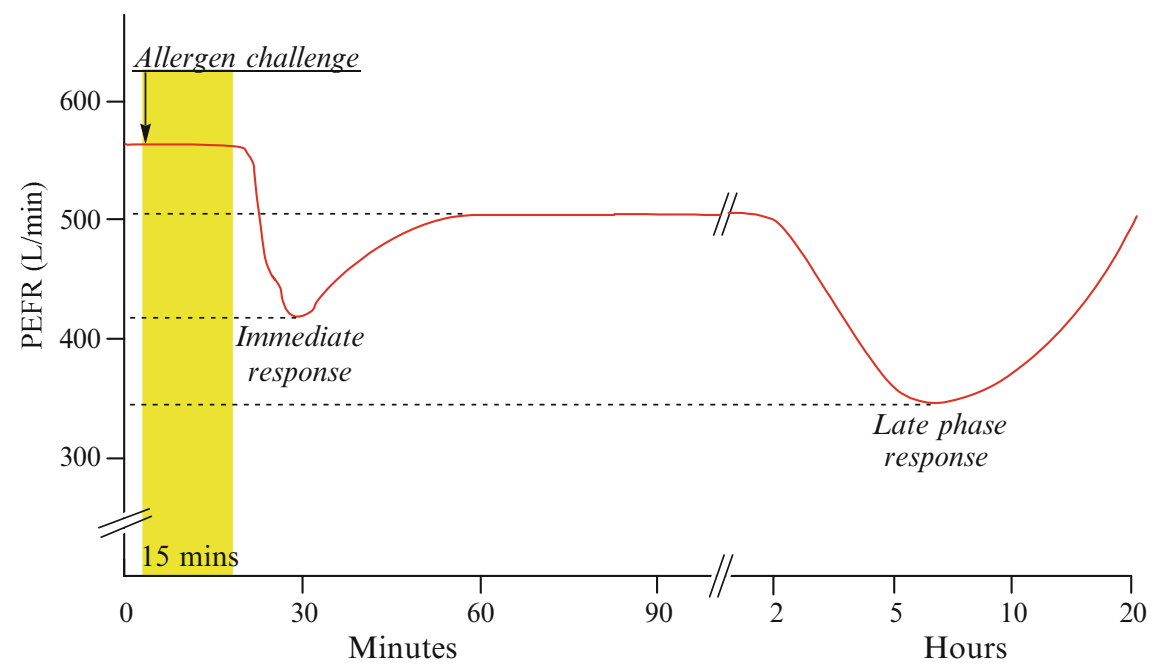

Fig.3.14 A typical lung function result as measured by peak expiratory flow rates (PEFR) in an allergic patient following challenge with allergen. An immediate reac- tion at about $30 \mathrm{~min}$ is followed by a late phase response which reaches a maximum 5-10 $\mathrm{h}$ after allergen challenge 


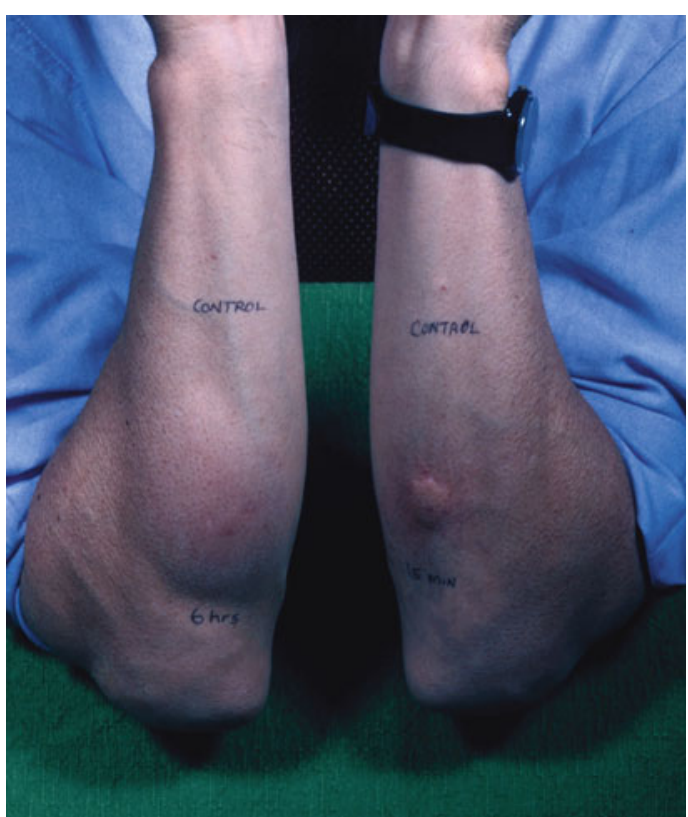

Fig.3.15 An immediate wheal and flare cutaneous reaction in an allergic patient 15 min after intradermal injection of antigen shown alongside a late phase edematous response $6 \mathrm{~h}$ post injection (Photograph kindly provided by Professor S. R. Durham)

\subsubsection{Early Studies: Implication of IgE Antibodies}

Late reactions have been known for many years with initial published reports dating back nearly 100 years, but investigations of the underlying cellular events and mechanisms involved were not pursued in any systematic way until the late 1960s when Pepys and colleagues studied patients with allergic bronchopulmonary aspergillosis and extrinsic allergic alveoltis, also known as hypersensitivity pneumonitis. They found edema, perivascular cellular infiltration, deposition of complement and serum immunoglobulin precipitins to Aspergillus fumigatus, and a variety of other extracts from organisms and agents that cause allergic alveolitis and concluded that the late reactions were the result of an Arthus or type III reaction. Soon after, other investigators came to a different conclusion failing to consistently find precipitins and complement but strongly implicating $\mathrm{IgE}$ antibodies in the reactions by a variety of methods including direct demonstration by induction of immediate and late responses with affinity-purified allergenspecific IgE antibodies followed by allergenic challenge. Another important finding was the observation that lymphocytes were the predominant cell in the cellular infiltrates together with a significant number of eosinophils and basophils. It should be remembered, however, that the investigations implicating $\mathrm{IgE}$ antibodies in late reactions to Bacillus subtilis enzyme, ragweed pollen, and other inhalant allergens do not necessarily refute the conclusion of a type III Arthus reaction to Aspergillus species and other allergens responsible for hypersensitivity pneumonitis conditions such as bagassosis and farmer's, bird-fancier's, coffee worker's, malt worker's, and mushroom worker's lung. These are very different conditions to hypersensitivities to allergen sources such as ragweed pollen and dust mites and are characterized by different antigenic stimuli, symptoms of cough, dyspnea, pleurisy, fatigue, anorexia, and weight loss with interstitial granulomas and mononuclear and giant cells in the lungs.

\subsubsection{Cellular Responses in the Late Phase Reaction and Comparison with the Delayed-Type Hypersensitivity Response}

From undergraduates to clinicians and researchers, there has long been confusion over use of the terms "late" and "delayed" with the late phase of the immediate wheal and flare reaction sometimes being labeled and referred to as a delayedtype hypersensitivity reaction, a type IV reaction, or simply "DTH." There was therefore a need to research, compare, and contrast these reactions and this was done in an important study in which both responses were provoked in the same individuals and studied with the same panel of cell marker monoclonal antibodies together with immunohistologic methods. Skin biopsies from atopic individuals with late phase allergic skin reactions to intradermal challenge with grass 
pollen or house dust mite were sectioned and examined for evidence of infiltration and activation of $\mathrm{T}$ cells and eosinophils. A substantial number of $\mathrm{CD} 3+$ and $\mathrm{CD} 4+$ cells but far fewer CD8+ cells were observed together with clearly different CD4+: CD8+ ratios in the sampled tissue and the peripheral blood. Infiltrated cells bearing receptors for IL-2 and evidence for IFN- $\gamma$ secretion suggested that $\mathrm{T}$ cells had become activated. Activated eosinophils were also detected and there was a strong correlation between these cells and the numbers of CD4+ cells $24 \mathrm{~h}$ after the allergen challenge, suggesting that $\mathrm{T}$ cells participate in the late phase inflammatory reaction. In fact, about $50 \%$ of cells infiltrating a late phase reaction site are T lymphocytes. It is therefore of interest to compare the late phase response with the delayed-type hypersensitivity reaction since it seems that $\mathrm{T}$ lymphocytes are important in both responses. In the comparison, grass pollen and house dust mite extracts were used to elicit late phase reactions while tuberculin challenge was used for delayed hypersensitivity responses. Both responses showed accumulation of CD4+ T cells, but overall the cells were more dispersed in denser accumulations and cells were still being recruited at $48 \mathrm{~h}$ in the delayed reactions. This is in contrast to the situation in late phase reactions where cell numbers usually plateau between 24 and $48 \mathrm{~h}$. Other differences found were greater activation of eosinophils in late phase reactions, the detection of small numbers of these cells in atopics and non-atopics at $24 \mathrm{~h}$ but not at $48 \mathrm{~h}$ in delayed-type hypersensitivity, and greater $\mathrm{T}$ cell activation (demonstrated by expression of IL-2R) in the latter response. The release of inflammatory cytokines in both reactions was indicated by endothelial expression of HLA-DR. The allergen-induced late phase reaction then has features of a cell-mediated hypersensitivity response, but it shows some significant differences from the classical delayed hypersensitivity response in atopic subjects. The difference is perhaps best illustrated by the different cytokine profiles. Employment of labeled RNA probes for some cytokines showed that infiltrating cells from allergen-induced late phase cutaneous reactions have a Th2-like cytokine profile expressing mRNA for the cytokine gene cluster IL-3, IL-4, IL-5, and granulocyte macrophage colony-stimulating factor (GM-CSF). Cells from tuberculin biopsies on the other hand preferentially expressed mRNAs encoding for IL-2 and IFN- $\gamma$, that is, cells preferentially expressing a Th1 cytokine profile. Comparisons of the accumulation of inflammatory cells and cells expressing mRNA for different cytokines in late phase and delayed-type responses in the same subjects showed a relatively rapid (1-6 h) accumulation of $\mathrm{T}$ cells and granulocytes in the former case and a much longer accumulation time (24-48 h) for $\mathrm{T}$ cells, macrophages, and other cells expressing Th1-type cytokines in delayed hypersensitivity responses. At $48-96 \mathrm{~h}$ in the late phase response, some cells increasingly expressed Th1-type cytokines. This may be an indication of a classic delayed hypersensitivity response earlier masked by the IgE antibodymediated reaction. Again, with the delayed-type response the distinction from the late phase response was not totally clear since a small number of cells in some individuals expressed mRNA encoding IL-4 and IL-5.

\subsection{Drug-Induced Hypersensitivity and Immune Receptors}

\subsubsection{Background}

An antibody response to a chemically reactive drug or hapten is said to occur after the drug-protein complex is recognized, processed, and presented as a drug-peptide conjugate to $\mathrm{T}$ cells that recognize the drug-modified peptide. A low molecular weight free, unconjugated drug is thought to remain unrecognized and not equipped to elicit an immune response. For drugs, however, immunological dogma is often found wanting on at least two counts. Firstly, despite the requirement that "small" molecular weight compounds or haptens (generally less than $1,000 \mathrm{kDa}$ ) need attachment to a macromolecular carrier to become immunogenic, many haptens or drugs that remain uncomplexed and apparently too 
small do in fact elicit a clear immune response. Secondly, despite the pioneering findings of Landsteiner and other early immunochemists, and the conclusion that previous exposure to an allergen is a prerequisite for allergic sensitization and reactivity, the dogma of prior exposure does not always hold. Previous contact with a drug is not necessarily a prerequisite for a drug-induced immune hypersensitivity response. Although these inconsistencies were emphasized by the author and some other investigators over 20 years ago (see monograph on drug allergy, Further Reading), general acceptance of exceptions to the dogma has only recently been forthcoming.

\subsubsection{Recognition and the Immune Response to Free, Unconjugated Drug}

The implications for drug allergy from the basic and applied research on $\mathrm{T}$ cell recognition of haptens initiated just over 20 years ago, were perhaps best summed up by Weltzien who, in commenting on the advances, declared simply that the work may "contribute to a better understanding of what defines an antigen as an allergy-inducing allergen." Perhaps this will eventuate but since the fledgling discipline of hypersensitivity research moved beyond the embryonic stage in the early half of the twentieth century and matured over a 60 -year period to provide impressive insights into the effector processes in the immediate allergic response, in particular the roles of $\operatorname{IgE}$ antibodies, mast cells, inflammatory mediators, and their receptor-controlled end organ responses, the longstanding question of what makes an allergen an allergen has remained obscure. Whether approaches utilizing $\mathrm{T}$ cell recognition of antigens in eliciting delayed hypersensitivity responses can soon provide the experimental and clinical opportunities to obtain the necessary insights and answers remains to be seen.

How then do small molecular weight, nonreactive chemicals such as many drugs stimulate $\operatorname{IgE}$ antibody production and provoke immune hypersensitivity reactions ranging from mild rashes to severe, life-threatening anaphylaxis? It must be understood that Landsteiner's studies on the sensitizing properties of some chemicals in the form of "small" molecules linked to a protein carrier constituted the initial investigations of contact hypersensitivity and the findings and interpretations from studies on protein conjugated chemicals should not automatically be used to explain all delayed reactions and certainly not $\operatorname{IgE}$ antibody-mediated type I reactions. An early clue to specific immune recognition of "small," unbound chemicals and hence drugs was the demonstration by Sinigaglia and his group of selective interaction of nickel (Ni) ions with an MHC-II-bound peptide. Ni-specific $\mathrm{T}$ lymphocyte clones from a patient with contact dermatitis to Ni responded to the metal ions when $\mathrm{Ni}$ salts were presented by APC in association with DRw11.1(5) molecules. Direct evidence that Ni was bound to the MHCassociated peptide was provided by NMR spectroscopy. These results, the first direct evidence of interaction between hapten and a MHC-bound peptide, not only demonstrated a model for $\mathrm{Ni}$ recognition by $\mathrm{T}$ cells from patients with $\mathrm{Ni}$ hypersensitivity but also indicated that a variety of chemically reactive groups, not only reactive metal ions, might attach to MHC-bound molecules to induce MHC-restricted responses to the conjugates. Further work with Ni hypersensitivity and the occupational lung disease berylliosis established that these conditions were MHC-IIlinked CD4+ delayed-type hypersensitivity responses and that the high frequency of Ni-reactive $\mathrm{T}$ cells occurs by formation of reversible coordination complexes in which $\mathrm{Ni}$ interacts with the MHC and TCR via His81 of the HLA-DR $\alpha$-chain and Tyr29 and Tyr94 of the CDR1 $\alpha$ region of the TCR. This coordination complex of $\mathrm{Ni}$ ions directly linking the MHC peptide and TCR is similar to the action of a weak superantigen. In extending the studies on $\mathrm{Ni}$ to investigations on the T cell recognition of haptens, Weltzien and others have shown, somewhat surprisingly to some, that MHC-restricted hapten-specific T cell receptors react to hapten-peptide conjugates within the MHC peptide-binding groove. This opened up a new approach for studying the molecular mechanisms underlying hapten recognition by $\mathrm{T}$ cells. 


\subsubsection{Abacavir and the MHC- Presented Altered Peptide Model of Drug Hypersensitivity}

More recently, some interesting HLA associations in drug hypersensitivities have been reported. A strong association of hypersensitivity to the guanosine-related pro-drug and reverse-transcriptase inhibitor abacavir was found with the well-defined 57.1 MHC haplotype encoding the MHC class I allotype HLAB*57:01 (see Sect. 1.3). Multi-organ reactions to abacavir, termed abacavir hypersensitivity syndrome or AHS, manifests as fever, rash, malaise, nausea, and diarrhea. It occurs in approximately $2-8 \%$ of patients with human immunodeficiency virus-1 (HIV-1) infection and can be severe enough to cause death in some rechallenged patients. Abacavir-specific CD8+ T cells secrete TNF and IFN $\gamma$ and are cytotoxic to abacavirAPCs. In a 2008 study, implication of the finestructural specificity of the 6-cyclopropylamino group of abacavir as a possible reactive site in the HLA-restricted CD8+ T cell response was demonstrated by lack of recognition of the abacavir structural analogs carbovir, didanosine, and guanosine by abacavir-reactive $\mathrm{T}$ cells (Fig. 3.16). Specificity of the interaction was further mapped to the $\mathrm{F}$ pocket (one of six, termed A-F), of the MHC-1 antigen-binding cleft where it was thought that abacavir, or a metabolite, binds to one or more self-peptides. At that stage, whether the binding was covalent or not had yet to be determined. It was predicted that the demonstration that AHS is an MHC-I-restricted cellular hypersensitivity response mediated by $\mathrm{CD} 8+\mathrm{T}$ cells might prove to be a forerunner for our better understanding of the basis of immune receptor recognition in drug hypersensitivities and, more specifically, for elucidating the pathogenesis of some of the life-threatening drug-induced systemic reactions such as toxic epidermal necrolysis (TEN) and StevensJohnson syndrome (SJS).

Right at the time of the completion of this monograph, newly published results explaining the molecular basis of AHS give every indica-
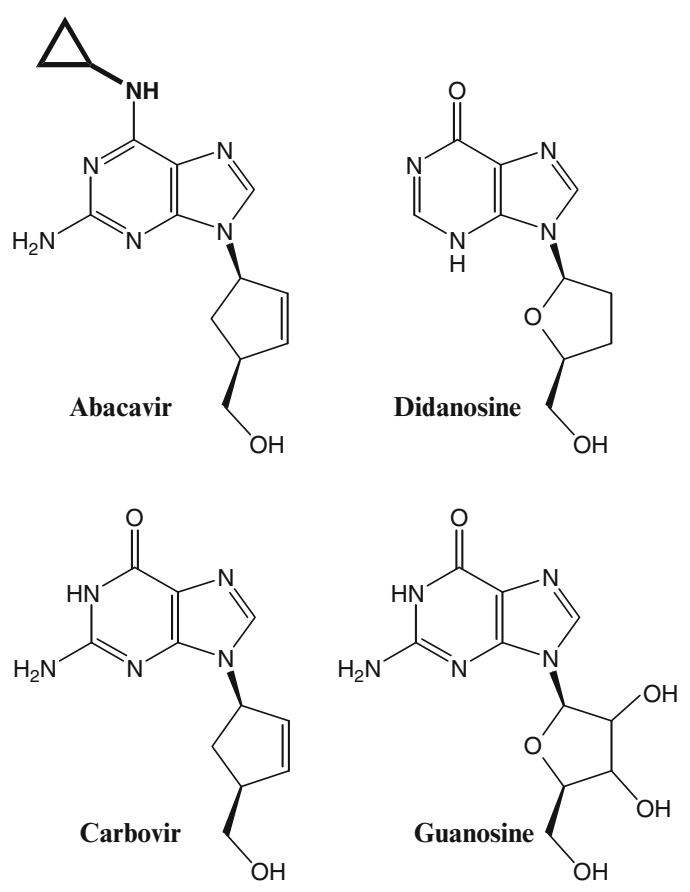

Fig. 3.16 Structures of abacavir and three purine analogs didanosine, carbovir, and guanosine. The 6-cyclopropylamino group of abacavir is highlighted

tion of having profound implications for understanding the origins and general molecular processes of autoimmunity. AHS is mediated by abacavir-specific activation of cytotoxic CD8+ T cells that require HLA-B*57:01 antigenpresenting cells, but abacavir-specific $\mathrm{T}$ cells are not activated by cells expressing the closely related allotypes HLA-B*57:02, HLA-B*57:03, and HLA-B*58:01, each of which is insensitive to abacavir and not linked to AHS. Two amino acid residues, Asp114 and Ser116, distinguish HLA-B*57:01 from the abacavir-insensitive alleles and abacavir reacts with these two amino acid residues. In extending the finding that the abacavir-HLA-B*57:01 association results from specific binding of the drug to the HLA F pocket, amino acid sequences of a large number of HLAB*57:01- and HLA-B*57:03-bound peptides from untreated and abacavir-treated cell lines were determined. Abacavir-treated HLA-B*57:01 cells, but not treated HLA-B*57:03 cells, contained unmodified drug but no metabolites 
indicating that abacavir bound non-covalently and specifically with HLA-B*57:01. Up to $25 \%$ of the peptides bound to HLA-B*57:01 following treatment with abacavir proved to be different to those before treatment but a change was not seen with peptides bound to HLA-B*57:03 or HLA-B*58:03. These results again suggested that abacavir binds specifically to the antigenbinding cleft of HLA-B*57:01 and this alters the repertoire of self-peptides bound by HLAB*57:01 but not the repertoire bound by the other HLA alleles. Sequences of peptides that bind HLA-B*57:01 contained Trp $\rightarrow$ Phe at the $\mathrm{C}$ terminus $(\mathrm{P} \Omega)$ but for HLA-B*57:03 $\mathrm{P} \Omega$ was reversed, i.e., Phe $\rightarrow$ Trp. After abacavir treatment, an increased number of peptides with Ile or Leu at $P \Omega$ bound HLA-B*57:01. In another recent study, peptides eluted from an HLA$B * 57: 01$ single allele-transfected cell line treated or not treated with abacavir were analyzed. A significant number of peptides with Val at the C-terminus were identified in the presence of abacavir but no peptides with Val at the C-terminus were found in untreated cells. Significant numbers of peptides with terminal Ile and fewer peptides with Trp and Phe also occurred in the presence of abacavir. Taken together, the results of the abacavir-HLA binding studies indicate that the drug positions itself at the bottom of the antigen-binding cleft extending, via the cyclopropyl moiety (Fig. 3.16), into the F pocket and changing the shape of the cleft. This results in preferred binding of smaller amino acids, an alteration in the repertoire of self-peptides that bind HLA-B*57:01, and a $\mathrm{T}$ cell response to self-proteins presented only in the presence of abacavir. Extension of this investigative approach to the antiepileptic carbamazepine, a drug strongly associated with HLA-B*15:02 (see below), showed that the drug binds to this allotype and, again, an altered repertoire of presented self-peptides results. This raises the possibility that antigen-presenting molecules may be susceptible to modulation by drugs (and perhaps even toxins, environmental chemicals, etc.) causing altered T cell immunity. If this is a general mechanism, investigations of associations of other drug hypersensitivities with antigen-presenting molecules may reveal further fascinating insights into some poorly understood, unpredictable, and potentially life-threatening adverse drug reactions and ultimately lead to a better understanding of the immunopathogenesis of autoimmunity, infectious diseases, and cancer.

\subsubsection{Carbamazepine and Other HLA-Drug Hypersensitivity Associations}

In addition to the associations of HLA-B* 57:01 with abacavir hypersensitivity and flucloxacillin-induced liver injury (Sect. 5.1.10), HLA-DRB1*15:01 with lumiracoxib-induced hepatotoxicity, and HLA-B*58:01 with allopurinol-induced SJS (see below), HLA$\mathrm{B} * 15: 02$ is strongly associated with carbamazepine-induced SJS and TEN. As mentioned in Sect. 3.4.3 above, the generality of the abacavir-HLA binding results was tested in a preliminary way in an examination of the wellestablished strong association between HLAB*15:02 and carbamazepine-induced SJS/TEN in Asian populations. A non-covalent association between carbamazepine and HLA-B*15:02 was established by purifying HLA-B*15:02peptide complexes and sequencing of bound peptides. This revealed a preference for smaller amino acids at key positions and significant increases in the presence of some hydrophobic residues. Comparisons with HLA-B*15:01 show that this allele is not associated with carbamazepine-induced SJS and an important difference between HLA-B*1502 and HLA$\mathrm{B} * 15: 01$ is at position 156 (Leu for the former, Trp for the latter) near where the drug is thought to bind in HLA-B*15:02.

The carbamazepine-HLA-B*15:02 interaction has also recently been used by S-I Hung and collaborators in Taiwan as a model for the study of the pathologic role of HLA in delayed-type drug hypersensitivity. No intracellular metabolism or antigen processing was detected in the interaction between carbamazepine and HLA-B*15:02 in patients with the bullous skin 
conditions and surface plasmon resonance assays showed that HLA-B*15:02, but not other HLA-B recombinant proteins, directly binds carbamazepine and the structurally related carbamazepine 10,11-epoxide. For drug presentation and activation of cytotoxic $\mathrm{T}$ lymphocytes, endogenous peptides in the antigen-binding groove were shown to be necessary. This is in contrast to abacavir which binds to HLA-B*57:01 without peptide loading. Modeling suggested that the Arg62 side chain, located in the B pocket of the HLAB*15:02 protein, was the most likely binding site for carbamazepine by forming a hydrogen bond with the ketone of its 5-carboxamide group on the tricyclic ring. Specific recognition of this group was supported by results obtained with selected structural analogs.

Allopurinol is an important treatment for hyperuricemia-related diseases, being used to lower uric acid in gout, kidney stones, and LeschNyhan syndrome. Unfortunately, the drug is also a frequent cause of adverse drug reactions, accounting, it is said, for up to $5 \%$ of severe cutaneous adverse reactions. Reactions include drug hypersensitivity syndrome, SJS, and TEN. In a Taiwanese study designed to identify genetic markers for allopurinol cutaneous reactions, the HLA-B*58:01 allele was identified in $100 \%$ of 51 patients with allopurinol-induced serious reactions but in only $15 \%$ (20) of 135 tolerant patients. These results indicate that in Han Chinese, allopurinol is strongly associated with HLA-B*58:01 and this allele is an important genetic risk factor for the serious cutaneous reactions with systemic symptoms.

The NSAID and phenylbutazone derivative, feprazone, was found to be associated with HLAB22 in a Scandinavian study-93\% of patients with a fixed drug eruption caused by the drug were HLA-B22 positive but no patients with fixed drug eruptions to other drugs were positive to HLA-B22 and this allele was found in $4 \%$ of healthy controls. However, a number of factors, including the absence of HLA-B22 in $7 \%$ of the Scandinavian patients with feprazone-induced fixed drug eruption, need further scrutiny before feprazone-HLA-B22 can be taken as a diagnostic marker. At the least, more extensive population studies are needed.
Other drug hypersensitivities or intolerances thought or claimed to be associated with HLA class I and/or class II alleles include trimethoprimsulfamethoxazole with HLA-A30, aspirin with a number of different haplotypes (see Sect. 9.5.5), hydralazine-induced systemic lupus erythematosus with HLA-DRw4, and nevirapine hypersensitivities with a surprising and confusing array of associations. Again, these findings highlight the need for extensive phenotyping studies and investigations in much larger populations.

\subsubsection{The Question of Direct Drug Activation of T Cells Without Involvement of a Specific Peptide}

Drawing on earlier speculations on the absence of prior sensitization in many drug reactions and the seminal studies of MHC-restricted metal ion and drug hypersensitivities mediated by $\mathrm{T}$ cell activation, others have suggested some modifications to the possible cellular and drug interactions involved in drug-specific recognition by cells of the immune system. A number of observations including the prevention of $\mathrm{T}$ cell activation after removal of drug by washing, rapid calcium influx into T cells after exposure to drug, and the fact that glutaraldehyde-fixed APC can still present drug have led to the suggestion that $\mathrm{T}$ cells rather than APCs recognize free, unprocessed parent drug in allergic individuals. Proponents of the so-called $\mathrm{p}-\mathrm{i}$ concept (derived from the proposed direct pharmacological interaction of drugs with immune receptors) state that "drugs bind specifically and reversibly to some of the highly variable antigen-specific TCR in a direct way, instead of covalently modifying the MHC-peptide complex." Direct and in-depth experimental findings of the sort presented in the $\mathrm{Ni}$, abacavir, and carbamazepine/HLA-B*15:02 investigations to support this hypothesis are lacking, and with, for example, abacavir bound at the bottom of the HLA-binding groove, it is difficult to see how the drug can directly contact, or by itself directly influence, the $\mathrm{T}$ cell receptor. Recently the proposed model restricted to $\mathrm{T}$ cell binding appears to have been modified to 
acknowledge and to try and accommodate the association and presentation of some drugs, or drugs with peptide, in the MHC peptide-binding groove. Given the apparent unequivocal definition of direct drug binding to the TCR without modification of the MHC-peptide complex, it is difficult to see how this accommodation can be achieved.

\subsection{Desensitization of Drug- Allergic Patients}

Only immediate type hypersensitivity drug reactions involving IgE antibodies and/or a mast cellmediated mechanism are considered eligible for desensitization.

An adverse reaction to a drug can be major problem in efforts to achieve successful treatment for common and important diseases including infections, arthritides, allergies, and malignancies. Adverse drug reactions occur frequently, and as the number, chemical nature, and novel pharmacological actions of registered drugs continue to increase, such reactions can seriously interrupt therapy and leave patients with less than optimal treatments. Rapid drug desensitization (RDD) can provide an effective and safe means to continue vital therapies while minimizing or avoiding the previously disruptive impediment. The aim of desensitization is to administer increasing amounts of drug in an incremental and stepwise manner while at the same time avoiding or minimizing lifethreatening, or even lesser adverse, symptoms. When successful, the procedure induces temporary tolerance to the drug allowing treatment to continue with optimal dosage.

In considering possible mechanisms leading to rapid desensitization to a drug, the mast cell and possibly the basophil appear to be the cells most likely to be involved. In drug reactions involving complementary IgE antibodies, RDD appears to result in the mast cells becoming temporarily tolerant to the drug. A convincing explanation of how RDD tolerizes mast cells or interferes with their activation is lacking and the subject is inadequately understood and in need of further inves- tigation of possible mechanisms. One current investigative approach involves the delivery of increasing quantities of antigen at fixed time intervals to mouse bone marrow mast cells in vitro together with the monitoring of granule release by detection of $\beta$-hexosaminidase and the metabolism of prostaglandins and leukotrienes. Both of these indicators were inhibited by desensitization and this was achieved by incremental increases in dosage. Importantly, the presence of antigen was necessary for desensitization-as long as antigen was maintained, and desensitization was maintained. Mast cells desensitized to dinitrophenol did not release preformed and de novo synthesized mediators such as TNF and IL-6. This may help to explain why desensitized patients are not at risk of a delayed reaction. Experiments in which mast cells were sensitized to dinitrophenol and ovalbumin showed that ovalbumin-desensitized cells responded fully to dinitrophenol, proving antigen specificity and that signaling transduction pathways have not been impaired during desensitization. Furthermore, FceRI-bound antigen-specific IgE molecules did not disappear from the cell surface during desensitization after becoming bound to small doses of antigen. These results are reassuring in that they support both the proposed inhibition of the mast cell response and the basis for the RDD procedures currently used. Over many years, a number of other mechanisms have been proposed to explain the state of clinical tolerance resulting from the practice of desensitization. The list includes the formation of IgG blocking antibodies, consumption or blocking of the drug-reactive IgE antibodies by the gradually increasing quantities of administered drug, tachyphylaxis or depletion of the released mediators, hapten inhibition by monovalent penicillin-protein conjugates, and desensitization of mast cells and basophils by gradually increasing quantities of multivalent drug-carrier complex. It must be concluded, however, that few truly revealing insights into the mechanisms underlying mast cell tolerance or hypo-responsiveness have been obtained so far.

Note that desensitization to a drug does not result in long-term tolerance to the adverse effects of the drug and this therefore means that 
patients need the desensitization procedure to be repeated each time they are again exposed to the drug. However, if the medication is maintained, for example, by daily dosage with pharmacologically active levels, the desensitization state can be maintained.

\subsection{Delayed-Type (Type IV) Hypersensitivity Drug Reactions}

Unlike types I, II, and III hypersensitivities, which are mediated by antibodies, delayed or cell-mediated hypersensitivity, classified as type $\mathrm{IV}$, is mediated by antigen-specific effector $\mathrm{T}$ cells and this means that the hypersensitivity response can be transferred by purified $\mathrm{T}$ cells or a cloned $\mathrm{T}$ cell line. Again in contrast to an immediate reaction, a delayed-type hypersensitivity reaction develops over a period of 24-72 h. Delayed hypersensitivity responses have been used for many years to assess patients' cellmediated immunity by the induction of induration and erythema 48-72 $\mathrm{h}$ after intradermal injection of so-called "recall" antigens from Mycobacterium tuberculosis, Candida and Trichophyton species, and tetanus toxoid.

\subsubsection{The Cellular Basis of Type IV Hypersensitivity Cutaneous Drug Reactions}

Delayed-type hypersensitivity reactions in the skin provoked by systemic drug administration usually occur 7-10 days after the commencement of therapy. Drug-induced skin reactions manifest mainly as exanthemas, mediated by CD4+ and CD8+ CD3+ T cells in the dermis and epidermis. Antimicrobial drugs, NSAIDs, and some analgesic drugs are the biggest causes of drug-induced adverse cutaneous reactions but a variety of other drugs including anticonvulsants (e.g., carbamazepine), local anesthetics (lidocaine), cardiovascular drugs (procainamide), and antipsychotics (clozapine) are well known to cause reactions. For most proteins and hapten-protein conjugates, processed antigen is presented to $\mathrm{CD} 4+\mathrm{T}$ cells via the MHC class II molecules on antigen-presenting cells. The cells involved in many type IV responses such as contact hypersensitivity and psoriasis are Th1 and CD8+ cytotoxic T cells while in a condition such as allergic contact dermatitis, CD4+ or CD8+ T cells can be activated depending on the antigen processing pathway. In general, CD4+ T cell activation seems to mediate maculopapular and eczematous drug hypersensitivities while CD8+ $\mathrm{T}$ cell activation produces the more severe skin reactions involving bullous manifestation.

In a hypersensitivity reaction in the skin such as allergic contact dermatitis, there are two phases of the hypersensitivity response, sensitization (or initiation or induction) and elicitation. In the sensitization phase following drug administration, free drug or drug bound to a protein carrier reaches the skin where it encounters keratinocytes, present in great numbers and thought to play a major role in the initiation of skin sensitization. As well as facilitating the formation of biologically active haptens and hapten binding to protein, keratinocytes release chemotactic factors CXCL8, CXCL9, CXCL10, and CXCL11 and adhesion molecules (e.g., ICAM-1) on exposure to sensitizing agents. These chemotactic factors attract more cells to the active skin sites, thus increasing local immune activity. Sensitization proceeds with drug-carrier complex being taken up by immature Langerhans' and dendritic cells. These migrate to the draining lymph node and, with the stimulus provided by co-stimulatory molecules, become $\mathrm{T}$ cellactivating cells. Processed antigen is expressed as a drug-peptide complex in association with MHC class I and II molecules on the surface of the mature antigen-presenting cells for presentation to $\mathrm{CD} 8+$ and $\mathrm{CD} 4+\mathrm{T}$ cells, respectively. Dendritic cells, Langerhans' cells, and skin macrophages express both MHC (class I and II) molecules and can activate CD4+ as well as CD8+ T cells. Keratinocytes are also important in the elicitation phase and can present antigen via MHC I and MHC II molecules. T cells are activated, undergo clonal expansion, and give rise to cells with different memory and effector 
functions, that is, Th1, Th2, or Th17 CD4+ or CD8+ $\mathrm{T}$ cells. By the time of the elicitation phase, $\mathrm{T}$ cells have gained access to the skin and following reexposure to the drug, skin symptoms occur within about $48 \mathrm{~h}$. Hapten-specific T cells recognize the hapten-peptide presented by dendritic cells and keratinocytes and the resultant activated $\mathrm{T}$ cells produce Th1 and Th17 cytokines such as IFN- $\gamma$, IL-12, IL-17, and IL-23. Note that although Langerhans' cells have long been considered to be the classical cell net to trap, process, transport, and present antigen to $\mathrm{T}$ lymphocytes, evidence, including mice lacking Langerhans' cells, has shown that dendritic cells can act in their place if Langerhans' cells are absent or functionally affected. The nature of the antigen, that is, the sensitizing drug or drug conjugate, seems to determine which MHC molecule is involved in antigen presentation. Extracellular antigens (for example, contact allergens) are generally presented via MHC class II molecules and intracellular antigens (for example, drug-protein conjugates formed intracellularly) via MHC class I. Presentation, for example, of the contact sensitizing agent nitrobenzene sulfonic acid, appears to be by MHC II molecules.

With the involvement of the co-stimulatory B7-CD28 interaction, $T$ cells are activated and memory $\mathrm{T}$ cells can be found in the dermis. Other co-stimulatory molecules have also been identified including OX-40-OX-40L, PD-1PD-L1 and PD-L2, RANK-RANKL, and CD40CD40L (CD154). The receptor OX-40, also known as CD134, and its ligand OX-40L are seen as secondary co-stimulatory molecules expressed after $\mathrm{T}$ cell activation and important in maintaining $\mathrm{T}$ cell memory. RANKL, involved with dendritic cell maturation, belongs to the TNF cytokine family while PD-1 and its ligands, belonging to the $\mathrm{B} 7$ family, negatively regulate $\mathrm{T}$ cell responses. Binding of the co-stimulatory molecule CD-40 on antigen-presenting cells to its ligand CD40L activates these cells. During subsequent exposure of the memory $\mathrm{T}$ cells to the sensitizing antigen, clonal expansion of the activated $\mathrm{T}$ cells occurs and this ultimately results in $\mathrm{T}$ cell-mediated inflammation and cell damage in the skin. Activation and proliferation of memory $\mathrm{T}$ cells in the dermis release chemokines and inflammatory cytokines such as IFN- $\gamma$ and tumor necrosis factor- $\alpha / \beta$ (hereafter referred to as TNF) that recruit macrophages to the site. Presentation of antigen by the newly arrived macrophages has the affect of further amplifying the response. The released chemokines and cytokines increase the permeability of blood vessels leading to local swelling and induce the expression of vascular adhesion molecules. IFN- $\gamma$ is the key cytokine and it plays a dominant part in delayed hypersensitivity, upregulating $\mathrm{T}$ cell activation markers and MHC molecules, and aiding Th1 while suppressing Th2 cell differentiation. TNF also has a central role in delayed hypersensitivity, inducing chemokine production, upregulating expression of adhesion molecules, and promoting the influx of inflammatory cells. CD4+ and CD8+ T cell-mediated cytotoxicity of skin cells presenting drug can result from interaction with Fas/FasL, release of the cytolytic protein perforin and the serine protease granzyme B from cytotoxic $\mathrm{T}$ lymphocytes, and release of granulysin from cytotoxic $\mathrm{CD} 8+\mathrm{T}$ cells. In response to inflammatory agents released by T cells, skin cells can in turn contribute to inflammation by releasing their own spectrum of cytokines and chemokines that stimulates further leukocyte recruitment into the skin. As understanding of the complexities of the mechanisms of the many processes that make up delayed-type hypersensitivity responses increases, two other agents, Il-12 and osteopontin, are attracting the interest of researchers. IL-12, produced mainly by antigen-presenting cells, aids the proliferation and differentiation of Th1 cells, augments IFN- $\gamma$ production by these cells, and enhances NK and CD8+ T cell cytotoxicity. Osteopontin (also known as ETA, early T lymphocyte activation-1), a phosphoglycoprotein with cytokine and chemotactic functions, has a Th2 suppressive effect augmenting Th1mediated allergy such as allergic contact dermatitis and supporting dendritic cell migration and Il-12 expression and secretion. Discussion of osteopontin's role in allergic contact dermatitis is continued briefly below in Sect. 3.6.3.1. 


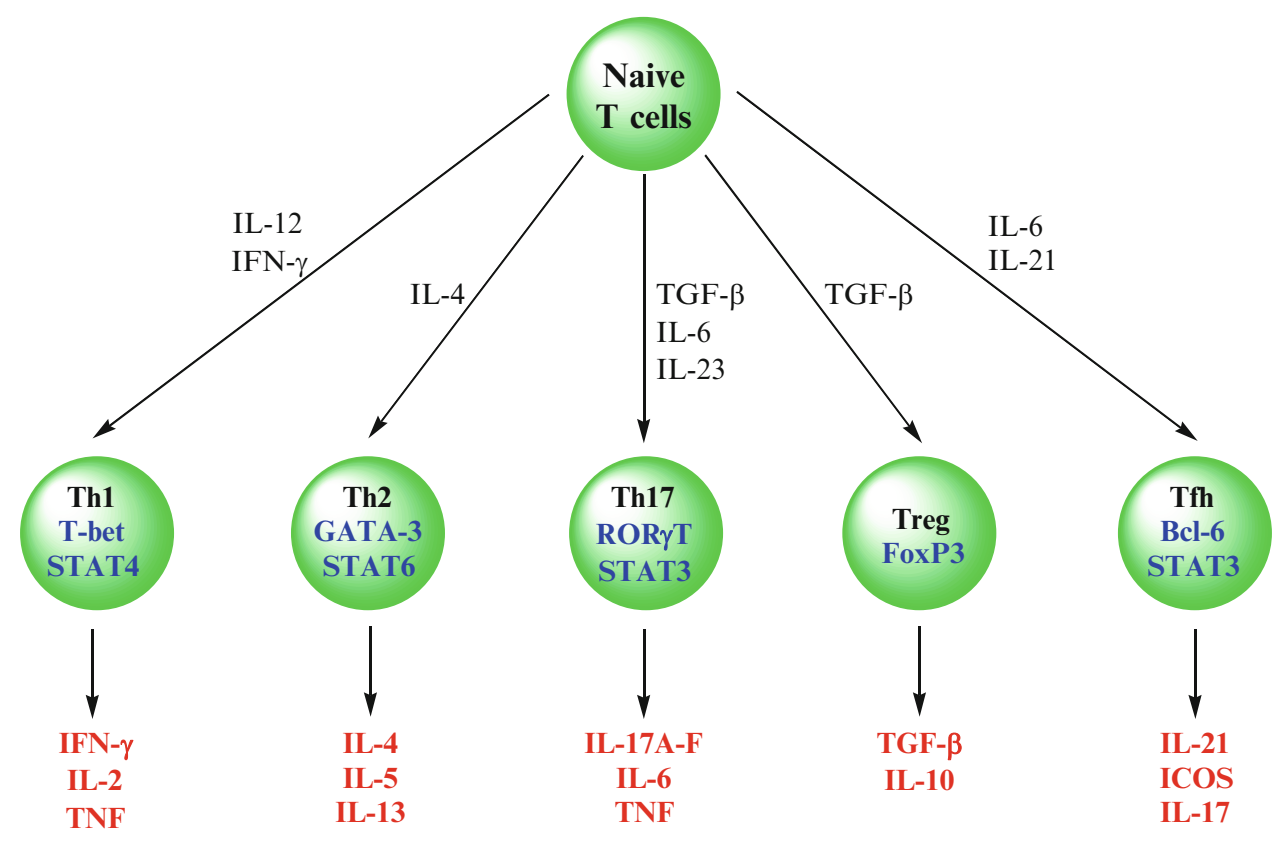

Fig. 3.17 Naive $\mathrm{T}$ cells, under the influence of cytokines produced by other immune cells, undergo activation and polarization to distinct Th subsets. Each subset displays a distinct cytokine secretion profile resulting in different effector functions, e.g., Th1 cells activate macrophages; Th2 cells promote allergic responses and

\subsubsection{T Helper Cell Responses and Th17}

As discussed, naive $\mathrm{T}$ cells differentiate into Th1 or Th2 cells during activation induced by interaction with dendritic cells with toll-like patternrecognition receptors that detect the nature of the antigen. This results in IL-12 production, the involvement of transcription factors T-bet, STAT4, or STAT1 within the T cell, the induction of Th1 differentiation, and production of IFN- $\gamma$. Th2 differentiation is the result of IL-4 cytokine and GATA-3 and STAT6 transcription factor involvement that drives production of IL-4, IL-5, and IL-13. TGF- $\beta$ and the transcription factor FoxP3 results in the $\mathrm{T}_{\text {reg }} \mathrm{T}$ cell subset that secretes TGF- $\beta$ (Fig. 3.17). After definition of the Th1 and Th2 subsets more than 20 years ago, relatively recent research has revealed a new class of $\mathrm{T}$ effector cells Th17, induced from naive $\mathrm{T}$ cells by the cytokines TGF- $\beta$ and IL- 6 and enhanced immune responses to parasites; Th17 cells promote inflammation by helping to recruit neutrophils and Treg cells exert a number of inhibitory actions via cell contact. A more recently identified CD4 T cell subset, termed follicular helper cells (Tfh), provide a helper function to B cells

by IL-23, a cytokine produced by keratinocytes, Langerhans' cells, dendritic cells, and macrophages. Th17 cells are characterized by expression of distinct transcription factors ROR $\gamma \mathrm{T}$, STAT3, and IRF-4 and the production of proinflammatory molecules of the IL-17 family comprising IL-17A, B, C, D, E, and F (Fig. 3.17). IL-17A gives rise to tissue inflammation by producing pro-inflammatory cytokines IL-6 and TNF and chemokines CCL2 (monocyte chemotactic protein-1 or MCP-1), CXCL1, and CXCL2 that activate macrophages and granulocytes. IL-25 and IL-27 negatively regulate Th17 cells while Th17 polarization is inhibited by IL-2, IL-4 (induces Th2), and IFN- $\gamma$ (induces Th1).

Another more recently identified CD4 T cell subset, termed follicular helper cells (Tfh), provides a helper function to $\mathrm{B}$ cells. Tfh cells are distinguished from Th1 and Th2 cells by expression of the chemokine CXCR5, their association with $\mathrm{B}$ cell follicles, and their B cell helper function. 
They produce ICOS (inducible $\mathrm{T}$ cell costimulator) and IL-21, a cytokine that stimulates B cells to differentiate into antibody-forming cells. This cytokine is particularly interesting for those concerned with understanding allergic mechanisms and the treatment of immediate-type allergies. IL-21 knockout mice express higher levels of IgE than normal mice and, in fact, IL-21 has already been used to attenuate allergic responses by reducing both $\mathrm{IgE}$ and inflammatory cytokine production in mouse models for rhinitis and peanut allergy.

\subsubsection{Delayed Cutaneous Adverse Drug Reactions}

For the first episode, these reactions generally begin 7-21 days after contact with drug. Subsequent reactions begin 1 or 2 days after reexposure. Specificity is usually demonstrated by oral challenge with small doses of the culprit drug, a positive patch test or intradermal test generally read after a delay of at least $48 \mathrm{~h}$, and perhaps a positive in vitro lymphocyte proliferation assay. Activated $\mathrm{T}$ cells are found in the skin and in some cases $\mathrm{T}$ cell lines and clones can be isolated from blood and/or skin sites. Distinct subsets of $\mathrm{T}$ cells with their accompanying profile of cytokines and chemokines promote the inflammatory and cytotoxic responses seen in the different clinical patterns characteristic of the various drug-induced adverse cutaneous hypersensitivities. Individual hypersensitivity eruptions are essentially the result of overlapping cytokine actions with one or a few such actions dominant and characteristic of the delayed drug hypersensitivity phenotypic pattern. This, and the lack of histological and immunocytochemical criteria, has consequences for the diagnosis of drug-induced skin reactions where considerable effort is needed in the development of reliable and specific tests that can be easily undertaken (see Chap. 4). Although the mechanisms underlying the different drug-related skin eruptions with an immunological pathogenesis are still far from precisely defined, summaries of the progress are set out below.

\subsubsection{Allergic Contact Dermatitis}

For a description of allergic contact dermatitis, see Sect. 2.2.4.1 and Figs 2.4 and 2.5. Not all contact dermatitis has an immune basis; some irritants such as organic solvents, highly alkaline drain cleaners, and sodium lauryl sulfate and some phototoxins like the psoralens, paradoxically used for the treatment of psoriasis, eczema, and vitiligo, may also provoke reactions. Common causes of allergic contact dermatitis include Ni metal, chromium, balsam of Peru, and Toxicodendron plants, for example, poison ivy, poison oak, and poison sumac. Causative agents tend to be reactive small molecules or haptens of less than 1,000 Da that can easily penetrate the skin barrier and form covalent adducts with cutaneous proteins. Allergic contact dermatitis is regarded as a Th1 and CD8+ T cell-mediated disease and Ni allergy (see also Sect. 3.4.2), which involves activation of HLA-restricted, skinhoming Ni-specific $\mathrm{T}$ cells by antigen-presenting cells, is perhaps its best-known commonly occurring form. Both sensitization and skin reactions to $\mathrm{Ni}$ are thought to be mediated by $\mathrm{CD} 4+$ and CD8+ effector T cells producing IFN- $\gamma$. During sensitization when no clinical symptoms are apparent, mature Langerhans' cells originating from skin sub-layers present Ni-peptide-MHC complex to $\mathrm{T}$ cells in local lymph nodes. Upon rechallenge with $\mathrm{Ni}$, the effector phase of allergic contact dermatitis is activated to produce cutaneous infiltration of Ni-specific and CCR4-positive $\mathrm{T}$ cells. Ni-specific cytotoxic CD8+ T cells release inflammatory cytokines that produce the characteristic skin lesions at the site of Ni sensitization (Chap. 2, Fig. 2.4). The T cell cytokine IL-17 can be found in the skin of patients with allergic contact dermatitis. Some Ni-specific CD4+ $\mathrm{T}$ cell clones isolated from the blood of allergic contact dermatitis patients express this cytokine which regulates the expression of adhesion molecules by keratinocytes and the synthesis and release of the chemokines IL-8 and RANTES. IL-17 has been shown to be locally released by Ni-specific Th0, Th1, and Th2 lymphocytes in the skin of patients with allergic contact dermatitis where it amplifies reactions and modulates the pro-inflammatory action of 
keratinocytes by acting together with IFN- $\gamma$ and IL-4. There still seems much to learn about the role of IL-17 in allergic contact dermatitis but already the importance of this cytokine in the pathomechanism underlying the condition is apparent.

The phosphoglycoprotein osteopontin is expressed by a number of different immune cells including effector $\mathrm{T}$ cells and keratinocytes in allergic contact dermatitis. The molecule is expressed in secreted and intracellular form, it enhances Th1 and Th17 immunity, and protects against apoptosis. Experiments in mice have shown that $\mathrm{T}$ cell clones secreting low levels of IFN- $\gamma$ may compensate by secreting high levels of osteopontin which, in turn, down-modulates $\mathrm{T}$ cell IL-4 expression. In allergic contact dermatitis, secretion of IFN- $\gamma$ by effector T cells induces osteopontin in keratinocytes which ultimately results in the attraction of inflammatory cells. The demonstrations that osteopontin-null mice display a reduced inflammatory response in contact hypersensitivity and anti-osteopontin antibodies partly suppresses established chronic contact sensitivity suggest that osteopontin may be a promising therapeutic target in allergic contact dermatitis.

\subsubsection{Psoriasis}

Clinical aspects of psoriasis are presented in Sect. 2.2.4.2 and Fig. 2.6. The classification of T cells into Th1 and Th2 cells, essentially on the basis of their defining cytokines IFN- $\gamma$ and IL-4, respectively, and the fairly recent identification of a new type of $\mathrm{T}$ cell, Th17, together with the realization of its importance in inflammation, has led to the reexamination of many diseases previously considered to be solely Th1 or Th2 mediated. So far, in murine models at least, some diseases, previously thought to be Th1-mediated responses, have been found to involve both Th1 and Th17 cells. Th17 cells produce IL-17, TNF, IL-6, IL-21, and IL-22 which are upregulated during inflammatory disorders and which produce thickening of mouse epidermis suggesting a role in psoriatic inflammation. Other findings suggestive of a role for Th17 cells in psoriasis include the reduction of levels of IL-17 and
IL-22 in the serum of patients whose psoriasis had been cleared by treatment with the TNF inhibitor etanercept; enhanced expression of IL-23 in patients with psoriatic lesions; and the demonstration of IL-17 mRNA in psoriatic lesions. Analysis of psoriatic skin lesions and peripheral blood for the presence of IL-17producing cells revealed Th17 cells localized in the lesions and the dermis. In addition, IL-17 mRNA expression returned to normal with cyclosporin therapy and IL-22 mRNA expression moved in parallel with IL-17 changes, suggesting that both Th1 and Th17 cells are active in the inflammatory stages of psoriasis. Following the demonstration that in addition to Th1 cells producing IFN- $\gamma, \mathrm{CD} 4+\mathrm{T}$ lymphocytes producing IL-17 were also important in the pathogenesis of psoriasis, attention turned to the possible importance of IL-17-producing CD8+ cells known to be present in psoriatic plaque. Investigations showed that CD8+ IL-17+ cells produced the Th1-related cytokines IFN- $\gamma$ and TNF as well as the Th17 cytokines IL-17, IL-21, IL-22, and upregulation of the transcription factor RORC. These results showing some common properties between $\mathrm{CD} 8+\mathrm{IL}-17+\mathrm{T}$ cells and Th17 cells and the intriguing finding that CD8+ cells, unlike Th17 cells, can also make IFN- $\gamma$ and TNF may prove significant in fully elucidating the pathogenesis of psoriasis.

Currently, the broad understanding of the events and mechanisms leading to psoriasis is as follows. Antigen-presenting cells, probably Langerhans' cells, in the skin migrate to regional lymph nodes where they interact with $\mathrm{T}$ cells. The nature of the presented antigen is not known but co-stimulatory factors from the antigen-presenting cell are believed to be intercellular adhesion molecule 1 (ICAM-1, CD54) and lymphocyte function-associated antigen 3 (LFA-3, CD58). These molecules interact with their complementary receptors on the T cell, lymphocyte function-associated antigen 1 (LFA-1, integrin), and LFA-2 (CD2), respectively. Activated T cells return to the skin where local effects in the dermis and epidermis of released pro-inflammatory cytokines such as TNF produce the inflammation and epidermal hyper-proliferation seen in psoriasis. 


\subsubsection{Maculopapular Exanthema}

A case of maculopapular exanthema induced by amoxicillin with lesions on the trunk and hands is shown in Fig. 2.7 together with a clinical description in Sect. 2.2.4.3. Lymphocytes (CLA+, $\mathrm{CD} 3+$, DR+, CD25+) expressing adhesion molecules are attracted from the blood by adhesion molecules expressed by endothelial cells and keratinocytes and by chemokines such as CCL27 (also called cutaneous $\mathrm{T}$ cell-attracting chemokine CTACK).

Both CD4+ and CD8+ T cells are found in the skin and blood of patients with maculopapular exanthema, but findings on the relative importance of these cells differ with some authors stating that $\mathrm{CD} 4+$ cells predominate and inflict cell damage by expressing high levels of perforin and granzyme B while CD8+ cells are found mainly in the epidermis. Other results have shown that CD8+ cells predominate in acute lesions of the epidermis and are the major drug-specific cytotoxic cell found in the blood of most patients with penicillin-induced maculopapular exanthema. Examination of cellular infiltration in the skin of patients during patch testing demonstrated rapid recruitment of CD8+ cells after skin contact with drug and before appearance of other cells particularly CD4+ T cells. Both type 1 and type 2 cytokines are produced; IFN- $\gamma$ (type 1) activates dendritic cells and keratinocytes; IL-5 (type 2) together with eotaxin (CCL11) recruits and activates eosinophils. Other chemokines including CCL20, CXCL9, and CXCL10 appear to be involved in skin homing. During the acute phase CD4+ cells express perforin.

\subsubsection{Acute Generalized Exanthematous Pustulosis}

Activated drug-specific CD4+ and CD8+ T cells producing the neutrophil-attracting chemokine CXCL8 (IL-8), infiltrate the skin of patients with acute generalized exanthematous pustulosis (AGEP) (Sect. 2.2.4.4) and can be detected in peripheral blood, in positive patch test biopsies, and in $\mathrm{T}$ cell lines and clones. CXCL8producing effector memory $\mathrm{T}$ cells express mainly IFN- $\gamma$, GM-CSF, TNF, and sometimes IL-4 and IL-5. These cells express the chemo- kine CCR6 and aid infiltration and survival of neutrophils leading to the sterile pustular eruptions found in AGEP patients (Fig. 2.8).

\subsubsection{Drug Reaction (Rash) with Eosinophilia and Systemic Symptoms}

The pathophysiology of drug reaction (sometimes designated rash) with eosinophilia and systemic symptoms (DRESS), also called druginduced hypersensitivity syndrome (DIHS), is still being worked out (see also Sect. 2.2.4.5). Activated CD4+ and CD8+ T cells expressing CCR10 and producing type 1 cytokines, chiefly IFN- $\gamma$, are found in the blood of DRESS patients in the acute phase and these cells increase in proportion to the severity of the skin reaction (Fig. 2.9). Interestingly, T cell clones from carbamazepine- and lamotrigine-sensitive patients react specifically with antigen-presenting cells apparently without the formation of reactive metabolites and processing, much like the situation with a superantigen. The $\mathrm{T}$ cell clones produce perforin and secrete IL-5 as well as IFN- $\gamma$, the former accounting for the eosinophilia associated with the syndrome. Many investigators believe that a concomitant human herpes virus 6 (HHV-6) reactivation with hypogammaglobulinemia caused by the drug is associated with the hypersensitivity syndrome. This remains to be established.

While mentioning DRESS, it is opportune to comment on drug-induced allergic hepatitis. As in DRESS, this condition is associated with fever, rash, eosinophilia, and liver infiltrates and the reaction is generally a type IV hypersensitivity response involving CD4+ cells, CD8+ cytotoxic lymphocytes, NK, Kupffer and dendritic cells. Type II hypersensitivities may also sometimes occur. There are two main hypotheses for the mechanism of drug-induced liver injury (DILI) caused by immune processes. First, the drug or active metabolite(s) acts as a hapten and binds to endogenous proteins forming conjugates that induce antibody- and/or T cell-mediated injury. Proponents of the second hypothesis suggest that most individuals are tolerant to immune-mediated DILI and reactions occur only when tolerance is 
overcome. Although the cellular events remain poorly defined, knowledge of underlying mechanisms of idiosyncratic DILI is even more fragmentary.

\subsubsection{Fixed Drug Eruption}

Mediated by activated CD8+ T cells, fixed drug eruption (FDE) is a disease instigated by drugs in more than $95 \%$ of cases. In regression, large numbers of $\mathrm{CD} 8+$ effector memory $\mathrm{T}$ cells of phenotype CD3+, CD45RA+, CD11b+, and CD27- are found in lesions in the epidermis. Reexposure to the culprit drug rapidly leads to a conversion of this benign state to one of aggressive cell damage. $\mathrm{T}$ cells secrete IFN- $\gamma$ in high amount as well as TNF, perforin, granzyme B, and Fas ligand (FasL) which initiates cell killing by binding to its receptor FasR on keratinocytes. The presence of the "dormant" CD8+ T cells in "resting" lesions explains why patch testing is negative on normal skin but reactivation occurs when patches are applied to areas of residual lesions. For a clinical description of FDE see Sect. 2.2.4.6 and Figs 2.10 and 2.11.

\subsubsection{Toxic Epidermal Necrolysis and Stevens-Johnson Syndrome}

These diseases (Sect. 2.2.4.8) are provoked by drugs in more than $90 \%$ of cases with sulfonamides, anticonvulsants, some NSAIDs, and allopurinol most frequently involved. It is not yet understood why and how a cutaneous adverse drug reaction very occasionally progresses to the life-threatening TEN or SJS. Clinical features of both syndromes are similar with the extent of necrotic epidermis/skin detachment greater in TEN (>30 \%; Fig. 2.14) than in SJS $(<10 \%)$ and the predominance of lesions around mucosal orifices in SJS (Fig. 2.15). In fact, the two disorders are considered by many to be variants of the same disease with different severity. In TEN, blister fluid contains many activated HLA class I-restricted, drug-specific CD8+ CD56+ cytotoxic $\mathrm{T}$ cells with natural killer $(\mathrm{NK})$ cell features. These kill lymphocytes and particularly keratinocytes via, according to different researchers, several mechanisms including the Fas/FasL (CD95/CD95L), TNF, granzyme B, perforin, TWEAK (TNF-like weak inducer of apoptosis), and TRAIL (TNF-related apoptosisinducing ligand) pathways. These cytotoxic mediators are found in the serum as well as in blister fluid where levels are high and where they occur with other cytokines including IFN- $\gamma$, IL-10, and IL-18. Several studies suggest that TNF has an important role in TEN and this appears to be supported by the success of the TNF-targeted monoclonal antibody infliximab (see chapter 11, Sect. 11.1.3.3) in promoting the resolution of lesions in a number of patients.

These outlined findings are the conclusions assembled from a number of different investigators, but the explanations leave significant doubts since some key points remain unexplained. In particular, the number of infiltrating inflammatory cells in the skin lesions is claimed to be too few to explain the widespread killing of keratinocytes. In the first place, both of the two favored pathways to cell death, viz., granzyme B- and perforin-mediated exocytosis and Fas-FasL killing, are not restricted to TEN and SJS-both pathways are upregulated in some other adverse cutaneous reactions such as maculopapular erythema where widespread cell destruction does not occur. The second inadequacy of the dual pathway explanation is the need for cell-to-cell contact for killing when there seems to be not enough inflammatory cells for this to occur. These doubts have been expressed by Chung and coworkers in Taiwan whose investigations recently provided a better understanding of the immune mechanisms and biomarkers of TEN and SJS and promise new approaches for the management of these diseases. Gene expression profiling, PCR, and immunohistochemical methods identified granulysin rather than Fas, FasL, soluble FasL, granzyme B, or perforin as the major cytotoxic molecule responsible for keratinocyte necrosis in TEN/SJS. Granulysin, a member of the saposin-like family of membranedisrupting proteins, is a cationic cytolytic and pro-inflammatory protein contained in the cytolytic granules of cytotoxic $\mathrm{T}$ lymphocytes and NK cells. Chung et al. showed that granulysin from blister fluid, in the $15 \mathrm{kD}$ secretory form (a precursor of the $9 \mathrm{kD}$ form), was present in a concentration two to four times higher that soluble 
FasL, granzyme B, and perforin. Depletion of granulysin reduced cytotoxicity and when it was injected into mouse skin it produced TEN- and SJS-like skin necrosis. In addition to its cytotoxic effects, granulysin is a chemoattractant for other inflammatory cells and aids the expression of some chemokines and cytokines including RANTES (CCL5), MIP-1 $\alpha$ (macrophage inflammatory protein-1 $\alpha$, CCL3), MCP-1 (monocyte chemotactic protein-1, CCL2), MCP-3 (monocyte chemotactic protein-3, CCL7), IL-1, IL-6, IL-10, and IFN- $\alpha$.

In summary, the demonstrations of a pathogenetic mechanism for TEN/SJS and that secretory granulysin is a key toxic molecule responsible for disseminated keratinocyte killing open the way for the development of new diagnostic and therapeutic targets for the diseases. However, important questions concerning operative mechanisms in TEN and SJS remain. For example, what are the precise molecular mechanisms involved in the interactions between the offending drugs, HLA, and the T cell receptor? What are the precise steps between taking the drug and the secretion of granulysin? How is secretion of the cytolytic protein regulated? What are the identities of the determinants recognized in the immune processes? The beneficial effect of infliximab when used for selective TNF blockade in some cases of TEN, and the importance of TNF in causing direct cytotoxicity and apoptosis, must also be considered and somehow incorporated into a satisfying explanation of the pathogenesis of this intriguing toxidermia.

\subsubsection{Delayed Cutaneous Drug Hypersensitivity Reactions. Conclusions}

In reviewing what is currently known about the pathophysiology and mechanisms underlying the $\mathrm{T}$ cell-mediated delayed allergic drug reactions it is apparent that knowledge of the different cutaneous reactions is still widely incomplete and agreement, even on some basic processes, is often inconsistent or lacking. Absence of agreement on the identity of the often-bewildering number and nature of cytokines and chemokines said to be involved is particularly apparent for some of the drug-induced reactions. For the prac- ticing clinician, especially those without specialty knowledge of immunology and dermatology, the field of drug-provoked cutaneous reactions is an area of great difficulty starting with the requirement of identifying the culprit drug, often amongst multiple drugs being taken. There then remains the need to undertake or order appropriate tests without further aggravating the condition; institute appropriate management measures; identify other drugs that may be a risk; and to take measures, including instruction of the patient, to avoid further reactions. A fairly recent interesting area of investigation that is particularly promising has emerged from demonstrated associations between HLA alleles, certain drugs, diseases such as TEN/SJS, and different human populations. Apart from the presentation of drug or drug metabolite to T cells, HLA alleles may also be responsible for genetic susceptibilities for drug-induced cutaneous reactions. As pointed out by Chung et al., "Understanding the molecular mechanism of the interaction of HLA, offending drugs and TCR, as well as CTLs/NK cells activation, would facilitate the development of new approaches for the management of SJS/ TEN." With relevance to pathomechanisms and regard to classification of reactions, attention has been drawn to the particular cell type(s) recruited during the so-called second step of drug-induced skin inflammation following the involvement of drug-specific $\mathrm{T}$ cells in the first step. The important involvements of eosinophils with DRESS and neutrophils with maculopapular exanthema and AGEP illustrate the point.

As discussed in Chap. 4, the demonstration or detection of individual or patterns of cytokines and chemokines is a promising approach for improving the reliability and specificity of diagnosing some drug-induced cutaneous hypersensitivity reactions. Surprisingly, this diagnostic strategy still seems to be underutilized but significant advancements probably depend on first reliably implicating a suitable disease-specific marker or spectrum of markers. Finally, the allergenic determinants recognized in the cellular immune processes remain largely unexplored and undefined. Identification of the structures of drug-peptide complexes presented by the MHC and fine-structural detail of drug determinants 
recognized by the $T$ cell receptor remain areas sorely in need of both investigation and secure findings. Progress on these points is needed to reliably identify potentially cross-reacting drugs for patients and offers the possibility of selecting or tailor-making interfering inhibitory or competing molecules to mitigate drug-specific reactions.

\subsection{Type II Hypersensitivity Drug Reactions}

The classical drug-induced type II hypersensitivity is the well-known immune cytotoxic reaction to high doses of penicillin that results from binding of the drug to red cells. This causes the red cells to be recognized as foreign, resulting in IgM and IgG antibodies reacting with the drug-cell membrane protein complex. The antibody-antigen complexes so formed activate the classical complement pathway causing cell lysis and death and the antibody-coated red cells can interact with macrophages leading to Fc-mediated cell destruction by the reticuloendothelial system. Another example of a type II cytotoxic antibodymediated drug reaction when the drug appears to form an antigenic complex with the red cell surface is drug-induced immune hemolytic anemia (DIIHA). The drugs most frequently associated with DIIHA are some cephalosporins (especially cefotetan and ceftriaxone) and penicillins (especially piperacillin). DIIHA can also be associated with red cell autoantibodies induced by the drug affecting the immune system without becoming bound to the red cell surface, that is, the drug does not participate in the antigen-antibody reaction. Such antibodies are referred to as drug-independent. Prototype drugs involved in drug-independent autoantibody formation are methyldopa and the chemotherapy drug, fludarabine. In this form of DIIHA the clinical and laboratory findings are identical to autoimmune hemolytic anemia. It is not known why drugs sometimes induce drug-independent autoantibodies to red cells or what mechanism is involved. The mechanism of DIIHA when the drug participates as the antigen is thought to proceed by attachment of the drug to the red cell in vivo, interaction with drug-reactive antibodies (usually
IgG but may be $\operatorname{IgM}$ ), and subsequent Fc-mediated cell destruction and clearance by macrophages. Activation of complement may occur leading to intravascular lysis and renal failure. Understanding the mechanisms involved in the action of drug-dependent antibodies is complicated by the observation that drugs that cause some of the worst reactions including hemolysis, renal failure, disseminated intravascular coagulation, and death appear to proceed via a different mechanism, often involving complement-activating antibodies. The so-called "unifying hypothesis" has been advanced to explain all three types of antibodies implicated in DIIHA. This hypothesis is based on known findings dating back to Landsteiner of the generation of three populations of antibodies to an injected haptenprotein complex-one population to the hapten, one to hapten plus carrier determinants, and one to the protein carrier. A further, and more recent, proposed mechanism for DIIHA is based on nonimmune adsorption of the drug onto the red cell membrane. Cefotetan, often used prophylactically in some surgical procedures, is the most common cause of DIIHA with another cephalosporin, ceftriaxone, the second most common cause. For the period 1985-1997, the FDA reported 85 cases of cefotetan-induced hemolytic anemia with $15(18 \%)$ fatalities. It is therefore usually recommended that all cephalosporins should be avoided in patients where DIIHA is thought to be a possibility but in vitro hapten inhibition experiments have shown that only cefotetan and cephalothin inhibited anti-cefotetan IgG and IgM antibodies. It would be prudent to remember, however, that these were in vitro findings and the in vivo consequences may be quite different especially if allergic reactions (and $\mathrm{IgE}$ antibodies) are involved. With piperacillin, the third most common drug causing DIIHA, immune complexes seem to be involved.

As well as erythrocytes, other cells including platelets (thrombocytes) and some hematopoietic precursor cells can be affected by drug-induced type II hypersensitivity reactions. Drug-induced thrombocytopenia for example is increasing as more drugs are released and used. A number of different mechanisms appear to be involved. Drugs may bind covalently to the platelet mem- 
brane producing a hapten-glycoprotein conjugate with an antigenic determinant(s) that is recognized by antibody. Drugs implicated in this form of thrombocytopenia include penicillins and cephalosporins in particular. Quinine, quinidine, sulfonamides, and NSAIDs may interact non-covalently with platelet membrane glycoproteins, including the von Willebrand factor receptor GPIb-IX-V (GP for glycoprotein) and activated integrins GPIIb/IIIa, forming drug-glycoprotein non-covalently linked complexes. For antibody binding to occur, the presence of the drug is essential-in the absence of the drug, antibodies do not bind to the platelet surface and thrombocytopenia does not occur. It remains uncertain whether the antibodies are directed to the drug alone or to the complex of drug and platelet glycoprotein. A third mechanism of drug-induced thrombocytopenia is seen with the antiplatelet GPIIb/IIIa inhibitor drugs lotrafiban, tirofiban, and eptifibatide, the novel cyclic heptapeptide from the venom of the southeastern pygmy rattlesnake. By binding to the glycoprotein complex, these drugs induce a conformational change and a new determinant to which antibodies bind and cause cell destruction. The drug does not physically form part of the determinant. Another inhibitor of platelet activation sometimes administered is abciximab, the Fab fragment of a chimeric human-mouse monoclonal antibody that binds to the platelet glycoprotein receptor GPIIb/IIIa. Some patients, even without prior exposure to the monoclonal agent, react to the mouse component of the hybrid, supporting the belief that natural antibodies may be involved in the recognition. Such recognition of murine antigens on a chimeric human-mouse antibody fragment is similar to the recognition by natural antibodies of the chimeric monoclonal antibody cetuximab (Sect. 3.1.1; Sect. 11.1.3.2). This humoral form of immune-mediated drug-induced thrombocytopenia is regarded as drug-specific since the antibodies are formed against the drug itself and platelets are destroyed in the process. In a fifth mechanism, drug induces the formation of autoantibodies to glycoproteins on the platelet surface. The antibodies bind to the platelet antigens without participation of the drug and the resultant thrombocytopenia can persist when the drug is withdrawn. The prototype drugs in this category are gold and procainamide. Finally, heparin and heparin-like drugs can induce thrombosis by binding to surface-bound soluble platelet factor 4 (PF4), a small chemokine CXCL4 that promotes coagulation and is released from the alpha granules of activated platelets during platelet aggregation. Antibodies to the heparinPF4 complex bind to receptors on the platelet surface via their $\mathrm{Fc}$ pieces producing platelet activation. This mechanism is basically different from the other five described mechanisms in that activation and aggregation of platelets is the result rather than cell lysis and hemorrhage making the reaction more like a type III than a type II hypersensitivity response.

Acute agranulocytosis is rare but when it does occur, drugs are responsible in more than $70 \%$ of cases. In its immune form, antibodies are produced to circulating neutrophils and/or myeloid precursor cells. Immune-mediated agranulocytosis is rapid in onset with symptoms generally occurring within a few days. Drugs commonly associated with the condition include quinine, quinidine, $\beta$-lactams, pyrazolones, propylthiouracil, clozapine, ticlopidine, carbamazepine, chlorpromazine, and some sulfonamides. Numerous other drugs have been implicated in one or only a few cases. Several mechanisms have been advanced although detailed and convincing evidence is not always offered. Some of the implicated drugs such as penicillins and aminopyrine are thought to act as haptens that elicit antibody formation against neutrophils and their subsequent destruction. In the case of aminopyrine-induced agranulocytosis, antibodies are directed to neutrophil cell membrane antigens modified by a reactive metabolite of the drug. Antibody recognition of metabolites was also demonstrated for metamizole and diclofenac in cases of agranulocytosis induced by these drugs. In addition to drug-dependent antibodies of the IgG and/or IgM class, autoantibodies were found in 13 cases of drug-related agranulocytosis due to penicillins, dimethylaminophenazone, propyphenazone, metamizole, and diclofenac. In the case of clozapine-induced agranulocytosis, the drug is converted to the reactive nitrenium ion which binds to cellular proteins and accelerates 


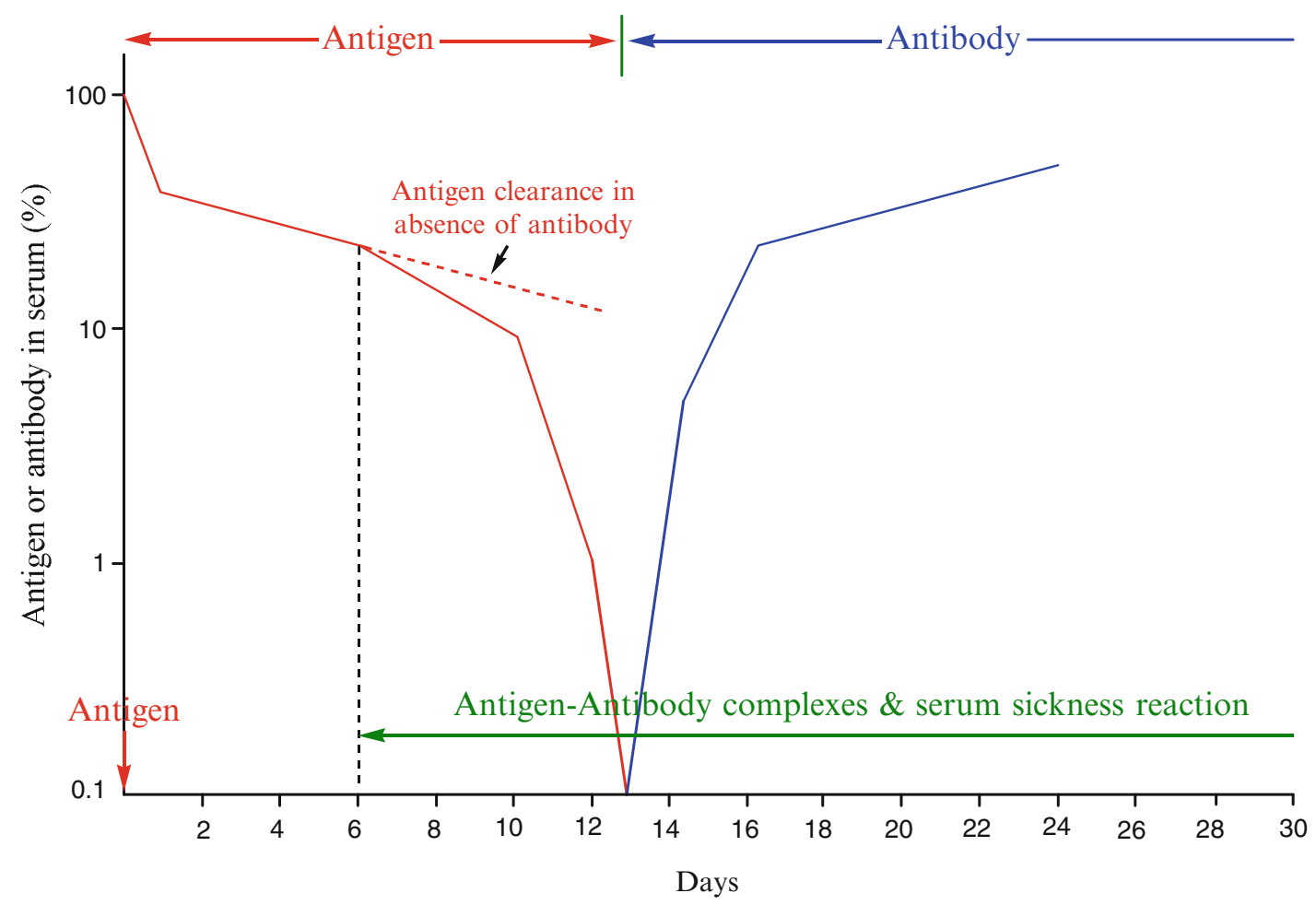

Fig.3.18 Relationship between antigen introduction, subsequent immunological events, and time in serum sickness

apoptosis of neutrophils. Propylthiouracil was shown to lyse neutrophils via a complementdependent mechanism. An immune mechanism does not seem to be involved with drugs such as ticlopidine, busulfan, chlorpromazine, and methamizole, each of which has a direct toxic effect on myeloid precursors.

\subsection{Type III Hypersensitivity Drug Reactions}

Serum sickness (see Sect. 2.2.3) can occur in response to foreign proteins such as streptokinase and to antitoxins, antivenins, and vaccines. As mentioned above in Sect. 3.2.8.2, type III druginduced hypersensitivities, that is, antigen-antibody complex-mediated reactions, occur in some cases that closely resemble classical serum sickness. Penicillin has long been known to become antigenic by conjugating to proteins in vivo to produce drug-protein complexes that mediate type III hypersensitivity reactions. Thus, it can be said that penicillins can cause all four types of hypersensitivity reactions. Other drugs that produce similar serum sickness-like reactions include cephalosporins, sulfonamides, ciprofloxacin, tetracycline, lincomycin, NSAIDs, carbamazepine, allopurinol, thiouracil, propranolol, griseofulvin, metronidazole, furoxone, captopril, gold salts, methyldopa, halothane, fluoxetine, barbiturates, and monoclonal antibodies. $\beta$-Lactam drugs are considered the most common cause of serum sickness elicited by nonproteins but drugs by themselves are thought to be poor antigens for the production of the good antibody responses necessary to induce serum sickness. Circulating antigen-antibody complexes are formed after drugs become protein bound in vivo and stimulate IgG and/or IgM antibodies. The liberation of vasoactive amines is thought to play a part in tissue deposition. Antigen also interacts with complementary IgE antibodies on mast cells and basophils leading to the release of PAF and other mediators, platelet aggregation, and further 
release of histamine and serotonin. The resulting increase in vascular permeability facilitates the deposition of immune complexes which, in turn, produces complement activation, the formation of $\mathrm{C} 3 \mathrm{a}$ and $\mathrm{C} 5 \mathrm{a}$, an influx of inflammatory cells to the sites of immune complex deposition, and release of further inflammatory mediators. Drug immune complexes are normally rapidly cleared via the antibody Fc piece or complement binding to cells of the reticuloendothelial cells but if this does not occur, for example, because of the high concentrations of immune complexes, deposition of complexes in glomeruli, arteries, endocardium, spleen, and other organs and influx of inflammatory cells may result. In a graph that relates the time of occurrence of tissue lesions to the clearance of antigen and developing antibody production, Fig. 3.18 summarizes the immunologic events in the patient after antigen exposure. Serum concentration of protein-bound drug initially decreases sharply as a result of intravascular and extravascular equilibration and levels continue to decrease normally as the protein is catabolized until antibody levels increase, causing rapid immune elimination. The dashed red line in Fig. 3.18 at about day 6 represents the course of antigen decline in the absence of antibodymediated antigen elimination. From about day 14, soluble circulating complexes of antigen with $\mathrm{IgG}$ or IgM form and may begin to deposit in a number of tissue sites leading to the clinical manifestations and pathologic findings of serum sickness.

Hypersensitivity vasculitis induced by drugs is another manifestation of a type III response. Drugs involved include some $\beta$-lactams, particularly, amoxicillin and cephalexin, cotrimoxazole, NSAIDs, monoclonal antibodies, and chemotherapeutic drugs such as tamoxifen and erlotinib. A proportion of small-vessel vasculitis patients have anti-neutrophil cytoplasmic antibodies. Although there is evidence of a pathogenic role for these antibodies and they are used as a diagnostic marker, operative mechanisms underlying this hypersensitivity state are still far from established.

Hypersensitivity reactions are one of a number of different mechanisms producing druginduced lung disease. These reactions result from interaction of drug with the immune system and involve drug-specific antibodies or, more usually, drug-specific $\mathrm{T}$ cells. Eosinophilic pneumonia can be caused by almost any medication while reports of drug-induced hypersensitivity pneumonitis, a combined type III and IV reaction in a Th1/Th17 response, are increasing, particularly to antineoplastic drugs.

\section{Summary}

- For many drugs it has not been possible to explain allergic reactions on the basis of their chemical reactivity, protein-binding capacity, their biotransformed or degradative products, or the presence of a reactive impurity.

- Some allergic responses, sometimes even lifethreatening as with anaphylaxis, occur on first exposure to a drug.

- There is at least one group of drugs, the neuromuscular blockers (and probably more to be identified), that can specifically elicit antibody-induced mast cell activation and release without first undergoing coupling to a macromolecular carrier. For these drugs, the di- or multi-valency which is an inherent part of the molecular structure, initiates mediator release by cross-linking cell-bound antibodies.

- The initial event in the activation of mast cells for mediator release is the binding of $\operatorname{IgE}$ antibodies to the high-affinity $\left(K_{\mathrm{a}} 10^{-10} \mathrm{M}\right) \mathrm{FceRI}$ IgE receptor abundantly expressed on the mast cell and basophil surfaces.

- Released preformed mediators of inflammation and anaphylaxis stored in the cytoplasmic granules of mast cells include histamine, heparin, platelet-activating factor (PAF), serotonin, the enzymes tryptase, chymase, and carboxypeptidase, and eosinophil, neutrophil, and monocyte chemotactic factors. Newly synthesized released mediators include prostaglandin $\mathrm{D}_{2}$, thromboxanes, and leukotrienes $\mathrm{LTB}_{4}, \mathrm{LTC}_{4}$, and $\mathrm{LTD}_{4}$. A host of cytokines (pro- and anti-inflammatory), chemokines, and chemotactic, stimulating, and growth factors are also released.

- A second receptor for IgE, the low-affinity receptor FceRII also known as CD23, is 
expressed on airways smooth muscle cells and several types of hematopoietic cells including mature B lymphocytes, macrophages, monocytes, dendritic cells, and eosinophils.

- Histamine is synthesized from L-histidine by the inducible enzyme L-histidine decarboxylase and inactivated by histamine $\mathrm{N}$-methyltransferase-catalyzed methylation of the imidazole ring and oxidative deamination of the primary amino group catalyzed by diamine oxidase.

- The physiological and pharmacological effects of histamine are mediated through four different receptors $\mathrm{H}_{1}, \mathrm{H}_{2}, \mathrm{H}_{3}$, and $\mathrm{H}_{4}$, all members of the 7-transmembrane g proteincoupled receptor (GPCR) family with amino terminal glycosylation sites and phosphorylation sites for protein kinases A and C.

- Pathophysiological effects resulting from stimulation of the $\mathrm{H}_{1}$ receptor include those responses seen in immediate allergic reactions, viz, redness, itch, swelling, asthma, anaphylaxis, bronchoconstriction, and vascular permeability.

- $\mathrm{H}_{2}$ receptors appear to mainly mediate suppressive activities of histamine including gastric acid secretion, heart contraction, cell proliferation, differentiation, and some effects on the immune response.

- The $\mathrm{H}_{3}$ receptor regulates the synthesis and release of histamine and also has a regulatory role in the release of neurotransmitters such as serotonin, dopamine, and norepinephrine.

- The $\mathrm{H}_{4}$ receptor is functionally expressed on mast cells, eosinophils, monocytes, dendritic cells, and CD8+ T cells. The receptor exerts a chemotactic effect on several cell types associated with immune and inflammatory responses such as allergy, asthma, rheumatoid arthritis, and inflammatory bowel disease.

- $\mathrm{LTC}_{4}$ and $\mathrm{LTD}_{4}$ are powerful mediators of asthma, airway hypersensitivity, and allergies inducing bronchoconstriction, increasing vascular permeability, and promoting mucous secretion. $\mathrm{LTE}_{4}$ is present in greatest amount in vivo where it induces bronchial eosinophilia and airway hyperresponsiveness. The bronchoconstriction provoked by $\mathrm{LTE}_{4}$ is strong in patients with aspirin-sensitive asthma but much weaker in other asthmatics. $\mathrm{LTD}_{4}$ is much more pronounced in asthmatic patients not sensitive to aspirin.

- Cysteinyl leukotrienes are generated de novo from arachidonic acid by phospholipase A2 with the initial participation of 5-lipoxygenase-activating protein and the enzyme 5-lipoxygenase.

- The two human cysteinyl leukotriene receptors $\operatorname{CysLT}_{1} \mathrm{R}$ and $\mathrm{CysLT}_{2} \mathrm{R}$ do not bind the three cysteinyl leukotriene ligands equally: for $\mathrm{CysLT}_{1} \mathrm{R}, \mathrm{LTD}_{4}>\mathrm{LTC}_{4}=\mathrm{LTE}_{4}$; for $\mathrm{CysLT}_{2} \mathrm{R}$, $\mathrm{LTC}_{4}=\mathrm{LTD}_{4}>\mathrm{LTE}_{4}$.

- PAF, 1-O-alkyl-2-acetyl-sn-glycero-3-phosphocholine, a phospholipid of relatively simple but unique structure, produces both the signs and symptoms of anaphylaxis. PAF is also an important mediator in asthma and septic shock. Recent findings in the mouse identified a second pathway of anaphylaxis involving the $\mathrm{IgG}$ receptor FcyRIII and the release of $\mathrm{PAF}$ as the major mediator.

- Recruitment of the Syk kinase and subsequent phosphorylation activation steps involving Lyn lead to mast cell activation demonstrating the importance of protein tyrosine kinases in the pathways that result in allergic inflammation and anaphylaxis.

- Sphingosine-1-phosphate, a major regulator of the vascular system and B and T cell trafficking, is elevated in the lungs of asthmatics where it regulates pulmonary epithelium permeability and is thought to contribute to the pathogenesis of anaphylaxis and rheumatoid arthritis.

- Mechanisms of anaphylaxis independent of IgE and including PAF-induced shock have been suggested.

- Urticaria is a heterogeneous disease with many subtypes caused by a range of agents and stimuli. Subtypes include urticaria due to genetic or immune mechanisms, urticaria with an autoimmune basis and nonimmunemediated urticaria, and angioedema.

- The combination of actions of ACE inhibitors of decreasing angiotensin II and aldosterone and increasing and maintaining bradykinin levels may lead to fluid extravasation into subcutaneous tissue ultimately producing angioedema. 
- Angioedema may also occur following administration of angiotensin II receptor-binding inhibitors such as losartan.

- The allergen-induced late phase reaction has features of a cell-mediated hypersensitivity response but shows some significant differences best illustrated by the different cytokine profiles.

- An early clue to specific immune recognition of "small," unbound chemicals and hence drugs was the demonstration of selective interaction of nickel ions with an MHC-IIbound peptide.

- Abacavir-HLA binding studies indicate that the drug changes the shape of the antigenbinding cleft. This results in preferred binding of smaller amino acids, an alteration in the repertoire of self-peptides that bind HLAB*57:01, and a $\mathrm{T}$ cell response to self-proteins presented only in the presence of abacavir.

- Carbamazepine, a drug strongly associated with HLA-B*15:02, binds to this allotype and alters the repertoire of presented self-peptides. The most likely binding site on the carbamazepine molecule is the ketone of its 5-carboxamide group on the tricyclic ring.

- The mast cell and possibly the basophil appear to be the cells most likely involved in the desensitization of patients to drug allergies.

- Drug-induced delayed-type cutaneous hypersensitivity reactions manifest mainly as exanthemas, mediated by CD4+ and CD8+ CD3+ $\mathrm{T}$ cells in the dermis and epidermis. There are two phases of the hypersensitivity response, sensitization (or initiation or induction) involving keratinocytes, Langerhans', and dendritic cells and elicitation via T cells.

- Some progress has been made in identifying mechanisms underlying the different drugrelated skin eruptions with an immunological pathogenesis but more precise definitions are needed. Individual important drug-induced delayed reactions include allergic contact dermatitis, psoriasis, maculopapular exanthema, AGEP, DRESS, FDE, TEN, and SJS.

- Drug-induced allergic hepatitis, as in DRESS, is associated with fever, rash, and eosinophilia.
The reaction is generally a type IV hypersensitivity response involving CD4+ cells, CD8+ cytotoxic lymphocytes and NK, Kupffer, and dendritic cells. Type II hypersensitivities may also sometimes occur. Knowledge of mechanisms underlying idiosyncratic drug-induced liver injury is limited.

- Granulysin appears to be a key toxic molecule responsible for disseminated keratinocyte killing in TEN/SJS.

- Examples of type II cytotoxic antibodymediated drug reactions include drug-induced immune hemolytic anemia, drug-induced thrombocytopenia where a number of different mechanisms are involved and acute agranulocytosis in which more than $70 \%$ of cases are caused by drugs

- Type III drug-induced hypersensitivities, that is, antigen-antibody complex-mediated reactions, occur in some cases that closely resemble classical serum sickness. Drugs implicated include $\beta$-lactams, sulfonamides, ciprofloxacin, tetracycline, lincomycin, NSAIDs, carbamazepine, allopurinol, thiouracil, propranolol, griseofulvin, metronidazole, furoxone, captopril, gold salts, methyldopa, halothane, fluoxetine, barbiturates, and monoclonal antibodies. Circulating antigen-antibody complexes are formed after drugs become protein bound in vivo and stimulate IgG and/or IgM antibodies. The liberation of vasoactive amines is thought to play a part in tissue deposition.

- Hypersensitivity vasculitis induced by drugs is another manifestation of a type III response. Drugs involved include some $\beta$-lactams, particularly, amoxicillin and cephalexin, cotrimoxazole, monoclonal antibodies, and NSAIDs.

- Hypersensitivity reactions are one of a number of different mechanisms producing drug-induced lung disease. Eosinophilic pneumonia can be caused by almost any medication while reports of drug-induced hypersensitivity pneumonitis, a combined type III and IV reaction in a Th1/Th17 response, are increasing, particularly to antineoplastic drugs. 


\section{Further Reading}

Adams DH, Ju C, Ramaiah SK, Uetrecht J, Jaeschke H. Mechanisms of immune-mediated liver injury. Toxicol Sci. 2010;115:307-21.

Austen KF, Maekawa A, Kanaoka Y, et al. The leukotriene $\mathrm{E}_{4}$ puzzle: Finding the missing pieces and revealing the pathobiologic implications. J Allergy Clin Immunol. 2009; 124:406-14.

Bäch M, Dahlèn E, Drazen JM, et al. International union of basic and clinical pharmacology. LXXXIV: leukotriene receptor nomenclature, distribution, and pathophysiological functions. Pharmacol Rev. 2011;63:539-84.

Baldo BA. Immunochemical perspectives of allergy: in the steps of Karl Landsteiner. In: Baldo BA, editor. Monographs in allergy, Molecular approaches to the study of allergens, vol. 28. Basel: Karger; 1990. p. 1-10.

Baldo BA, Pham NH. Structure-activity studies on druginduced anaphylactic reactions. Chem Res Toxicol. 1994;7:703-21.

Baldo BA, Smal MA, McCaskill C. A specific, sensitive and high-capacity immunoassay for PAF. Lipids. 1991;26:1136-9.

Bharadwaj M, Illing P, Kostenko L. Personalized medicine for HLA-associated drug-hypersensitivity reactions. Pers Med. 2010;7:495-516.

Brown JM, Wilson TM, Metcalfe DD. The mast cell and allergic diseases: role in pathogenesis and implications for therapy. Clin Exp Allergy. 2008;38:4-18.

Cauwels A, Janssen B, Buys E, et al. Anaphylactic shock depends on PI3K and eNOS-derived NO. J Clin Invest. 2006;116:2244-51.

Chessman D, Kostenko L, Lethborg T, et al. Human leukocyte antigen class I-restricted activation of $\mathrm{CD} 8^{+} \mathrm{T}$ cells provides the immunogenetic basis of a systemic drug hypersensitivity. Immunity. 2008;28:822-32.

Chung W-H, Hung S-I, Yang J-Y, et al. Granulysin is a key mediator for disseminated keratinocyte death in Stevens-Johnson syndrome and toxic epidermal necrolysis. Nat Med. 2008;14:1343-50.

Cooper AM, Hobson PS, Jutton MR, et al. Soluble CD23 controls IgE synthesis and homeostasis in human B cells. J Immunol. 2012;188:199-207.

Finkelman FD. Anaphylaxis: lessons from mouse models. J Allergy Clin Immunol. 2007;120:506-15.

Frenzel DF, Weiss JM. Osteopontin and allergic disease: pathophysiology and implications for diagnosis and therapy. Expert Rev Clin Immunol. 2011;7:93-109.

Gaga M, Frew AJ, Varney VA, et al. Eosinophil activation and $\mathrm{T}$ lymphocyte infiltration in allergen-induced late phase skin reactions and classical delayed-type hypersensitivity. J Immunol. 1991;147:816-22.

Garratty G. Drug-induced immune hemolytic anemia. Hematology Am Soc Hematol Educ Program. 2009;2009:73-9.

Gilfillan AM, Tkaczyk C. Integrated signaling pathways for mast-cell activation. Nat Rev Immunol. 2006;6:218-30.

Goncalo M, Bruynzeel DP. Mechanisms in cutaneous drug hypersensitivity reactions. In: Zhai $\mathrm{H}$, Wilhelm K-P, Maibach HI, editors. Marzulli and Maibach's der- matotoxicology. 7th ed. Boca Raton, FL: CRC Press; 2008. p. 259-68.

Gould HJ, Sutton BJ, Beavil AJ, et al. The biology of IgE and the basis of allergic disease. Annu Rev Immunol. 2003;21:579-628.

Greaves MW, Tan KT. Chronic urticaria: recent advances. Clin Rev Allergy Immunol. 2007;33:134-43.

Homy B, Alenius H, Müller A, et al. CCL27-CCR10 interactions regulate $\mathrm{T}$ cell-mediated skin inflammation. Nat Med. 2002;8:157-65.

Illing PT, Vivian JP, Dudek NL, et al. Immune selfreactivity triggered by drug-modified HLA-peptide repertoire. Nature. 2012;486:554-8.

Kanaoka Y, Boyce J. Cysteinyl leukotrienes and their receptors: cellular distribution and function in immune and inflammatory responses. J Immunol. 2004;173:1503-10.

Kenney B, Stack G. Drug-induced thrombocytopenia. Arch Pathol Lab Med. 2009;133:309-14.

Olivera A, Mizugishi K, Tikhonova A, et al. The sphingosine kinase-sphingosine-1-phosphate axis is a determinant of mast cell function and anaphylaxis. Immunity. 2007;26:287-97.

Reiter E, Ahn S, Shukla AK, et al. Molecular mechanism of $\beta$-arrestin-biased agonism at seven-transmembrane receptors. Annu Rev Pharmacol Toxicol. 2012;52:179-97.

Rivera J, Olivera A. Src family kinases and lipid mediators in control of allergic inflammation. Immunol Rev. 2007;217:255-68.

Romagnoli P, Labhardt AM, Sinigaglia F. Selective interaction of Ni with an MVC-bound peptide. EMBO J. 1991;10:1303-6.

Schmaier AH. The kallikrein-kinin and the renin-angiotensin systems have a multilayered interaction. Am J Physiol Regul Integr Comp Physiol. 2003;285:R1-13.

Schön MP, Boehncke W-H. Psoriasis. N Engl J Med. 2005;352:1899-912.

Shahid M, Tripathi T, Sobia F, et al. Histamine, histamine receptors, and their role in immunomodulation: an updated systematic review. Open Immunol J. 2009;2:9-41.

Svensson CK, Cowen EW, Gaspari AA. Cutaneous drug reactions. Pharmacol Rev. 2000;53:357-79.

Thierse H-J, Moulin C, Allespach Y, et al. Metal-protein complex-mediated transport and delivery of $\mathrm{Ni}^{2+}$ to TCR/MHC contact sites in nickel-specific human $\mathrm{T}$ cell activation. J Immunol. 2004;172:1926-34.

Vadas P, Gold M, Perelman B, et al. Platelet-activating factor, PAF acetylhydrolase, and severe anaphylaxis. N Engl J Med. 2008;358:79-81.

Valent P. Basophil activation antigens: molecular mechanisms and clinical implications. Open Allergy J. 2010;3:52-9.

Wei C-Y, Chung W-H, Huang H-W, et al. Direct interaction between HLA-B and carbamazepine activates T cells in patients with Stevens-Johnson syndrome. J Allergy Clin Immunol. 2012;129:1562-9.

Yang L, Chen J, He L. Harvesting candidate genes responsible for serious adverse drug reactions from a chemical-protein interactome. PLoS Comput Biol. 2009;5:e1000441. 